\title{
MEASURES TO COMBAT RACIAL DISCRIMINATION AND PROMOTE DIVERSITY IN THE LABOUR MARKET: A REVIEW OF EVIDENCE
}

Frances McGinnity, Emma Quinn, Evie McCullough, Shannen Enright, Sarah Curristan

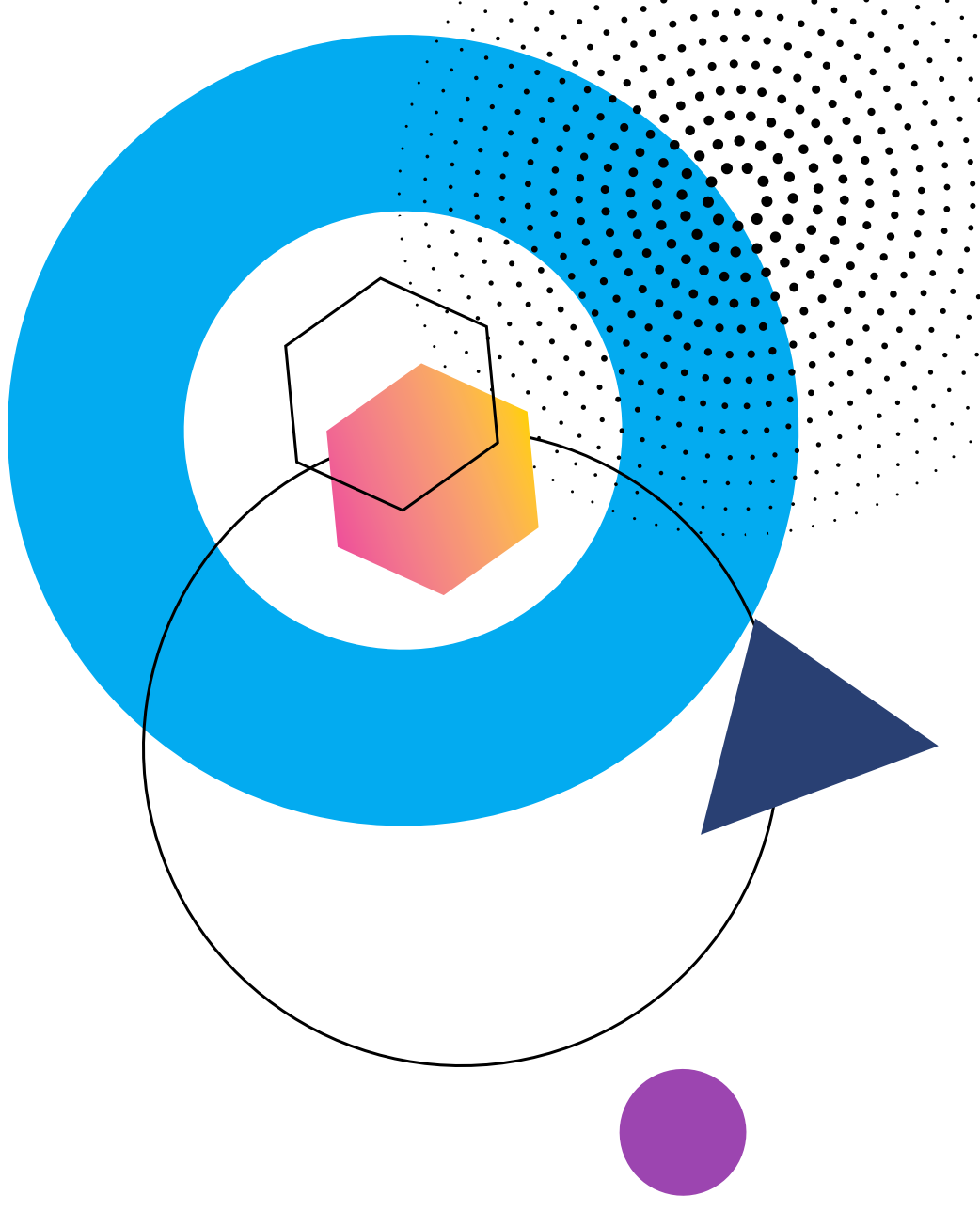


Funded by the Department of Children, Equality, Disability, Integration and Youth in line with the Migrant Integration Strategy 2017-2021 


\section{MEASURES TO COMBAT RACIAL DISCRIMINATION AND PROMOTE DIVERSITY IN THE LABOUR MARKET: A REVIEW OF EVIDENCE}

Frances McGinnity

Emma Quinn

Evie McCullough

Shannen Enright

Sarah Curristan

\section{December 2021}

Economic and Social Research Institute

Department of Children, Equality, Disability, Integration and Youth

Available to download from www.esri.ie

(C) 2021 The Economic and Social Research Institute

Whitaker Square, Sir John Rogerson's Quay, Dublin 2

https://doi.org/10.26504/sustat110

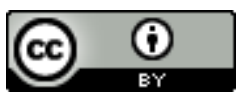

This Open Access work is licensed under a Creative Commons Attribution 4.0 International License (https://creativecommons.org/licenses/by/4.0/), which permits unrestricted use, distribution, and reproduction in any medium, provided the original work is properly credited. 


\section{ABOUT THE ESRI}

The mission of the Economic and Social Research Institute is to advance evidencebased policymaking that supports economic sustainability and social progress in Ireland. ESRI researchers apply the highest standards of academic excellence to challenges facing policymakers, focusing on 12 areas of critical importance to 21st Century Ireland.

The Institute was founded in 1960 by a group of senior civil servants led by Dr T.K. Whitaker, who identified the need for independent and in-depth research analysis to provide a robust evidence base for policymaking in Ireland.

Since then, the Institute has remained committed to independent research and its work is free of any expressed ideology or political position. The Institute publishes all research reaching the appropriate academic standard, irrespective of its findings or who funds the research.

The quality of its research output is guaranteed by a rigorous peer review process. ESRI researchers are experts in their fields and are committed to producing work that meets the highest academic standards and practices.

The work of the Institute is disseminated widely in books, journal articles and reports. ESRI publications are available to download, free of charge, from its website. Additionally, ESRI staff communicate research findings at regular conferences and seminars.

The ESRI is a company limited by guarantee, answerable to its members and governed by a Council, comprising 14 members who represent a cross-section of ESRI members from academia, civil services, state agencies, businesses and civil society. The Institute receives an annual grant-in-aid from the Department of Public Expenditure and Reform to support the scientific and public interest elements of the Institute's activities; the grant accounted for an average of 30 per cent of the Institute's income over the lifetime of the last Research Strategy. The remaining funding comes from research programmes supported by government departments and agencies, public bodies and competitive research programmes.

Further information is available at www.esri.ie. 


\section{THE AUTHORS}

Frances McGinnity is an Associate Research Professor at the Economic and Social Research Institute (ESRI), Adjunct Professor at Trinity College Dublin (TCD) and Visiting Senior Fellow at the Centre for the Analysis of Social Exclusion at the London School of Economics (LSE). Emma Quinn is Head of the Irish National Contact Point of the European Migration Network (EMN), within the ESRI. Evie McCullough is Information Assistant within EMN Ireland. Sarah Curristan is a Research Assistant at the ESRI and Shannen Enright was a Research Assistant at the ESRI at the time of writing.

\section{ACKNOWLEDGEMENTS}

This publication, to inform the work of the Anti-Racism Committee, forms part of a programme of research on integration and equality at the ESRI, funded by the Department of Children, Equality, Disability, Integration and Youth. We would like to express our thanks to the members of the programme steering board for comments on the study - Úna Ní Dhubhghaill, Edwina Steele and Anna Visser (Department of Children, Equality, Disability, Integration and Youth) and Professor Philip O'Connell (University College Dublin). We would also like to thank Helen Russell, ESRI, for her helpful input as editor of the report and to the internal ESRI reviewer who provided valuable comments. We wish to thank Liza Costello for copyediting the report and Sarah Burns for managing its publication.

This report has been accepted for publication by the ESRI, which does not itself take institutional policy positions. The report has been peer reviewed prior to publication. The authors are solely responsible for the content and the views expressed. The contents do not represent the views of the Anti-Racism Committee, the Department of Children, Equality, Disability, Integration and Youth or the Economic and Social Research Institute (ESRI). 

TABLE OF CONTENTS

GLOSSARY

EXECUTIVE SUMMARY

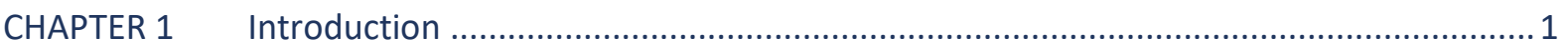

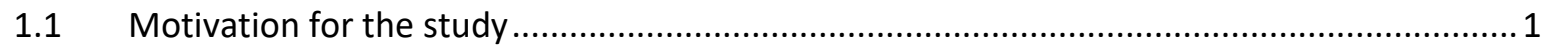

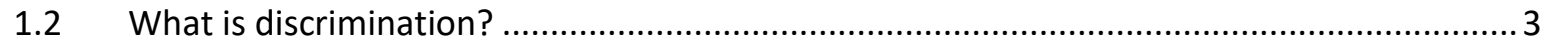

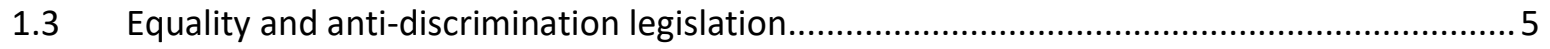

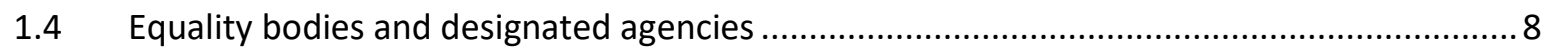

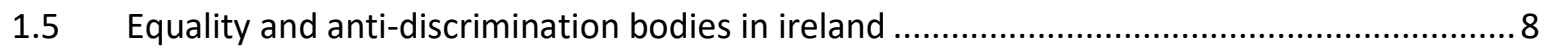

1.6 Diversity statements, strategies and action plans ......................................................... 10

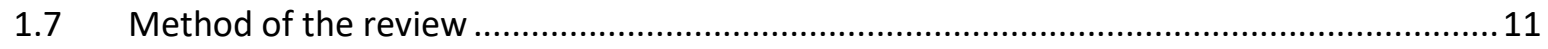

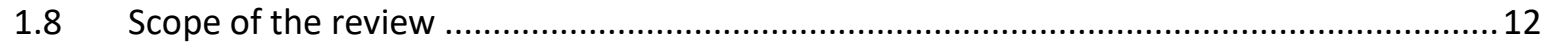

CHAPTER 2 Diversity and racial discrimination in the Irish labour market ................................... 15

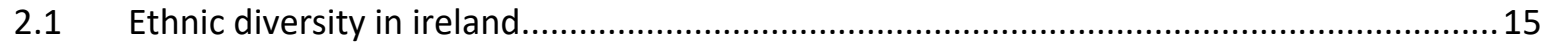

2.2 Measuring discrimination: Evidence from the Irish labour market................................... 18

2.3 Summary of evidence of racial and ethnic discrimination in the irish labour market..........27

CHAPTER 3 Law and equality policy to combat discrimination and promote diversity.................29

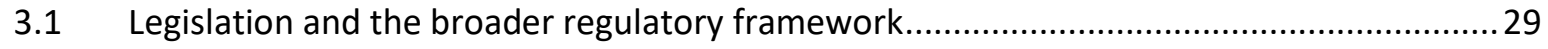

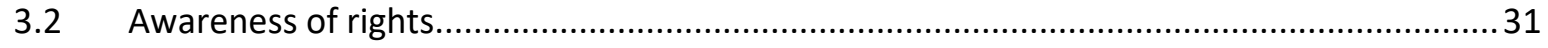

3.3 Consequences of non-compliance and methods of recourse ............................................ 32

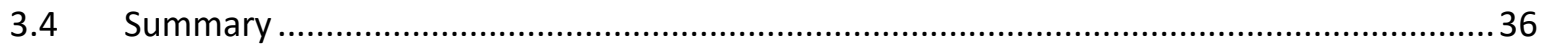

CHAPTER 4 Employment policy, financial incentives and organisational measures .....................37

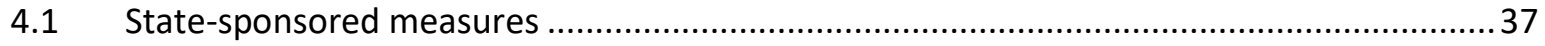

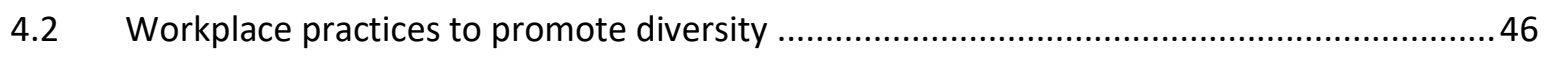

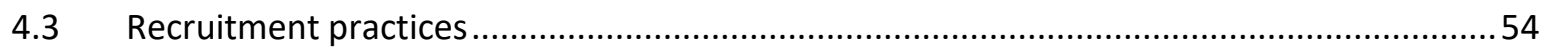

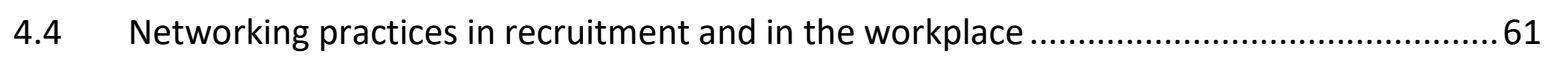

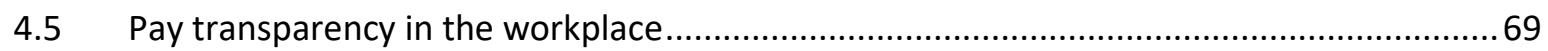

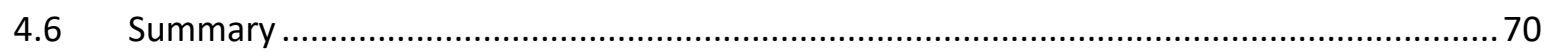

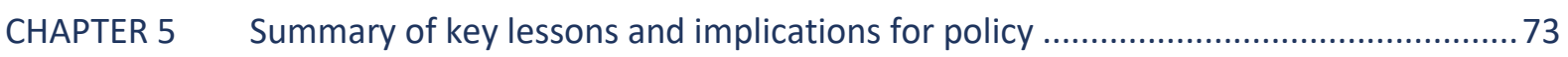

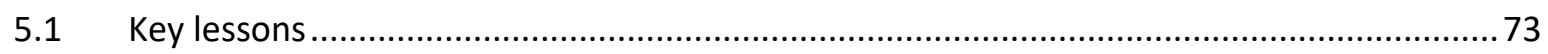

5.2 Implications for monitoring, future research and data needs.......................................... 78 


\section{LIST OF TABLES}

Table 2.1 Population by ethnic background 2006, 2011 and 2016 .17

\section{LIST OF FIGURES}

Figure 4.1 Most successful method to find current job (age 20-34) (EU-LFS, Q2 2016)...... 
GLOSSARY

AAP

ADR

ALMP

CJEU

CSO

DIF

EEA

EFTA

EMN

EU

FLAC

FRA

$\mathrm{HR}$

ICERD

IHREC

ILO

LFS

NCCRI

NGO

NHS

OECD

OWL

SAT

SICAP

SME

UBT
Anonymous application procedures

Alternative dispute resolution

Active labour market programmes

Court of Justice of the European Union

Central Statistics Office

Differential item functioning

European Economic Area

European Free Trade Association

European Migration Network

European Union

Free Legal Advice Centre

European Union Agency for Fundamental Rights

Human resources

International Convention on the Elimination of All Forms of Racial

Discrimination

Irish Human Rights and Equality Commission

International Labour Organization

Labour Force Survey

National Consultative Committee for Racism and Interculturalism

Non-governmental organisation

National Health Service (UK)

Organisation for Economic Co-operation and Development

Oireachtas Work Learning programme

Scholastic Aptitude Test

Social Inclusion and Community Activation Programme

Small and medium enterprise

Unconscious bias training 



\section{EXECUTIVE SUMMARY}

Racial discrimination in this report is understood to mean 'any distinction, exclusion, restriction or preference based on race, colour, descent, or national or ethnic origin' (ICERD, Article 1). Discrimination is distinct from racial prejudice (an attitude) and stereotypes (beliefs). Discrimination can be damaging to both individuals' life chances and their wellbeing, as well as to society (OECD, 2013; Fibbi et al., 2021). Yet discrimination is difficult to measure accurately. It is also challenging to devise measures to combat discriminatory behaviour and promote diversity. This report reviews international literature on racial discrimination in the labour market and the effectiveness of measures to combat it. The aim is to distil the evidence into a short report to inform measures addressing discrimination in the labour market, including the current development of the National Action Plan Against Racism. The focus is on specific measures that can be implemented now to address current racial discrimination in the labour market.

The evidence suggests that:

1. changing recruitment and workplace practice may be easier than changing people's attitudes, at least via a short-term intervention;

2. understanding the motivation for diversity initiatives and 'buy-in' from both majority and minority workers facilitates effective implementation;

3. it is very important to monitor outcomes for different groups, something that is not possible without an ethnic identifier; and

4. the most effective strategy is likely to involve the introduction and evaluation of a range of measures, as well as clear communication of their aims and effectiveness.

This review finds that anti-discrimination legislation is important in terms of sending signals about acceptable behaviour and attitudes within a society, but that such legislation is not self-enforcing. Its implementation and enforcement is challenging and its effectiveness in actually deterring discrimination is not always clear. Complex national legal systems contributing to lengthy proceedings, ambiguity around potential benefits for victims, lack of awareness of rights, risk of retaliation and a lack of support for victims all work towards a low proportion of cases being taken against discriminating employers. If very few cases are taken, the 
deterrent effect is lessened. Policies based purely on a 'punitive' approach are insufficient without complementary 'proactive' policies to promote equal opportunities and diversity.

In terms of policies that go beyond anti-discrimination legislation, linking grants for public contracts to diversity and equality measures through public procurement can be effective at motivating equality and diversity measures within organisations. Wage subsidies for hiring disadvantaged groups, when carefully implemented, can significantly improve employment rates among these groups.

Direct affirmative action instruments typically seek to increase diversity by setting numerical targets. Their effectiveness and sustainability greatly depend on how they are conducted and communicated. Affirmative action policies that rely on strict quotas and preferential treatment for minority groups have been shown to improve ethnic minority representation; however, such measures have experienced considerable backlash in the United States (US), linked to perceived violation of equality or merit-based norms, and have largely been discontinued (Fibbi et al., 2021). Tiebreak policies, whereby a minority is hired in the case of equal qualifications, generally experience less resistance, though again the aims and implementation need to be carefully communicated.

Diversity training can be difficult to evaluate as both content and the context in which it is delivered can vary. It tends to work best to increase minority representation if it is voluntary and its aims are well communicated. Unconscious bias training (UBT) can raise awareness of bias, but there is little evidence that it changes behaviour. There is also a risk that diversity training and UBT can be used to 'tick the box' regarding pro-diversity efforts, in that they can lead to the assumption that the problem of discrimination has been resolved and no further effort is required.

Formalised recruitment at its most basic level - with positions advertised and the use of interview boards - is generally associated with greater diversity of hires. When designing recruitment processes and job tests, recruiters do need to be careful that they do not unintentionally discriminate against certain groups by design. And by no means is all recruitment formal: survey evidence from 2016 suggests that one-third of young adults (aged 20-34) in Ireland got their jobs via social networks. This includes getting a job through friends, relatives and acquaintances, as well as instances where the employer contacted the applicant directly.

Anonymised application procedures, through removing names and other identifying information, have the potential to increase interview call-backs for 
minority groups, though such measures can only be implemented prior to personal interview, and cannot easily be combined with other methods seeking to improve minority representation such as affirmative action. Experiments using anonymised applications can usefully be applied to monitor discrimination in the shortlisting of job candidates.

Social networks, both within and outside organisations, play a significant and often underestimated role in both recruitment and progression or promotion. Many organisations fail to recruit ethnic minority groups because they receive no applications from these groups. Measures to combat low application rates can include outreach to schools and universities to 'recruit' minorities to apply for posts, as well as internships and traineeships. Within an organisation, cross-group mentoring and sponsorship have been shown to facilitate the progression of ethnic minority groups by providing support and career advice and in some cases changing majority attitudes.

The challenges and constraints of small companies are often overlooked in these debates, though in 2019, 64 per cent of private sector employees in Ireland worked in companies with less than 100 employees. Small and medium enterprises (SMEs) can not only learn from initiatives introduced in large organisations but may also need extra support to promote diversity.

What is really important is to monitor outcomes, to document the extent of disadvantage to motivate change in practice, and to monitor effectiveness of measures to combat discrimination and facilitate diversity. For this, ethnicity needs to be regularly measured on survey data, such as the Labour Force Survey, and an ethnic identifier needs to be included on administrative data and organisationallevel data. Without a more widely applied measure of ethnicity linked to a measure of outcomes, combatting racial discrimination will be almost impossible.

In recent years, measures to combat discrimination and promote diversity in the workplace have become widespread and popular, though their effectiveness is often not evaluated. It is extremely important to carry out impact evaluations of measures introduced both in order to evaluate the effectiveness of current measures, such as diversity training or UBT, and also to inform the development of future measures. Ideally, built-in evaluations would accompany the introduction of a measure.

Perhaps the main lesson from this review is that there is no magic solution - no single measure to combat ethnic discrimination in the labour market. Ideally a range of measures would be introduced, some of which cannot be implemented simultaneously. These measures will need to be monitored and evaluated in terms 
of ethnic minority outcomes. Introducing a range of measures, combined with monitoring and communicating their effectiveness may represent the most promising route ahead. 


\section{CHAPTER 1}

\section{Introduction}

\subsection{MOTIVATION FOR THE STUDY}

Amid growing concerns about racism and discrimination in Ireland and internationally, with Black Lives Matter protests taking place throughout 2020, and in light of the current development of a National Action Plan Against Racism for Ireland (Anti-Racism Committee, 2021), this report considers evidence on the effectiveness of measures to combat or reduce labour market discrimination. The Anti-Racism Committee was established by the Minister for Children, Equality, Disability, Integration and Youth in 2020 to review current evidence and practice and to recommend how Ireland should strengthen its response to racism by developing a National Action Plan against Racism (Anti-Racism Committee, 2021). The Committee is considering issues related to education, racism in employment, access to justice and policing, with the present study informing its consideration of the employment sphere. The aim is to distil the evidence into a short report to inform the development of measures to address discrimination in the labour market.

Our understanding of racial discrimination in this report is based on the description outlined in the International Convention for the Elimination of Racial Discrimination (ICERD), which states that racial discrimination 'shall mean any distinction, exclusion, restriction or preference based on race, colour, descent or national or ethnic origin' (ICERD, Article 1). This is consistent with the approach of the Anti-Racism Committee (2021). Much of the evidence cited in this report, particularly from the US, centres on discrimination on the basis of ethnicity or race, as this is how racial discrimination is usually defined there (Pager and Shepherd, 2008). Ethnicity, as defined in the Irish Census, includes the categories 'White nonIrish', 'Irish Traveller', 'Black, Asian and other ethnicity'. ${ }^{1}$ Given the breadth of the ICERD definition of racial discrimination, and the overlap between nationality, country of birth and ethnic groups in Ireland (see Section 2.1 for a discussion), some evidence of discrimination on the basis of nationality and/or immigrant status is also considered where this adds to the discussion, but race and ethnicity are the primary focus. Behaviour is a defining feature of discrimination. Discrimination is thus distinct from racial prejudice (an attitude) and racial stereotypes (beliefs) (see Box 1).

All of these ethnic group names are capitalised throughout the report. A number of commentators in Ireland have highlighted the limits of the Census measure of ethnicity (see Section 2.1 for further discussion). What is captured and understood by the term ethnicity also varies considerably between countries (Simon et al., 2015). 
Combatting labour market discrimination is important, as discrimination can be damaging to both individuals and to society. Work is core to many people's livelihood, identity and wellbeing (Eichhorst et al., 2018). Lack of work is closely linked to poverty and deprivation (Watson et al., 2012), poor health (McKee-Ryan et al., 2005) and inadequate housing. Discrimination in the labour market is a contributing factor to inequalities between groups in access to jobs. Discrimination often results in poorer quality jobs for minority group members (Fibbi et al., 2021): where systematic discrimination persists, equality can never be achieved. Discrimination may have damaging consequences for the individuals involved both in terms of individual wellbeing and underperformance of the minority group (Schmitt et al., 2014; Safi, 2010; Esses, 2021). It has been shown that perceived racial discrimination at work is positively associated with turnover intent: people leave their jobs because of negative treatment (Triana et al., 2010); perceived racial discrimination is also associated with poor health, especially mental health (Paradies et al., 2015; Esses, 2021). To the extent that individuals who experience discrimination feel marginalised and deliberately excluded from society, this could present a threat to social cohesion (De Vroome et al., 2014). Finally, discrimination in the labour market may be economically inefficient, as the skills and competencies of individuals are not efficiently utilised (OECD, 2013; Esses, 2021). Thus, developing measures to reduce discrimination and promote diversity, though challenging, is important for society and the economy.

Prejudice refers to an unjustifiable negative attitude toward a group and its individual members.

Stereotypes are beliefs about the personal attributes or characteristics of a group of people and can be over-generalised, inaccurate and resistant to change in the presence of new information.

Bias is a prejudice against or in favour of a person or group of people. These can be conscious or unconscious. Unconscious biases are biased attitudes towards a group of which the individual is unaware, whereas conscious biases are those biased attitudes of which the individual is aware.

Discrimination refers to unjustifiable negative behaviour towards an individual based on their membership, or perceived membership, of a specific group. Discrimination can be direct or indirect: direct discrimination refers to instances in which a person is treated less favourably than another person in the same situation due to their characteristics or group membership, whereas indirect discrimination usually includes practices that do not appear to be discriminatory but have discriminatory impacts.

Racism refers to prejudice or discrimination by an individual, a group or people, or institutions, against a person based on their membership of a specific racial or ethnic group.

Notes: Definitions of concepts based on those provided in Quillian (2006). 
In reviewing the international evidence on what works to combat labour market discrimination, we begin by considering, in this chapter, what constitutes discrimination and the national and European context regarding antidiscrimination policy, before discussing the criteria for including studies in this report. As measures to combat racial discrimination should be underpinned by evidence, Chapter 2 considers evidence on the existence of racial discrimination in the Irish labour market using different research methods and sources of evidence. Chapter 3 reviews the evidence from international studies, discussing first the effectiveness of anti-discrimination legislation and national equality strategies. Chapter 4 considers non-legal or 'proactive' tools, distinguishing measures by nature of the intervention and level of analysis, considering affirmative action policies and financial incentives, diversity training within organisations, recruitment practices and outreach strategies to promote diversity.

\subsection{WHAT IS DISCRIMINATION?}

Building on the simple definition of discrimination as unequal treatment on the basis of group membership, social science scholars often distinguish between differential treatment and disparate impact, creating a two-part definition (Blank et al., 2004; Quillian, 2006; Pager and Shepherd, 2008). For racial discrimination, Blank et al. (2004) proposed: (1) differential treatment on the basis of race that disadvantages a racial group; and (2) treatment on the basis of inadequately justified factors other than race that disadvantages a racial group. The first form of discrimination concerns one racial group receiving different treatment than another group because of race, with negative consequences for that racial group. It is sometimes referred to as direct discrimination or differential treatment. The second form refers to a behaviour or practice that treats individuals or groups equally according to a given set of rules that nonetheless disadvantages one group over another without a sufficiently compelling reason. This is broadly consistent with legal definitions of disparate impact discrimination and is sometimes called 'indirect discrimination' (see Fibbi et al., 2021, and Pager and Shepherd, 2008, for further discussion).

Measuring the causes of discrimination is even more difficult than measuring its extent. Much of the literature on discrimination focuses on the individual level or interpersonal interactions, in particular prejudice (an affect or feeling) and stereotypes (beliefs) at an interpersonal level, which scholars argue comprise the root causes of discrimination (see Box 1). Discrimination may be based on prejudice, with employers irrationally preferring ethnic majorities or non-migrants, for example, ignoring 'efficient workers' in favour of 'their own' (Becker, 1957). Or it may be that in the absence of information on unobservable skills such as motivation or productivity, employers wrongly use migrant or ethnic/racial 
minority status as an indicator of productivity (Allport, 1954; Arrow, 1973). ${ }^{2}$ Both these forms of discrimination are illegal under anti-discrimination legislation.

It can of course be difficult to measure prejudice and stereotypes accurately and, as noted above, the link between prejudice and behaviour is not always clear. Despite these issues, sociologists in particular direct our attention towards the organisational contexts in which people operate (Pager and Shepherd, 2008; Small and Pager, 2020). Much of the literature exploring organisational mechanisms of discrimination considers how organisational practices mediate the cognitive bias and stereotypes of individual actors (Reskin, 2000; Small and Pager, 2020). This includes the ways in which organisational structures and practice may influence decision makers (for example in recruitment and promotion), but also the role of social networks and more broadly practices in an organisation that are not intended to be discriminatory but may have a discriminatory impact.

Of course, decisions in organisations take place within broader social contexts. Members of minority groups may not just be discriminated against by the wilful acts of individuals, but because the prevailing structures of opportunities and constraints favour one group over the other (Blank et al., 2004). Pager and Shepherd (2008) outline the following understandings of what they call 'structural discrimination'. These draw our attention to broader, largely invisible contexts in which group-based inequalities may be structured and reproduced.

1. A legacy of historical discrimination can contribute to present-day inequalities in jobs, income or housing. Pager and Shepherd (2008) argue that a past history of discrimination is important in 'breathing new life into stereotypes' (p. 198); for example, that a given ethnic group is poor and welfare dependent.

2. Other understandings of structural discrimination focus on contemporary policies and practices in a particular jurisdiction that systematically disadvantage certain groups (Blank et al., 2004; Pager and Shepherd, 2008). These may be very obvious, deliberate and pervasive, such as the (past) apartheid system in South Africa, which codified racial discrimination in law. Policies can also systematically disadvantage certain groups, often unintentionally. For example, Smyth et al. (2009) described how some migrant families in Ireland find it very difficult to find places in schools due to admissions policies favouring settled communities, such as schools requiring parents to add their child's name to a waiting list at birth. While such policies were not designed to exclude recently arrived migrant children, this was an

Researchers differ in perspectives regarding the usefulness or accuracy of stereotypes. For social psychologists, these may be 'faulty or inflexible generalisations', while economic theories of statistical discrimination emphasise the utility of stereotypes for dealing with uncertainty (Arrow, 1973). See Pager and Shepherd (2008) and Neumark (2018) for further discussion of these theories of discrimination. 
outcome of them. ${ }^{3}$ Indeed, any reliance on long waiting lists or duration of residence for access to services will tend to disadvantage migrants, particularly recent arrivals (see McGinnity et al., 2020). Another example relates to conditions set out by banking institutions for an account to be opened: until recently, both applicants for international protection and refugees in Ireland struggled to open bank accounts here, as they were routinely unable to provide the required identification documents given the nature of their residence permission. ${ }^{4}$

3. The third approach to structural discrimination focuses on the accumulation of disadvantage (Blank et al., 2004; Pager and Shepherd, 2008). This relates to the extent to which the effects of discrimination in one domain or area of life, or at one point in time, can have consequences for a much broader range of outcomes. For example, as discussed above, labour market discrimination is likely to influence income, housing and health outcomes. Discrimination in the private rental sector may influence school choice. Single-point estimates of discrimination may underestimate the way disadvantage is triggered in other life domains. Discrimination may also accumulate across the life course of an individual - discrimination in the education system, for example, can have a serious impact on later employment chances (Blank et al., 2004). ${ }^{5}$

\subsection{EQUALITY AND ANTI-DISCRIMINATION LEGISLATION}

Anti-discrimination law is an important line of defence against racism and discrimination. At the international level, the Universal Declaration of Human Rights, the International Covenant on Economic and Social Rights and the International Covenant on Civil and Political Rights provide a fundamental framework for anti-discrimination (OECD, 2013). The relevant principles have been applied in two main conventions that specifically target racial discrimination: the International Convention on the Elimination of all forms of Racial Discrimination (ICERD) adopted in 1965 and ratified by Ireland in 2000 and the International Labour Organization (ILO) Convention 111 on Discrimination (Employment and Occupation), which was adopted in 1958 and ratified by Ireland in 1999. ${ }^{6}$

In Europe, the Racial Equality Directive, adopted in 2000, implements the principle of equal treatment between persons irrespective of racial or ethnic origin. ${ }^{7}$ It

This situation has changed somewhat with the introduction of the Education (Admission to Schools) Act 2018. Following engagement with the IHREC, one major public bank (Bank of Ireland) is now accepting alternative forms of identification for refugees and asylum seekers; see https://www.ihrec.ie/access-to-bank-accounts-confirmed-forasylum-seekers/.

5 See Watson et al. (2017) for a discussion of the role of low educational qualifications in contributing to poor labour market outcomes among Irish Travellers.

Ratified by 175 of 187 member countries.

Council Directive 2000/43/EC of 29 June 2000 implementing the principle of equal treatment between persons irrespective of racial or ethnic origin. 
distinguishes between direct and indirect discrimination and prohibits both. The Employment Equality Directive was also adopted in $2000 .^{8}$ These directives align with other European ones on discrimination in gender, age, disability, religion and sexual orientation. The Framework Decision on combatting racism and xenophobia by means of criminal law aims to ensure that serious incidents are punishable by criminal penalties. ${ }^{9}$ Non-discrimination is also enshrined in Articles 20 and 21 of the Charter of Fundamental Rights and in Article 14 of the European Convention on Human Rights. Both the Racial Equality Directive and the Employment Directive are currently under review (Crowley, 2020).

Almost all OECD countries have integrated anti-discrimination provisions in the field of employment into their national legal framework (OECD, 2020). Discrimination is prohibited by legislation on a wide range of grounds, with race and ethnicity among the most common ones identified, along with gender, sexual orientation, age and religion (OECD, 2020).

In Ireland, protection against discrimination is legislated for by the Employment Equality Acts 1998-2015, which prohibit discrimination in employment-related areas, and the Equal Status Acts 2000-2018, which prohibit discrimination in the provision of goods and services, accommodation and access to education. Under the Employment Equality and Equal Status Acts, discrimination is deemed to occur when a person is treated less favourably than another person is, has been or would be treated in a comparable situation on the grounds of gender, civil status, family status, age, disability, race, sexual orientation, religious belief or membership of the Traveller community. ${ }^{10}$ Discrimination on the ground of race is described as discrimination on the basis of being of different race, colour, nationality or ethnic or national origins. ${ }^{11}$

In June 2021, the Minister for Children, Equality, Disability, Integration and Youth announced a review of the functioning of the Equality Acts and their effectiveness in combatting discrimination and promoting equality (Department of Children, Equality, Disability, Integration and Youth, 2021).

The Employment Equality Acts 1998-2015 aim to ensure equality of opportunity in relation to employment for both Irish and non-Irish nationals. The Acts prohibit discrimination in the context of recruitment, working conditions, training in the workplace, harassment and other employment-related areas. If a person considers

8 Council Directive 2000/78/EC of 27 November 2000 establishing a general framework for equal treatment in employment and occupation.

9 Council Framework Decision 2008/913/JHA of 28 November 2008 on combatting certain forms and expressions of racism and xenophobia by means of criminal law.

10 Employment Equality Act 1998, as amended, s 6(1); Equal Status Act 2000, as amended, s 3(1). In in the case of the Equal Status Acts 2000-2015, receipt of housing assistance is a tenth ground.

11 Employment Equality Act 1998, as amended, s 6(2)(h). 
that they have been discriminated against on the grounds of race they may seek redress via the Workplace Relations Commission and on appeal to the Labour Court. ${ }^{12,13,14}$

The Acts address both direct and indirect discrimination (see Section 1.2): direct discrimination occurs when a person is treated less well than another person in the same situation or circumstances under any of the ten grounds covered in the Acts; indirect discrimination refers to practices or policies that do not appear on the face of it to be discriminatory but which have a discriminatory impact.

In addition to equality legislation, the Public Sector Equality and Human Rights Duty was established under the Irish Human Rights and Equality Commission Act 2014. This statutory obligation requires public bodies to recognise the need to promote equality, prevent discrimination and protect the human rights of employees, customers and service users. ${ }^{15}$

Finally, the Prohibition of Incitement to Hatred Act 1989 has provisions against racist hate speech. Ireland has seen an increase in racist and far-right mobilisation (IHREC, 2021). Hate speech can incite others to commit acts of discrimination and even intimidation or violence (ECRI, 2015). A detailed discussion of hate speech and hate crime is beyond the scope of this report, but it is worth noting that the narrow scope of existing Irish legislation has been criticised (Haynes and Schweppe, 2017) and that, following a period of public consultation, the General Scheme for a Criminal Justice (Hate Crime) Bill 2021 was published in April 2021. Under the new Bill, a hate crime will become a specific criminal offence for the first time. A range of characteristics will be protected: race; colour; nationality; religion, ethnic (including membership of the Traveller community) or national origin; sexual orientation; gender; and disability.

12 Employment Equality Act 1998, as amended, s 77. Decisions are published at www.workplacerelations.ie/en/cases. Note that the Workplace Relations Commission also handles claims regarding service-related discrimination under the Equal Status Acts 2000-2015, though the majority of cases are employment-related cases. Note that access to a remedy for discriminatory refusal of entry to a licensed premises (including bars, public houses, hotels and clubs) is governed by section 19 of the Intoxicating Liquor Act 2003, rather than by the Equal Status Acts. Therefore, these cases must be taken to the District Court, rather than the Workplace Relations Commission. The IHREC has highlighted that this is a procedurally complex route and that the majority of applications have been lodged by Travellers and have been either struck off, withdrawn or adjourned (IHREC 2019; 2021).

13 Employment Equality Act 1998, as amended, s 83. Prior to 2015, employment-related discrimination claims were made to the Equality Tribunal.

$14 \quad$ FLAC has commented on challenges regarding access to justice when equality claims go to the superior courts; see comments made by Eilis Barry at 'Ireland's Evolving Equality Architecture' event, June 2021, which was part of the '20 Years of the Equal Status Acts - FLAC Seminar Series'. Irish Human Rights and Equality Commission Act 2014, s 42. 


\subsection{EQUALITY BODIES AND DESIGNATED AGENCIES}

Anti-discrimination or equality law typically provides for the creation of agencies responsible for monitoring its application and implementing its programmes. The creation of an independent equality body or bodies is a requirement under the Racial Equality Directive and almost all Member States have now complied. ${ }^{16}$ The Racial Equality Directive foresees that such bodies should assist victims pursuing complaints, as well as conduct and publish research and make recommendations on discrimination (FRA, 2011). The European Commission recommended that standards for equality bodies provide further detail on the assistance function of such bodies, to include: receiving and handling complaints; providing legal advice to victims; representing complainants in court; acting as amicus curiae or expert; engaging in mediation/conciliation and strategic litigation; issuing recommendations in cases of discrimination; issuing legally binding decisions; and gathering relevant evidence and information. ${ }^{17}$

At the EU level, the European Union Agency for Fundamental Rights (FRA) is tasked with providing independent and evidence-based advice on fundamental rights, including by reporting on the application of the Racial Equality Directive. At national level, equality bodies initially tended to specialise on specific grounds, but more recently some have merged into single bodies (Crowley, 2018; Fibbi et al., 2021). In a 2018 review of equality bodies in 31 EU Member States and EFTA countries, 14 multi-mandate bodies were identified in 14 countries, including Ireland (Crowley, 2018).

The powers of national equality bodies vary across countries. Typically, activities range from awareness raising among public authorities, employers and the general public, to co-ordinating equality policies, to receiving complaints. ${ }^{18}$ In most OECD countries, national equality bodies may investigate discrimination claims (OECD, 2008a). Equality bodies may also take legal actions in some countries (such as Belgium, Denmark, Sweden and the UK), in such cases tending to prioritise strategic cases which serve the public interest (Fibbi et al., 2021; OECD, 2008a). Chapter 3 includes a discussion of evidence on their effectiveness.

\subsection{EQUALITY AND ANTI-DISCRIMINATION BODIES IN IRELAND}

Ireland's equality and anti-discrimination infrastructure began with the establishment of the National Consultative Committee for Racism and

\footnotetext{
16 In Poland, no entities were specifically 'designated' but the core tasks of assistance to victims, research and making recommendations fall within the remit of a range of existing bodies (FRA, 2011).

17 European Commission (2018) Commission Recommendation (EU) 2018/951 of 22 June 2018 on standards for equality bodies.

18 In Ireland, the function of receiving complaints is carried out by the Workplace Relations Commission (see Section $1.5)$.
} 
Interculturalism (NCCRI) in 1998, followed by the Equality Authority in 1999 and the Irish Human Rights Commission in 2001. The State's first National Plan Against Racism 2005-2008 was published in 2005 (see below). However, the 2008-2012 recession saw significant funding cuts, which resulted in the closure of the NCCRI and reduced the capacity of Ireland's equality and anti-discrimination bodies. For example, funding of the Equality Authority was cut by 43 per cent in 2009 (McGinnity et al., 2011). Fanning and Michael (2017) argue that much of the institutional infrastructure for monitoring, reporting and responding to racism and discrimination in Ireland was dismantled during this recesssion period and had not been replaced.

Today, the Irish Human Rights and Equality Commission (IHREC) acts as Ireland's national equality and human rights body. The IHREC's role is to promote and protect human rights and equality, working toward the elimination of discrimination, including in the areas covered by the Employment Equality Acts and Equal Status Acts 2000-2015. ${ }^{19}$ The organisation is also tasked with supporting a culture of respect for human rights, equality and intercultural understanding. In its latest strategic plan, the IHREC commits to playing a leadership role in combatting racism and hate speech and promoting intercultural understanding (IHREC, 2019).

The IHREC was established in 2014, under the Irish Human Rights and Equality Commission Act 2014, which merged the Equality Authority and the Irish Human Rights Commission. It is tasked with providing information to the public on the Acts, reviewing the effectiveness of the Acts and, where it deems necessary, making proposals to the Minister to amend the Acts. ${ }^{20}$ The IHREC may apply to appear as amicus curiae (friend of the court) in cases related to human rights or equality and in some circumstances provide legal assistance to persons who wish to bring a discrimination claim to the Workplace Relations Commission. ${ }^{21}$ The IHREC can also prepare codes of practice relating to the elimination of discrimination, ${ }^{22}$ and can invite particular organisations to carry out an equality review. ${ }^{23}$ The IHREC also promotes the implementation of the Public Sector Equality and Human Rights Duty by public bodies. ${ }^{24}$

Irish Human Rights and Equality Commission Act 2014, s 10.

Irish Human Rights and Equality Commission Act 2014, s 30(1).

Irish Human Rights and Equality Commission Act 2014, s 40.

Irish Human Rights and Equality Commission Act 2014, s 31.

The IHREC can itself carry out reviews of organisations with more than 50 employees to determine whether the policies and practices are conducive to the promotion of equality of opportunity (Irish Human Rights and Equality Commission Act 2014, s 32). See https://www.ihrec.ie/our-work/equality-review for further details.

24 Irish Human Rights and Equality Commission Act 2014, s 10(2). See Section 3.1 for further discussion of the Public Sector Equality and Human Rights Duty. 


\subsection{DIVERSITY STATEMENTS, STRATEGIES AND ACTION PLANS}

\subsubsection{EU level}

While legal prohibition of discrimination is important and necessary, it is widely acknowledged that legislative measures are not enough. Most OECD countries have implemented additional measures such as proactive strategies and plans (OECD, 2020). In June 2020, the European Commission sought to build on legislative prohibition against racial or ethnic discrimination by publishing the first European Union Anti-Racism Action Plan (2020-2025). The Plan commits to increased awareness raising of racism and stereotypes and encourages all Member States adopt an anti-racism plan by the end of 2022. It stresses the need to address discriminatory attitudes, in particular by law enforcement authorities. The Plan states that implementation of EU non-discrimination legislation will be reviewedthe extent to which hate speech and hate crimes are criminalised at national level is highlighted as a particular concern. Where necessary, the Commission will seek to strengthen the legal framework. In line with a commitment under the Plan, the first EU anti-racism coordinator was appointed May 2021 (European Commission, 2020).

\subsubsection{National level}

Several national-level strategies and action plans have been adopted which address racism and anti-discrimination in Ireland. Ireland is a signatory to the UN Durban Declaration and Programme of Action of 2001. Arising from those commitments, the first National Plan Against Racism 2005-2008 was published in 2005. It had five main objectives: effective protection and redress against racism; recognition and awareness of diversity; accommodating diversity in service provision; economic inclusion and equality of opportunity; and full participation in Irish society (Department of Justice, Equality and Law Reform, 2005). In 2008, Migration nation: A Statement on Integration Strategy and Diversity Management set out the government's vision for Ireland's increasingly diverse society. This was followed almost ten years later by the Migrant Integration Strategy 2017-2020 (Department of Justice and Equality, 2017), which seeks to identify and address barriers to integration in order to enable migrants or persons of migrant origin to participate on an equal basis with those of Irish heritage in Irish society. The Strategy recognises racism and discrimination as barriers to integration and includes commitments to combat racism and xenophobia, through: strengthening hate crime legislation; intercultural awareness and training; working with communities affected by stigmatisation; and developing appropriate relationships with minority communities. The National Traveller and Roma Inclusion Strategy 2017-2021 sets out a range of objectives and actions aimed at improving conditions for the Traveller and Roma community in Ireland, including in relation to anti-discrimination and equality (Department of Justice and Equality, 2017). 
Most recently, an independent Anti-Racism Committee was established by the Irish government in 2020 to review current evidence and practice and to recommend how Ireland should strengthen its response to racism. Its work will include producing a new National Action Plan Against Racism. The Anti-Racism Committee interim report, which was published in April 2021, contains several interim recommendations as well as priority issues for further consideration. The latter includes a focus on adequate complaint and redress mechanisms, the role of information and communications, as well as supports for victims. The Committee is considering issues related to education, racism in employment, access to justice and policing (Anti-Racism Committee, 2021). A public consultation on the Action Plan was conducted, closing in July 2021. The present study constitutes part of the Committee's consideration of the employment sphere.

Section 1.7 provides a description of the method undertaken. It is followed by Section 1.8 which sets out both the scope and the limitations of this research.

\subsection{METHOD OF THE REVIEW}

This study consolidates major studies of labour market discrimination, including by the Organisation for Economic Co-operation and Development (OECD), which distinguish measures to combat discrimination in the labour market. We started by reviewing a number of major overviews carried out by the OECD (OECD 2008a, 2013,2020 ), as well as a recent overview of migration and discrimination (Fibbi et al., 2021), in order to identify and classify policy, initiatives and measures for consideration in this study. We drew upon the reference lists cited in these sources for the identification of further relevant studies ('ancestry searching'). For each of the measures under discussion in Chapter 4, we also searched databases such as Google Scholar and Stella Search. We searched for literature on specific interventions: affirmative action and equal opportunities policies; financial incentives, including wage subsidies; diversity and unconscious bias training; formalisation of recruitment, including new technologies; and networking practices in recruitment and in the workplace. These terms were paired with those for relevant initiatives, such as 'effectiveness' and 'discrimination'. Studies were also found by scoping bibliographies and references of relevant publications found by database searching. In terms of time bands, we sought to include studies that were published after 2000. However, where studies carried out prior to 2000 were particularly relevant we opted to include them. The literature search was linguistically bound in that it was limited to the English language. ${ }^{25}$ While the majority of academic journal articles in the field are in English, we expect this language limitation may rule out some policy evaluation literature in other European countries that is written for national audiences in the country's native

25 There were three exceptions: two studies in German and one in Norwegian, to which we were alerted as being of particular relevance. 
language. We supplemented the literature search by queries to individual experts in the field to point us to further literature sources.

The focus of this report is on collating the best available evidence, and priority is given to rigorous evaluations of whether measures are effective or not. In some cases, the studies included in the review centre on anti-discrimination measures but no evaluations of these measures are provided: this is signalled in the text. In other cases, studies evaluated multiple measures simultaneously, with efforts made to distinguish the effects of each measure; however, it was not always possible to do so. Sometimes the content of a particular measure, for example diversity training, varied substantially from programme to programme, making it difficult to compare and generalise regarding overall efficacy. While priority was given to newer evaluations published in the last decade, in cases where robust evaluations did not exist, older ones were considered.

The main purpose of this review is to assess the impact of given measures and policies on outcomes, isolating impact from other external influences (see Bilgili et al., 2015). The following principles were applied in identifiying those evaluations or studies to be included in this review.

- Evaluations of methods should have clear research questions, outcome variables and indicators.

- Research should use the appropriate statistical tests to determine the effects of the various measures on diversity or discrimination in the workplace/ labour market.

- Where possible, preference is to be given to evaluations that employed experimental methods to uncover causal mechanisms.*

- For non-experimental studies, preference is to be given to studies that use report evidence from before and after the introduction of the measure, ideally accounting for any other changes.

- For a more thorough assessment of the impact of a measure, short-, medium- and longterm effects should be considered.

- Random samples are the preferred sampling strategy; however, studies that use other sampling approaches are also considered in cases where the sampling strategy is considered robust and necessary for the research question at hand.

Note: $\quad *$ Randomised, controlled experiments allow causal inferences as they present carefully constructed and controlled comparisons (Neumark, 2018). See Section 2.2.6 for further discussion.

\subsection{SCOPE OF THE REVIEW}

In order to limit the scope of this review, the focus is on the labour market. Clearly, the consequences of labour market discrimination can spill over into many other areas of people's lives, as discussed in Section 1.2. At the same time, solutions to discrimination within the labour market may be very different to those found in 
the education system, the health service or public transport. While this review involves consideration of some behaviour-related measures to combat prejudice and bias, most of the focus is on changing behaviour to combat discrimination and promote diversity specifically in the labour market.

Useful measures can be put in place by relevant government departments and agencies, as well as by employers and workplaces; the latter comprises an important aspect of the literature review in Chapter 4. Many measures also depend on the cooperation of co-workers, managers and other colleagues in the workplace. We return to the importance of a 'whole of society' approach in the conclusion. Another important point is that policies to combat discrimination more broadly and to promote equality and diversity on other grounds - such as gender, age and disability - though not the main focus of this review may also be relevant and useful to promote racial and ethnic diversity and combat discrimination.

We acknowledge that discrimination may be intersectional, though this is not an explicit focus of this review. According to Collins (2015), the term intersectionality refers to the critical insight that race, class, gender, sexuality, ethnicity, ability, nationality and age, rather than operate as mutually exclusive identities, interact in certain ways to shape complex patterns of social inequality. Thus the combination of numerous specific characteristics can lead to distinct forms of discrimination or disadvantage. For example, the experience of Black men may be different from that of Black women (Crenshaw, 1989). For this review, this would also imply that the effectiveness of programmes might differ for minority men and women, or for ethnic minority lone parents compared to married/cohabiting parents, or minority young people compared to older people. Studies reviewed typically do not distinguish between different groups like this, but where studies report differences in effects for ethnic minority men and ethnic minority women, this is reported. Applying intersectionality as an analytic strategy for both research and policy is challenging, as multiple combinations of characteristics are possible, and it can be difficult to justify which to prioritise (OECD, 2020).

The focus of this review is on measures that can be implemented to address current discrimination in the labour market: while we acknowledge issues such as the accumulation of disadvantage by individuals and the interconnectedness of disadvantage in different areas of people's lives (work, poverty, housing), this issue is not addressed within this report, as its specific focus is the labour market. Similarly, this report concentrates on the current situation and the future of the labour market. As such, aside from acknowledging the role and legacy of historical discrimination, this aspect of labour market discrimination is not explored in depth.

Chapter 2 considers what we know about the extent of racial discrimination in the Irish labour market. Chapter 3 then looks at legal mechanisms for reducing 
discrimination and their effectiveness. Finally, Chapter 4 considers those practices within organisations that can either mitigate or reduce the prejudice of individuals, as well as those that can unwittingly contribute to the systematic disadvantage of certain groups. 


\section{CHAPTER 2}

\section{Diversity and racial discrimination in the Irish labour market}

Before presenting the international review of the effectiveness of measures to combat discrimination, we consider evidence about the extent and nature of racial discrimination in the Irish labour market. We begin by documenting increased ethnic diversity in Ireland. Efforts to introduce measures to combat racial discrimination are strengthened by evidence on the extent of the problem.

\subsection{ETHNIC DIVERSITY IN IRELAND}

The marked increase in immigration that accompanied the economic boom of the late 1990s and early 2000s known as the Celtic Tiger brought considerable ethnic and national diversity to Ireland (Fanning, 2021). The proportion of the population who are foreign nationals (those who do not claim Irish citizenship) more than doubled between 2002 (5.8 per cent non-Irish) and 2010 (12.3 per cent non-Irish). ${ }^{26}$ Most immigration of non-Irish nationals to Ireland has been from other EU countries; in 2019 for example, 74 per cent of non-Irish nationals were from other EU countries (McGinnity et al., 2020). ${ }^{27}$ Many migrants of non-EU origin have acquired Irish citizenship through naturalisation, so while they were born outside the EU they have the same rights and responsibilities as Irish citizens born in Ireland (McGinnity et al., 2020).

While nationality is based on an individual's country of citizenship and immigrant status relates to whether or not they were born abroad, ethnicity is usually selfdefined. Information on ethnicity was collected for the first time in the Irish Census in 2006 and was subsequently collected in 2011 and 2016. ${ }^{28}$ A number of commentators have highlighted limitations with the measure used. King-O'Riain (2007), for example, argues that there is an inherent compromise in using simple categories to measure diversity and the complex lived reality of race and ethnicity. The result is ethnic 'meta-categories', which are limited in both number and explanatory power. While we acknowledge these limitations, there are no alternatives currently available in Ireland. The advantage of measuring ethnicity in in this way is that it allows us to capture not only those born abroad, but those

26 McGinnity et al. (2018), Table 1.1, using Census data for 2002 and CSO Population and Migration estimates for later years.

27 McGinnity et al. (2020), Table A1.1 based on Labour Force Survey data and counting the UK as part of the EU, as it was in 2019. Census respondents were asked: 'What is your ethnic or cultural background?' See https://www.cso.ie/en/media/csoie/census/census2016/2016censusforms/65995_English_Household_2016_New_V ersion_Do_Not_Complete.pdf, question 11 for detailed answer categories. 
from ethnic minority groups who were born in Ireland, including Ireland's indigenous minority group, Irish Travellers.

Table 2.1 presents the population of Ireland by ethnic background, from 2006 to 2016. It shows that the number and proportion of people who indicated an ethnicity other than 'White Irish' increased significantly between 2006 and 2016. Of the population who indicated an ethnicity other than 'White Irish', 'other White' remains the largest group, at 9.5 per cent of the population in 2016. This group comprises a range of regions of origin, with 'EU East' dominating, followed by the UK, 'EU West' and 'White non-EU'. ${ }^{29}$ The proportion of people in the 'other White' category increased substantially between 2006 and 2011, in tandem with a rapid rise in immigration, particularly from eastern Europe (McGinnity et al., 2018, based on population and migration estimates).

Asian or Asian Irish accounted for just over 2 per cent of the population in 2016. Numbers in the Asian ethnic group almost doubled, from just over 52,000 in 2006 to just under 100,000 in 2016. The number of people in the 'Black or Black Irish' category also grew over the period, though not as dramatically, from 44,000 in 2006 to 65,000 in 2016, when this group made up 1.4 per cent of the total population.

While ethnicity, country of birth and nationality overlap, they are not the same. This is illustrated by the fact that 38 per cent of those in the 'Black or Black Irish' category were born in Ireland and 62 per cent were born abroad, mostly in Africa; 50 per cent of the Black ethnic group hold Irish citizenship (McGinnity et al., 2020).

29 This is based on McGinnity et al. (2018a) using QNHS (Labour Force Survey) Equality modules from 2004, 2010 and 2014. 
TABLE 2.1 POPULATION BY ETHNIC BACKGROUND 2006, 2011 AND 2016

\begin{tabular}{|l|r|r|r|r|r|r|}
\hline $\begin{array}{c}\text { Reported ethnic or } \\
\text { cultural background }\end{array}$ & \multicolumn{2}{|c|}{2006} & \multicolumn{2}{c|}{2011} & \multicolumn{3}{c|}{2016} \\
\hline & Persons & \multicolumn{1}{c|}{$\%$} & Persons & $\%$ & Persons & $\%$ \\
\hline White & $3,956,609$ & 94.8 & $4,264,465$ & 94.2 & $4,331,940$ & 92.4 \\
\hline Irish & $3,645,199$ & 87.4 & $3,821,995$ & 84.5 & $3,854,226$ & 82.2 \\
\hline Irish Traveller & 22,369 & 0.5 & 29,495 & 0.7 & 30,987 & 0.7 \\
\hline Other White & 289,041 & 6.9 & 412,975 & 9.1 & 446,727 & 9.5 \\
\hline Black or Black Irish & 44,318 & 1.1 & 65,078 & 1.4 & 64,639 & 1.4 \\
\hline Asian or Asian Irish & 52,345 & 1.3 & 84,690 & 1.9 & 98,720 & 2.1 \\
\hline Other, including mixed & 46,438 & 1.1 & 40,724 & 0.9 & 70,603 & 1.5 \\
\hline Not stated & 72,303 & 1.7 & 70,324 & 1.6 & 124,019 & 2.6 \\
\hline Total & $4,172,013$ & 100.0 & $4,525,281$ & 100.0 & $4,689,921$ & 100.0 \\
\hline
\end{tabular}

Source: Census 2006; Census 2011; Census 2016.

The 'other, including mixed' category accounted for 1.5 per cent of the population in 2016, including those from a mixed-ethnicity background and those who did not feel they fitted into any of the other categories. McGinnity et al. (2018) note this category is very diverse and includes people from Poland, Romania, Brazil and the UK, among other countries. ${ }^{30}$

The number of Irish Travellers enumerated in Census 2016 was around 30,000, similar to the figure for 2011. In 2016, Irish Travellers made up 0.7 per cent of the population. While the proportion of Irish Travellers enumerated in the Census rose between 2006 and 2011 (see Table 2.1), Watson et al. (2017) noted evidence of greater under-coverage of the Traveller population in the 2006 Census than in 2011. As a result, it is not clear to what extent these differences are due to a real change in circumstances or to improved coverage of Travellers living in conventional accommodation in 2011 (ibid.).

McGinnity et al. (2018) found that of the labour market active population, ${ }^{31}$ a much higher proportion of other ethnic groups have third-level educational qualifications than the White Irish group. ${ }^{32}$ These other ethnic groups are also more concentrated in the 25-44-year-old age group than White Irish. Evidence also suggests these groups may be treated differently to White Irish.

\footnotetext{
30 We cannot rule out the possibility that some respondents had difficulties answering the question. Note this is separate to 'not stated', which refers to those who did not respond to this question.

31 I.e. employed plus unemployed groups.

32 These data do not identify Irish Travellers. They are also based on data from 2004, 2010 and 2014.
} 


\subsection{MEASURING DISCRIMINATION: EVIDENCE FROM THE IRISH LABOUR MARKET}

Racial discrimination is understood in this report to mean the unequal treatment of people based on their group membership ('who they are') as opposed to their skills and qualifications ('what they can do'). Assessing the extent and nature of discrimination is crucial to developing effective responses, but it is very challenging to measure the concept accurately. There are a variety of methods used (Blank et al. 2004; Pager and Shepherd, 2008; Fibbi et al., 2021). Each has its own strengths and limitations, and each provides different insights, suggesting they provide complementary forms of evidence, as opposed to competing ones, and that it is in gathering evidence from a range of sources that discrimination can best be assessed. They include: differential-outcome studies using statistical analysis, or the 'ethnic penalty' approach; an analysis of legal caseloads or cases taken to bodies such as the Workplace Relations Commission; evidence from other reporting mechanisms; analysis of attitudes of the majority population and attitudinal climate; self-reports of discrimination to surveys; and finally evidence from experiments.

\subsubsection{Comparing ethnic group outcomes and the 'ethnic penalty'}

At its most basic, comparing group outcomes, such as unemployment rates, wages or other features of job quality, can be informative (McGinnity et al., 2020, McGinnity et al., 2021). This is sometimes known as equality monitoring. It allows researchers and policymakers to assess the scale of inequality between groups, and which groups are most disadvantaged. It can also be used for assessing 'direction of travel' - that is, for measuring change over time, or for comparing outcomes before and after a given policy or practice has been introduced to the workplace.

A common extension of this in research is to compare group outcomes, such as unemployment, wages, or other working conditions, and then control for nondiscriminatory sources of difference, such as skills and experience, using statistical modelling (Pager and Shepherd, 2008). This allows the analyst to assess the extent to which group differences are related to these characteristics. The remaining difference between ethnic groups, after these other factors have been accounted for, is known as the 'ethnic penalty' (Heath and Cheung, 2007). However, as the Organisation for Economic Co-operation and Development (OECD) (2013) point out, it is important to note that the residual (or unexplained) disadvantage cannot be assigned solely to discrimination. Discrimination may be a component of this difference, but not the sole contributor. Minority groups may lack knowledge about potential openings in the labour market, or they may lack networks and personal contacts through which many vacancies are filled, or they may lack knowledge about the process of applying for a particular job. Note also that 
educational qualifications and experience can be a function of previous discrimination in either education or employment (see Darity and Mason, 1998). Here, the focus is on current discrimination, with the acknowledgement that it may underestimate discrimination.

This method is important for assessing (in)equality or disadvantage, and for monitoring outcomes for disadvantaged groups and groups that may need policy support, but it is not the most precise way of capturing the extent of discrimination. Quillian (2006) argues models of the ethnic penalty are perhaps best understood as how much of the ethnic or racial gap is caused by measured factors, rather than as a method to measure discrimination per se.

In Ireland, research on the labour market outcomes of different ethnic groups has found clear and consistent evidence of disadvantage of the Black ethnic group in terms of access to the labour market, particularly among those who are not Irish citizens and/or are born abroad. McGinnity et al. (2018) found Black non-Irish nationals are significantly less likely to be employed than White Irish, controlling for educational qualifications, age, gender, family type, broad region and length of time living in Ireland. ${ }^{33}$ McGinnity et al. (2020) further found that this effect remains even after accounting for these factors, as well as language skills and the probability of having come through the protection system. ${ }^{34}$ The Asian ethnic groups, by contrast, show a different pattern. McGinnity et al. (2018) demonstrate that the Asian non-Irish group does not differ from White Irish in terms of overall employment rates; in fact, those categorised within the Asian Irish group are actually more likely to be working in professional managerial occupations than White Irish (ibid.).

Of all ethnic groups considered, labour market outcomes are poorest for Irish Travellers. Travellers show exceptionally low employment rates (11 per cent in 2016) and extremely high unemployment rates (80 per cent in 2016) (McGinnity et al., 2021, using 2016 Census data). When Watson et al. (2017) modelled the ethnic penalty in employment using 2011 Census data, they found that two-thirds of this difference in employment rates is due to the extremely low education levels among Travellers. This suggests that if Travellers had the same level of education as non-Travellers, their employment rate would still be almost two times lower than that of non-Travellers (instead of the observed six times lower). This residual difference suggests that it is not just education differences that underly the disparity.

33 McGinnity et al (2018a) use data from 2004, 2010 and 2014 and the International Labour Office definition of employment, which counts low hours of work as employment.

34 McGinnity et al (2020) use Census 2016 microdata which measures unemployment using the principal economic status. 


\subsubsection{Evidence of discrimination from legal cases and tribunals}

A second approach to assessing discrimination is to use evidence from decisions on legal cases, tribunals or other reporting mechanisms. After all, courts require a stringent standard of evidence, and these cases are thoroughly evaluated. In Ireland, examples include cases taken to the Work Relations Commission, or on appeal to the Labour Court (see Chapter 1). The advantage of monitoring and analysing these cases is that the review of evidence is thorough, and cases are comprehensively evaluated: they do not rely on individuals' own assessments. The cases also provide rich detail on treatment at an individual level. For example, in 2020, 210 of 1,260 complaints referred to the Work Relations Commission under the Employment Equality Acts were based on the race ground, comprising 17 per cent of all complaints made. Of 452 complaints referred under the Equal Status Acts, 76, or 17 per cent, were based on the race ground (Work Relations Commission, 2021). However, no data are available on the ethnicity of these complainants (ibid.).

A problem here is that cases are likely to represent only a small fraction of the number of those who actually experience discrimination. Only those with sufficient financial and other resources will be in a position to take a case; therefore, numbers of such cases only represent the 'tip of the iceberg' (OECD, 2013). We know from representative surveys of the experience of discrimination (see below) that only 10 per cent of those experiencing discrimination take any formal action, including making a formal complaint in their organisation or taking legal action (McGinnity et al., 2012). ${ }^{35}$ Those who do take formal action tend to be wellinformed about their rights, well-resourced and Irish citizens (McGinnity et al., 2012), so solely considering legal cases would give a distorted picture about which groups in the population experience discrimination.

\subsubsection{Evidence of reporting of racist incidents}

Non-governmental organisations (NGOs) provide informal means of reporting discrimination and racism in the workplace. For example, in 2013 the Irish Network Against Racism established the online iReport Racist Incident Reporting System (www.ireport.ie). Evidence from racist incident monitoring during 2020 demonstrates that the group most commonly reporting experience of both crime and discrimination is the Black ethnic group (Black-Irish, Black-African, Blackother). Together, those in these categories experience one-third of all crime cases and one-third of all discrimination cases reported on iReport (Michael, 2021). ${ }^{36}$

\footnotetext{
35 Respondents who experienced discrimination were asked the follow-up question: 'May I ask what action, if any, did you take in reaction to discrimination you have experienced? In particular have you complained verbally, in writing, made an official complaint or taken legal action?' McGinnity et al. (2012) combined 'official complaint' and 'legal action' because of small numbers. By contrast, 40 per cent of those who had experienced discrimination took verbal action.

36 See Michael (2021) for details of how racist incidents are measured.
} 
According to its latest report, 700 incidents of racism and discrimination were received by iReport in 2020. Of these, 99 concerned instances of illegal discrimination, of which 22 concerned discrimination within the workplace or by people seeking work (Michael, 2021). Importantly, the report notes that workplace incidents had decreased from previous years, which may have been as a result of lockdown measures imposed due to COVID-19. Though supported by legislation which prohibits discrimination, 44 (44 per cent) of the 99 instances of illegal discrimination reported to iReport in 2020 were not reported to any other body. Clearly, the costs of reporting an incident to iReport are much lower for the individual than taking a case to court or the Workplace Relations Commission and the tool is very useful. Even so, an individual still needs to be informed about the system, have the resources (linguistic, technical, know how) to actually report a racist incident, and believe that it is worthwhile to do so. Thus, under-reporting may be a concern here as well. Individuals may also differ in their understanding of what constitutes a racist incident. Moreover, while growth in awareness of the tool will improve its effectiveness, it will also make it difficult to ascertain whether any increase in reported racist incidents is due to that or whether it signals an actual increase in racist incidents.

\subsubsection{Attitudes and attitudinal climate}

Another method is that of surveys to measure the attitudes of the whole population to minority groups. In Ireland, much of this kind of evidence comes from large-scale European social surveys like the European Social Survey or the Eurobarometer. Research can focus on attitudes to immigrants and their economic and cultural contribution (McGinnity et al., 2018), specific groups such as Muslim immigrants (Fahey et al., 2019) and Roma (FRA, 2016), or social distance to minority groups (MacGreil, 2008). These studies are useful for giving insight into the attitudinal climate towards a particular group, how this changes over time and how it varies according to group characteristics. Attitudes of employers or other recruiters may be more indicative of labour market discrimination (Fridberg and Mitboen, 2018). A key problem for measuring discrimination is that holding negative attitudes towards a group does not equate to treating them unfairly, though the two may be related. Pager and Quillian (2005) investigated the relationship between employers' actions and attitudes, by matching results from a field experiment measuring actual behaviour with a telephone survey of the attitudes of those employers who were included in the field experiment. They found a large discrepancy between what employers said in the survey and who they actually called to interview in practice. A much greater proportion of employers stated they would hire a job applicant with a criminal record in the survey (around 60 per cent for both White and Black applicants), compared to the 
experiment, where 17 per cent of White applicants were called to interview and 5 per cent of Black applicants were called to interview (ibid.). ${ }^{37}$

Social desirability bias refers to a tendency means among survey respondents to not reveal negative attitudes. McGinnity et al. (2020) found that respondents in Ireland were considerably more supportive of Black immigration when asked directly (66 per cent supported this), compared to only half of respondents supporting Black immigration when offered anonymity via a list experiment. ${ }^{38}$ This is important because recruitment decisions are typically taken in private, behind closed doors (ibid.).

No such 'masking' of negative sentiment was found for Muslim immigration to Ireland, with about half of respondents supporting Muslim immigration when responding directly or anonymously, suggesting that this masking of negative attitudes depends on the minority group in question (ibid.). Byrne (2014), in an ethnographic study of Irish professionals, also contrasts the public-facing welcome to immigrants and ethnic minorities, with hostility to minority groups displayed in private circles, among friends. In particular, racial distancing and the use of racial tropes such as the 'sexually predatory Black man, the terrorist Muslim, the criminal Roma, the violent Traveller' to distance White Irish professionals from other ethnic groups was only done in private (Byrne, 2014, p. 15).

Another method for assessing attitudinal climate is to analyse the expression of negative attitudes and stereotypes using media evidence. Haynes et al. (2006) analysed the framing of migrants in print media in Ireland, finding particularly negative frames for asylum seekers and refugees, whose statuses are often conflated. By contrast, Haynes et al. (2009) found that media-informed perceptions of Polish migrants to Ireland are more positive. A particularly innovative recent study in Ireland by Siapera et al. (2018) used data scraped from Twitter and Facebook to analyse patterns of 'racially-loaded toxic' online speech. Anti-immigrant discourse was found to be focused on a perceived financial or fiscal burden of immigration (welfare and housing) and the extent to which immigrants are considered morally deserving. Racist speech against Black people incorporated anti-immigrant and Islamophobic tropes, but speech also reinforced stereotypes, such as laziness and criminality (Siapera et al., 2018). While this gives a sense of the 'content' of negative attitudes in a way that surveys do not, and also reveals the 'attitudinal climate', there is still the issue of how representative these views are of others in society: not everyone, particularly in decision-making positions, are 
active on social media, or express negative views there. Furthermore, it is not always clear where such content originates, as web content is global in scope.

Conventional media reporting and social media posts can provide a useful indicator of racist sentiment in society; when racist sentiment occurs there, it can be damaging to the wellbeing of those being discriminated against (Sizemore and Milner, 1994; Cano et al. 2020). However, as with attitudes expressed in social surveys, they may not be clearly related to unequal treatment in recruitment or in the workplace.

\subsubsection{Asking people directly: Self-reports of discrimination}

A final tool for monitoring discrimination over time is to ask respondents directly about their experience of discrimination. This can be done via qualitative interviews or surveys. Surveys aim to be representative of the population they study, making their findings generalisable. In Ireland, the special modules of the QNHS (Labour Force Survey) on equality and discrimination, which was fielded by the CSO (2004, 2010 and 2014), and a later smaller survey (CSO, 2019) are good examples of this approach. ${ }^{39}$ The strengths of these surveys lie in the size and representativeness of the sample, the diversity of social groups reporting their experience and the range of situations covered. Crucially, these data allow us to compare the experiences of minority groups with those of the majority. For example, they help us to understand whether the experience of workplace discrimination (such as in pay, promotion, harassment) is more commonly reported by a specific group, or a general feature of working life in Ireland (McGinnity et al., 2017). ${ }^{40}$ In addition, follow-up questions can be asked about the impact of discrimination on people's lives and the actions they may or may not have taken, such as reporting it or taking a case to a tribunal, which in turn allows us to assess the proportion of incidents that are reported and actions that are taken (see above) (McGinnity et al., 2012). These surveys can also track change over time.

A key strength of these surveys on the experience of discrimination is that they give voice to those affected, allowing respondents to report discrimination. This is also a key limitation: interpretations of discrimination are subjective. Unlike legal cases, there is no independent arbitrator to assess whether discrimination took place. Discrimination in recruitment may be underreported because it is not observable to the job applicant or overreported if, in an ambiguous situation,

39 The first three (2004, 2010 and 2014) were special modules of the Labour Force Survey, with large samples of adults - from 15,000 to almost 25,000. Identical questions were fielded in 2019 as part of the General Household Survey; here, the sample size was less than 4,000, which severely limits analysis of small population groups such as ethnic minorities (see McGinnity et al., 2021).

$40 \quad$ It also allows us to analyse a very wide range of important aspects of people's lives - not just when they apply for a job, but, for example, also when they use public services, public transport and health services. 
respondents falsely attribute their treatment to discrimination when it is in fact due to some other reason (for example, poor performance). Some of this subjectivity can be reduced by question wording, and the CSO surveys of equality and discrimination mentioned above are examples of good practice in this regard. ${ }^{41}$

Based on pooled analysis of three of these CSO surveys of discrimination (carried out in 2004, 2010 and 2014), McGinnity et al. (2018) found that the Black ethnic group reports higher rates of discrimination in recruitment than White Irish, White EU nationals or the Asian ethnic group, with the 'other/mixed' ethnic group in an intermediate position. This is particularly true of Black non-Irish, who are five times more likely to report recruitment discrimination than White Irish. ${ }^{42} \mathrm{~A}$ study based on the 2014 survey of discrimination found that Irish Travellers report the highest recruitment discrimination - 10 times that of White Irish (McGinnity et al., 2017).

In these CSO surveys of discrimination, respondents were also asked about their experience of discrimination in the workplace. Workplace discrimination includes bullying or harassment, unfair treatment in terms of working conditions, promotion, pay and other forms of discrimination. Bullying or harassment is closest to notions of 'everyday discrimination' or microaggressions (Deitch et al., 2003; Cortina, 2008). This refers to acts of discrimination that occur in day-to-day interactions, and can often more subtly pervade the work environment. While often not intentionally injurious, this subtle or interpersonal discrimination can be just as detrimental to individual wellbeing (Jones et al., 2016). ${ }^{43}$ Based on the data collected through the CSO surveys, McGinnity et al. (2018) examined all types of workplace discrimination. The findings revealed that all non-White ethnic minorities (and some White non-Irish groups) reported more discrimination in the workplace than White Irish - with Black non-Irish experiencing the highest rate of workplace discrimination (McGinnity et al., 2018). Rates of workplace discrimination were also higher among than White Irish for White EU-East, White non-EU, Asians and other/mixed ethnicity than among White Irish (ibid.). Importantly, the experiences of Travellers are not captured in survey estimates of workplace discrimination as their sample size in the dataset (those who were employed) was too small to permit analysis.

Comparative surveys of the experience of racism and discrimination can usefully situate Ireland in a comparative context. One challenge here is that countries vary in the ethnic and national composition of their populations, and the most useful comparisons concern the same ethnic or national group (for example, FRA, 2017;

41 Respondents are given a definition of discrimination in Irish law; they are asked about a range of specific life domains and about a limited time period (two years).

42 Evidence of change over time suggests increasing discrimination against the Black ethnic group, while discrimination against White non-Irish fell (ibid.).

43 Jones et al. (2016) define subtle discrimination as concerning interpersonal interactions, compared to 'formal discrimination', which they define as unfair treatment in pay, promotions, recruitment and access to resources. 
McGinnity and Gisbjerts, 2017). A comparative survey by the European Agency for Fundamental Rights (FRA) in early 2016 reveals that the highest rates of discrimination in the workplace experienced by sub-Saharan African respondents are documented in Luxembourg, Sweden and Ireland (in the 12 months prior to the survey) (FRA, 2017). A recent FRA survey of Travellers and Roma (2020) reports that discrimination experienced by Irish Travellers in seeking work was the highest among all Traveller and Roma groups in the six countries studied and that their paid employment rate was the lowest. ${ }^{44}$

As well as large-scale social surveys, experiences of discrimination can be investigated by a more in-depth approach. Joseph (2017) conducted semistructured interviews and found evidence of a racial hierarchy in the Irish labour market, with Irish at the top, followed by West Europeans (Spanish), East Europeans (Polish) and Africans (Nigerian). Mullen et al. (2021) conducted in-depth interviews with Irish Travellers in the mainstream labour market, revealing barriers and enablers to employment. Studies such as these considerably enhance our understanding, but are not generalisable to the minority population, and usually do not facilitate comparisons with other groups.

\subsubsection{Labour market experiments}

The limitations of other methods of assessing labour market discrimination, particularly in recruitment, are partly addressed by experimental methods. The strength of experimental approaches to studies of discrimination is their capacity to isolate causal effects; that is, the direct effect of ethnicity on the chances of being invited to interview. In a randomised control trial, just as in medical trials, there are clear, randomly assigned 'treatment groups' and 'control groups'. This randomisation means the only difference between the groups concerns basic information about their candidate nationality or ethnicity; once sample sizes are large enough, any differences in how those candidates are treated can be confidently attributed to their nationality or ethnicity. These experiments may be in a laboratory setting, online, or in actual job applications ('field' experiments).

The most direct measure of recruitment discrimination comes from field experiments. Field experiments allow a direct test of discrimination by measuring the actual responses of employers to matched fictitious candidates (for example, applying for a job). They retain key elements of experiments (matching, random assignment) and apply them to real-world contexts (job applications, house hunting). Typically, researchers send applications for two matched fictitious candidates (one from a majority group, one from a minority group) for the same 
job or accommodation and responses are recorded, allowing researchers to measure the extent of discrimination from the number of call-backs. Applications can be in person, or written/electronic, the latter being much more common. ${ }^{45}$ In written/electronic applications, CVs are equivalent except in the characteristic of interest, for example ethnicity or country of origin (Quillian et al., 2019). Ethnicity or immigrant status is typically signalled by the name. Field experiments in the labour market have grown rapidly, especially of immigrant and/or ethnic minorities. Findings differ depending on country context, the groups and occupations measured (Zshirnt and Ruedin, 2016; Bertrand and Duflo, 2017; Quillian et al., 2019).

In most Western countries where experiments have been conducted, discrimination against White immigrants is significantly lower than discrimination against non-White groups (Quillian et al., 2019). In Ireland, there has only been one field experiment of discrimination in the Irish labour market (McGinnity et al., 2009; McGinnity and Lunn, 2011). ${ }^{46}$ In their experiment in 2008, McGinnity et al. (2009) developed matched CVs for Irish, African, Asian and German fictitious candidates and sent out equivalent CV pairs in response to 240 job advertisements in lower administration, lower accountancy and retail sales in $2008 .{ }^{47}$ They found that candidates with Irish names were over twice as likely to be called to interview as candidates with African, Asian or German names. The discrimination rate is high by international standards. The experiment results suggested that discrimination was somewhat higher against African applicants, but given the sample size, this difference was not statistically significant, meaning the evidence was not robust enough to establish a difference between groups. ${ }^{48}$ This contrasts with findings in other Western countries, where, as noted above, discrimination against non-White minorities is typically significantly higher than against White minorities (Quillian et al., 2019). McGinnity et al. (2009) also found no difference in discrimination rates between lower administration, accountancy or retail sales.

While experiments provide compelling evidence in areas they test, they are limited in terms of the aspects of labour market discrimination that can be tested (Gaddis, 2019). For example, experiments are better suited to testing recruitment than promotion within a job or workplace harassment. Field experiments are also easier to conduct using written applications: these tests are much more challenging to

45 In-person audit studies typically use either actors or graduate students as candidates. These have been criticised for a number of reasons, and it can be difficult to demonstrate equivalence of testers (Neumark, 2012). This criticism does not apply to written/electronic applications, where equivalence can be demonstrated, and CVs rotated.

46 See McGinnity et al., 2009, for further details.

47 One CV was always from the Irish candidate and the other alternated between the African, Asian or German candidates. Four CVs were not sent out together to avoid detection. For equivalence, the CVs were rotated across identities.

48 Irish candidates were 2.4 times as likely to be called to interview relative to African candidates. Irish candidates were 1.8 times as likely to be called to interview as Asian candidates and 2.1 times as likely to be called to interview as European applicants. However, as noted, the difference between minority groups is not statistically significant. 
conduct if the application process is in person, not only in terms of logistics but also in demonstrating the equivalence of testers. This can rule out many low-skilled jobs, for example in construction or the hospitality sector. Moreover, the nature of discrimination in construction or hospitality may differ from that in other occupations. The fact that written tests are easier to conduct also means testing is usually limited to the first stage of the application process (call to interview), though some experiments have tested both stages (Boevenkerk et al., 1995). Experiments are also more difficult to conduct in sectors dominated by very large employers, or in highly networked professions (such as academia or law), as the risk of detection is higher. ${ }^{49}$ Gaddis (2019) also argues that while field experiments are an excellent methodological tool to investigate the 'what', 'where' and 'when' aspects of racial-ethnic discrimination, they are less appropriate by the 'how' and 'why' aspects of discrimination: for this they need to be combined with other methods.

One prominent example of a laboratory experiment from social psychology is the Implicit Association Test. This test evaluates a person's positive or negative associations between concepts, images or words and is based on the principle that the time it takes to respond to a particular stimulus is an indicator of the strength of association (Noon, 2017). In quick succession, participants evaluate different pictures of different groups (men and women, people with and without a disability, race - White, Black and Asian) and are asked to associate these with either positive or negative characteristics. The idea is to investigate stereotypical associations with 'in groups' and 'out groups' (Al Ramiah et al., 2010). Of course, as with other research investigating attitudes (see 2.2.4), the link between implicit attitudes and behaviour has been established in certain situations but is far from straightforward (Dovidio et al., 2002). Other approaches use 'vignettes', where participants, either in a laboratory setting or online, assess different CVs and rank candidates, only differing in, for example, the ethnicity of the job candidate (Fibbi et al., 2021).

\subsection{SUMMARY OF EVIDENCE OF RACIAL AND ETHNIC DISCRIMINATION IN THE IRISH LABOUR MARKET}

This chapter has documented the extent of ethnic diversity in Ireland, in so far as it is measured. It has discussed methods to measure discrimination and summarised evidence about what we know in Ireland. To summarise, multiple sources of information demonstrate that ethnic minority groups are discriminated against in the Irish labour market. However, the evidence is not always consistent regarding the prevalence of discrimination, which can vary depending on the

49 Detection by the recruiter can invalidate the results. 
nature of the discrimination (for example, whether it occurs during the recruitment process or in the workplace).

There is clear evidence for discrimination against the Black ethnic group arising from ethnic penalty analyses, informal reporting of racism, list experiments to assess masking of negative attitudes, large representative surveys of self-reports of discrimination and a field experiment on interview call-backs. While caveats apply, if we combine these sources, it would be difficult to make the argument that labour market discrimination against this group, either in recruitment or in the workplace, does not exist. While Asian and White non-Irish groups do not report higher discrimination in recruitment than White Irish, earlier experimental evidence indicates that recruitment discrimination against these groups does in fact occur.

Reported discrimination in the workplace is also somewhat higher for non-Irish ethnic groups such as Asian, White non-Irish, EU and White EU-east. However, occupational attainment is actually quite high for some of these groups, particularly for Asians, but also for the White EU-west, and White non-EU. Reported Irish attitudes towards Polish immigrants tend to be more positive, and the attitudinal climate is perceived by Poles in Ireland as relatively positive. By contrast, Irish Travellers have the lowest employment rates, and the highest rate of discrimination in recruitment of all the groups considered. Low rates of employment make assessing discrimination even more difficult for this group.

In the rest of the report, we consider both legal and non-legal measures to combat this discrimination and their effectiveness. 


\section{CHAPTER 3}

\section{Law and equality policy to combat discrimination and promote diversity}

There is a large variety of policies and measures that can potentially contribute to tackling discrimination and racism against disadvantaged groups in the labour market. These range from anti-discrimination legislation to equal employment policies, affirmative action and other strategies to promote diversity. The focus of this chapter is on the effectiveness of anti-discrimination legislation and awareness of the law. Existing consequences for non-compliance and available methods of recourse under the law are discussed. The role of equality bodies in the successful implementation of such policies is also considered. In line with our objective to collate international experience, much of the evidence discussed below is EU-wide or at the Organisation for Economic Co-operation and Development (OECD) level rather than specific to Ireland.

\subsection{LEGISLATION AND THE BROADER REGULATORY FRAMEWORK}

The act of prohibiting discrimination against certain groups sends a strong signal that can help to shape societal norms and attitudes (Valfort, 2018). The existence of a macro-regulatory framework also has the effect of driving the implementation of antidiscrimination policies at the corporate level (Dobbin and Kalev, 2013; Fibbi et al. 2021). Punitive sanctions, though they may not be effective in themselves (see below), can also create a normative environment which promotes equality; however, this appears to be true of gender more than racial discrimination (Hirsch, 2009).

It is difficult to measure the precise impact of anti-discrimination law, as its effect materialises over time, within a changing context, regarding public opinion, for example, and a developing capacity for enforcement. Research on the impact of regulation on the incidence of discrimination is limited and much of it focuses on the US context (OECD, 2020; Fibbi et al., 2021). However, available empirical evidence suggests that laws barring discrimination did help to improve the relative labour market situation of ethnic minorities, in terms of both earnings and employment (OECD, 2008a). In the US, the Civil Rights Act and related employment commissions initially improved the situation of Black workers, but this positive effect decreased over time (OECD, 2008a; 2020).

Anti-discrimination law may have unintended effects. Employers can find antidiscrimination law complex and burdensome (OECD, 2008a; Phillips et al., 2007). 
Research on the impact of anti-discrimination legislation on workers with disabilities in the US suggests that if increased regulation is perceived by employers as creating high costs, it could decrease the employment of a protected group (Acemoglu and Angrist, 2001). ${ }^{50}$ Valfort (2018) also suggests that fear of litigation when terminating contracts could lead to employers avoiding recruiting members of protected groups.

The effectiveness of EU anti-discrimination legislation is debated, partly because consistent application is challenging: different concepts of equality are applied at national level. Different legal and organisational contexts across the EU result in variations in the efficiency of the legal antidiscrimination framework, and in outcomes of legal actions against discrimination (Fibbi et al., 2021). Shifting the burden of proof-meaning that the defendant (such as the employer) has to prove that differential treatment was disconnected from any discriminatory intents or practices - is also not sufficiently in place in all European countries, and in those where the provision does exist, it does not apply to all judicial procedures (FRA, 2012; Fibbi et al., 2021).

Discrimination in recruitment is particularly difficult to tackle through legislation, mainly because it is so hard to prove (relative to discrimination in the workplace, for example). In a meta-analysis of recruitment field experiments conducted in OECD countries between 1990 and 2015, Zschirnt and Ruedin (2016) found that discrimination remained widespread throughout the period. After comparing the discrimination rates in the EU before and after the adoption of the Racial Equality Directive and the Employment Equality Directive, the authors concluded that there is no evidence that the Directives impacted on levels of ethnic discrimination in hiring. ${ }^{51}$

In Ireland, the requirement of public sector bodies to promote equality, prevent discrimination and protect human rights - the Public Sector Equality and Human Rights Duty - is set out in section 42 of the Irish Human Rights and Equality Act 2014. Public bodies are obliged to assess what equality and human rights issues are relevant to them, to set out how such issues will be addressed and to report annually on developments and achievements. The IHREC (2021) stresses that the availability of data on ethnicity is essential to fulfilling such obligations.

50 Note that the Americans with Disabilities Act (ADA) prohibited discrimination and required employers to accommodate workers with disabilities adequately in the workplace; it is not known which provision impacted negatively on the employment of workers with disabilities.

51 Council Directive 2000/43/EC of 29 June 2000 implementing the principle of equal treatment between persons irrespective of racial or ethnic origin (Racial Equality Directive) and Council Directive 2000/78/EC of 27 November 2000 establishing a general framework for equal treatment in employment and occupation (Employment Equality Directive). 


\subsection{AWARENESS OF RIGHTS}

Individual cases are core to the implementation of legislations and for this reason individual awareness of rights is important. Individuals must be aware of laws prohibiting discrimination and their rights as victims of discrimination (OECD, 2008a), yet often this knowledge is lacking. For example, in 2008, the OECD reported that less than half of the population of European countries knew that discriminating in recruitment on the basis of gender or ethnic origin was unlawful (OECD, 2008a). Eurobarometer data have demonstrated that public awareness of non-discrimination provisions did increase between 2007 and 2015; however, less than half of the population knew their rights if they were to become a victim of discrimination or harassment (OECD, 2020). Furthermore, data from the World Justice Project show that people from the most discriminated against groups are most likely to take no action, due in part to a lack of knowledge of their rights and the supports available to them (OECD, 2020).

Based on the Central Statistics Office (CSO) survey module on equality and discrimination fielded in 2010,52 McGinnity et al. (2012) looked at levels of knowledge of rights under Irish equality law across a range of social groups. They found that knowledge is lower among ethnic minority groups of respondents than among the White group of respondents. Some 30 per cent of White respondents claimed to know 'a lot' about their rights, compared to 25 per cent of Black respondents and 23 per cent of Asian or other respondents. Taken together, these studies illustrate low awareness of rights where it concerns matters of discrimination and equality.

Equality bodies play an important role in raising awareness of discrimination and the relevant legal provisions, as well as sharing information on supports available to victims of discrimination. The OECD (2008a) reported that equality or other specialised bodies had run information campaigns targeting public opinion in 19 out of 23 OECD countries, while 20 had run campaigns to inform the public of their legal rights. Informing employers of their legal obligations is also a priority, particularly in small firms, where, due to their size, the incidence of litigation is lower (ACAS, 2006) and awareness can be particularly weak (OECD, 2008a). Information campaigns on the legal obligations of employers tend to be less systematic than those targeted at potential victims of discrimination. Good practice codes for employers were issued by equality bodies in seven of the 23 surveyed countries (OECD, 2008a). Supplying data on the local population by ethnicity could help local employers assess their performance, so the limited availability of such data is a challenge (Phillips et al., 2007).

52 These are the survey modules discussed in Chapter 2. The 2010 module surveyed approximately 16,800 adults. 
In Ireland, the Irish Human Rights and Equality Commission (IHREC) and the Work Relations Committee in particular play a key role in such awareness-raising activities. Non-governmental organisations (NGOs) and trade unions are also important. The Migrant Rights Centre Ireland ( $\mathrm{MRCl})$, an NGO, has raised concerns about a lack of awareness of employment rights among migrant workers in the agri-food sector and stressed the importance of language skills and increasing the presence of trade unions there ( $\mathrm{MRCl}, 2020$; Bloomer et al., 2020).

The principal of equal treatment is well established in OECD countries and while only a minority of complaints against discrimination actually result in litigation, discrimination cases and their court outcomes can be important drivers of cultural change if well enough publicised (OECD, 2008a).

\subsection{CONSEQUENCES OF NON-COMPLIANCE AND METHODS OF RECOURSE}

A wide range of recourse mechanisms exists across the $O E C D$, ranging from the courts, labour courts and specialised tribunals, to alternative dispute resolution mechanisms such as mediation. However, significant barriers are faced by individuals who feel they have been discriminated against, which might deter them from taking action. It can be costly and time-consuming and is often an adversarial process in the workplace (FRA, 2012). For example, the majority of representatives of equality bodies surveyed by the EU Fundamental Rights Agency (FRA) (2012) found legislation and access to justice paths overly complex or unclear. Similarly, the OECD (2008a) rated the legal anti-discrimination framework as of medium or high complexity in 17 of 23 states surveyed. ${ }^{53}$ Even if legal action is taken, discrimination cases often fail because firm evidence is hard to provide (Fibbi et al., 2021; FRA, 2012). A qualitative study of pregnancy discrimination in the workplace found that reputational damage was a major barrier for women taking legal action, as they feared they would be seen as a difficult employee and not get a reference for future job applications (Davis et al., 2005). The authors also stressed the psychological toll on employees taking legal action (ibid.). Consequently, taking action may not be an appealing option.

Anti-discrimination law is most likely to have an impact where the individual is supported to take legal action against perceived discrimination (OECD, 2008a; FRA, 2012). In most OECD countries, plaintiffs may receive some free legal advice from either national equality bodies, NGOs, trade unions or other relevant bodies

53 High, medium and low, respectively, refer to a situation where the core legal framework to ban discrimination in the labour market is built: on both specific legislation and general laws or codes (be they labour, civil or penal codes, employment acts or constitutional laws); on a combination of anti-discrimination laws covering specific areas (e.g. equal pay or working conditions) or grounds (gender, ethnicity); or on a single, comprehensive anti-discrimination law (covering all grounds) (OECD, 2008a). 
(OECD, 2008a). However, access to legal aid or the existence of legal expenses insurance varies greatly between EU Member States and often carries severe restrictions for cases of discrimination (FRA, 2012). In Ireland, a statutory entitlement to legal aid does not exist for most discrimination cases. This lack of legal aid available for racial discrimination claims brought to the Workplace Relations Commission has been criticised by the UN Committee on the Elimination of Racial Discrimination, which recommended an extension of the scope of legal aid to areas of law that may particularly affect Travellers and other ethnic minorities (Committee on the Elimination of Racial Discrimination, 2019). ${ }^{54,55}$

The European Commission recommendation on standards for equality bodies stresses the support and litigation function of equality bodies for victims of discrimination. ${ }^{56}$ While equality bodies usually do not provide legal representation in individual cases, they can take strategic legal actions in some countries, focusing on cases that serve the public interest; for example, by clarifying the law (OECD, 2008).

As discussed in Section 1.5, in Ireland the IHREC supports strategic litigation using their amicus curiae (or friend of the court) function with the Superior Courts. In a well-known example (NHV $\vee$ Minister for Justice and Equality and the Attorney General), the IHREC supported a case which resulted in the Supreme Court finding that the absolute prohibition on asylum seekers seeking employment in Ireland, coupled with no maximum time limit on the processing of asylum applications, was in breach of the constitutional right to seek employment. ${ }^{57}$ Equality agencies surveyed by FRA (2012) viewed strategic litigation as a way to establish precedents that could motivate others in similar situations to take action; about half of the agencies surveyed had been involved in strategic litigation. Free Legal Advice Centres (FLAC) has cautioned that settlements out of court and confidentiality clauses can compromise the effectiveness of such cases. ${ }^{58}$

In about one-third of Member States, equality bodies always aim for settlements before discrimination cases reach the courts (European Commission, 2021b).

54 The Committee recommends that the State party extend the scope of the Legal Aid Board to the areas of law that are particularly relevant to Traveller and other ethnic minority groups, including by designating the Social Welfare Appeals Office and Workplace Relations Commission as prescribed tribunals under Section 27(2)(b) of the Civil Legal Aid Act 1995.

$55 \quad$ FLAC has commented on unmet need for such services among Roma and Traveller groups in particular: See comments made by Eilis Barry at 'Ireland's Evolving Equality Architecture' event, June 2021, which was part of '20 Years of the Equal Status Acts - FLAC Seminar Series'.

56 European Commission (2018) Commission Recommendation (EU) 2018/951 of 22 June 2018 on standards for equality bodies.

57 The IHREC supported this test case which resulted in the Supreme court finding that the absolute prohibition on asylum seekers seeking employment, coupled with the absence of a maximum time limit on the processing of asylum applications, meant the prohibition was in breach of the constitutional right to seek employment. [2017] IESC 35.

58 See comments made by Eilis Barry at 'Ireland's Evolving Equality Architecture' event, June 2021, which was part of '20 Years of the Equal Status Acts - FLAC Seminar Series'. 
Alternative dispute resolution (ADR) mechanisms, such as mediation at an early stage, may be quicker and cheaper for individuals (see OECD, 2008; OECD, 2020; Fibbi et al., 2021). However, while ADRs can be effective in individual discrimination cases, these mechanisms are more limited when dealing with more systemic discrimination and structural causes of group exclusion. Some suggest these mechanisms may be used by perpetrators to avoid responsibility (Wladasch, 2015).

The OECD (2020) argues for recourse mechanisms that are designed on the basis of a clear understanding of the nature of potential discrimination cases, based on data on groups experiencing discrimination, at-risk sectors, occupations and employment processes, as well as information on specific access barriers faced, such as cost, complexity and length of procedures.

Possible sanctions for companies found to be discriminating vary, from negative publicity to the cancellation of public contracts to fines and even prison sentences (OECD, 2008a). Guidelines have been issued by the Court of Justice of the European Union (CJEU) on sanctions for breaches of national provisions implementing the Racial Equality and the Employment Equality Directives. The CJEU states that symbolic sanctions are insufficient, and that measures must be proportionate, guarantee real and effective judicial protection and ensure a genuinely deterrent effect; this may involve imposing penalties even in the absence of an identifiable victim. In addition, monetary compensation must be adequate and not subject to a pre-determined upper limit (European Commission, 2021a).

In practice, there is significant variation at national level, with the appropriate compensation frequently not specified in anti-discrimination law (OECD, 2008a), and national courts tending to favour lower levels of compensation or nonmonetary compensation (Crowley, 2020; European Commission, 2021a). A 2015 European study on the sanction regime in discrimination cases found that EU Member States most commonly apply sanctions based on civil law provisions, including compensation for damages as well as fines and administrative sanctions, but that criminal sanctions are also used in cases of hate crime (Wladasch, 2015). The success of sanction measures depends on complainants' ability to access justice and effective enforcement mechanisms when a sanction is issued (Wladasch, 2015). A 2012 FRA report on access to justice in discrimination cases in eight EU Member States found that compensation payments were often criticised by intermediaries (lawyers, NGOs, trade unions) and this was linked to limiting the effectiveness and dissuasive power of the sanctions. ${ }^{59}$ Although the majority of the 213 complainants interviewed reported that the outcome of the complaint

59 The participating Member States were Austria, Belgium, Bulgaria, the Czech Republic, Finland, France, Italy and the UK. 
procedure was in their favour, less than one-fifth reported an improvement in the situation resulting from their complaint, with a small number saying that their situation had even worsened (FRA, 2012). Dissatisfaction with outcomes came from, for example, a lack of recognition of discrimination and non-binding decisions (for example, involving only recommendations or opinions).

The report found that in monitoring outcomes, equality bodies tended to focus on defendants' follow-up actions, rather than the situations of complainants (FRA, 2012). The FRA report highlights the importance of these follow-up procedures. Most Member States' equality bodies lack procedures to ensure effective followup of decisions made, which risks limiting compliance and effective enforcement of legislation and sanctions (European Commission, 2021b). Equality bodies in Croatia, France and the Netherlands are identified by Crowley (2018) as leaders in terms of rigorous follow-up of decisions in cases brought before them, resulting in a high level of compliance with decisions and implementation of recommendations made.

Wladasch (2015) emphasises that the 'ideal' sanction to apply in cases of discrimination depends on the 'objective' of the sanction (compensative, punitive or preventive) as well as the interests represented in the individual case. Based on input from representatives of equality bodies, Wladasch suggests good practices for sanctions systems that might be considered, depending on the context. ${ }^{60}$ It can be good practice to make available a range of non-monetary measures, such as the implementation of anti-discrimination policies or the publication of a decision. Taking account of the financial status of the perpetrator and the level of salaries in the relevant country in determining compensation can also be effective, as can the practice of withdrawing licenses to run a business or excluding companies from public procurement or funding. The case of Belgium is also cited, where the perpetrator can be ordered to pay a lump sum in order to compensate for financial and non-financial loss.

Reinstatement of a position with back pay is another common remedy but, due to impact on the employment relationship, it may not be effective (OECD, 2008a). Schindlauer (2007) argues that in the case of Austria no effective remedy or sanction exists in practice because many victims of discrimination refuse to return to a discriminatory employer. The risk of retaliation may also deter individuals from taking action, or from testifying at an action. The level of protection offered to plaintiffs against victimisation or retaliation for their claim also varies. In 12 of the 23 OECD states examined, plaintiffs were protected against victimisation in cases related to ethic discrimination. In the other 11 countries, such protections were

60 Information provided by representatives of equality bodies published in Milieu (2011): Comparative study on access to justice in gender equality and anti-discrimination law, study prepared for the European Commission. 
'limited' (OECD, 2008a). ${ }^{61}$ FRA (2012) argues for legal measures to protect against re-victimisation of complainants and witnesses in cases of discrimination.

\subsection{SUMMARY}

Anti-discrimination legislation is important in terms of sending signals about acceptable behaviour and attitudes within a society. However, the implementation and enforcement of the legislation is challenging and its effectiveness in actually deterring discrimination is less clear. Awareness of rights under the legislation is critical. Complex national legal systems contributing to lengthy proceedings, ambiguity around potential benefits for victims, risk of retaliation and a lack of support for victims all work towards fewer cases being taken against discriminating employers, and without sufficient numbers of cases being taken, the deterrent effect is lessened.

Regulatory policies do not address the underlying beliefs about different groups; neither can they systematically identify and prevent discrimination (Valfort, 2008; see also Chapter 1). The legal anti-discrimination framework can be complemented by more proactive or positive strategies to influence practice and processes in the labour market, such as affirmative action and equal employment policies. These are the subject of the next chapter.

61 Limited protection against victimisation/retaliation refers to: cases where the claimant employee, or any employees providing evidence or participating as a witness in a proceeding against discrimination, are protected against wrongful discharge only; or cases where the standard of proof as regards victimisation is more demanding than for 'simple' discrimination (OECD, 2008a). 


\section{Employment policy, financial incentives and organisational}

\section{measures}

This chapter sets out measures used in the labour market to promote diversity and reduce discrimination in the workplace. We discuss common practices used internationally to increase diversity and evaluate their effectiveness through reviewing existing research evidence. The previous chapter discussed legislative tools, sanctions and supports; this chapter is focused on measures at the level of organisations, which can of course be supported by government. It groups four different types of measures: those that can be implemented by the State (particularly affirmative action, but also wage subsidies); training practices; recruitment practices; and finally networking practices. These measures can focus on recruitment, but also on the workplace (in areas such as promotion, retention and harassment). Some measures focus on changing attitudes or stereotypes, while others emphasise behaviour. Some are mandatory, some voluntary. Measures also vary in 'strength' of intervention - be that from ensuring equality in the labour market to positive action (Wrench, 2007). These features are discussed where relevant. Studies were chosen on the basis of the selection principles outlined in Box 2, insofar as was possible.

One challenge with evaluating evidence of effectiveness is that studies do not always specify details of the intervention measures and what they entail; this is noted where relevant. Due to the lack of relevant monitoring and evaluation data in an Irish context, our analysis in this chapter relies heavily on international evidence.

\subsection{STATE-SPONSORED MEASURES}

This section considers practices that seek to reduce discrimination and improve diversity and which can be implemented by the State. We first present research on the effects of affirmative action policies as, although affirmative action policies are typically implemented by private organisations without state supervision, some jurisdictions, such as the US, have implemented mandatory affirmative action policies within both the public sector and organisations contracted by the public sector. We then move on to discuss financial incentives created by states to entice private companies to employ disadvantaged groups such as migrants, focusing specifically on wage subsidies. 


\subsubsection{Affirmative action policies}

In the field of recruitment, affirmative action is broadly defined as policies that address the under-representation of disadvantaged groups which go beyond simple non-discrimination legislation (Crosby et al., 2006; OECD, 2020). The goal of affirmative action is to correct or compensate for discrimination in the past or present and to prevent it from happening in the future (Kravitz, 2008). Affirmative action is broad in definition and different actions vary in strength. The weakest forms are policies designed to enhance opportunities, such as training, mentoring or outreach measures, which help targeted groups but do not directly impact employment decisions (Kravitz, 2008). These are sometimes referred to as indirect affirmative action and outreach (Sabbagh, 2011), and are discussed separately in Chapter 4. Stronger versions of affirmative action policies are 'tiebreak' policies and fixed quotas, sometimes also referred to as 'direct affirmative action' (Sabbagh, 2011). Tiebreak affirmative action policies are where a member of a minority group is selected over the majority group when they have equal qualifications, and the minority group is under-represented. The strongest version of affirmative action policies are fixed quotas, whereby a target number of underrepresented group members needs to be reached, meaning in some cases group members may be selected over more qualified non-group members (Besley et al., 2017). Direct affirmative action policies are the primary focus of this section; where possible, we specify whether a study refers to a quota or tiebreak policy. However, sometimes an organisation introduces a variety of measures of different 'strengths' simultaneously, and the nature of the policy is not specified in the research, so it is not always possible to distinguish them.

In the US, where most of the research is focused, employers seeking significant federal contracts are required to develop an affirmative action programme to address under-representation of those from minority groups, women or individuals with disabilities. Affirmative action legislation does not specify how companies are to reach specified targets but the instruments most commonly used include compulsory quotas, tiebreak rules and aspirational goals, which carry different sanctions for non-compliance. Kalev et al. (2006) found that where one person within an organisation was assigned responsibility for complying with affirmative action requirements, this was a crucial factor in successful implementation.

Research on the impact of affirmative action on diversity shows that such actions tend to increase the proportion of applicants and employees from minority groups (OECD, 2020). For example, using a survey of 3,200 employers in the US, Holzer and Neumark (2000) found that employers who implement affirmative action in 
hiring practices obtain more job candidates from minority groups. ${ }^{62}$ Affirmative action applied to recruitment decisions in this way yields more female and (ethnic) minority employees whose credentials are somewhat weaker, though their performance is generally not (ibid.). Similarly, using employer information reports for 1978-2003 (100,000 records), Kurtulus (2012) examined how federal contract status impacted the occupational advancement of minorities. ${ }^{63}$ Organisations with federal contracts are required to implement affirmative action policies and are subject to compliance reviews, though the types of reviews conducted are unclear. In Kurtulus' (2012) study, being a federal contractor increased the share of White women in professional occupations, Black women in professional, clerical and manual occupations, Black men in technical and manual occupations, and Hispanic ${ }^{64}$ women in technical occupations (ibid.). Over the same time period, White men's share of professional, technical and clerical occupations declined over while, interestingly, Hispanic men were not found to benefit from affirmative action.

As a further example of the positive impact of affirmative action policies, Miller (2017) found that when affirmative action regulation is applied to firms with sizable federal contracts, the Black share of employees increases. ${ }^{65,66}$ Five years after an establishment committed to regulation, the Black share of employees increased by an average of 0.8 percentage points and it continued to grow after the establishment was deregulated. The author argues this may be because affirmative action induces employers to improve their screening methods for potential hires and this improvement persists (ibid.). Other research in the US found that following affirmative action legislation, which did not apply to small firms, there was a trend of female and minority employment moving to larger firms. This move to larger companies, which typically offer better pay, had a positive impact on wage growth for women and minorities (Carrington et al., 2000). ${ }^{67}$ US studies also found that

62 The authors carried out a survey on over 3,200 employers in Atlanta, Boston, Detroit and Los Angeles between June 1992 and May 1994. The survey was carried out via telephone questionnaire interviews with those responsible for hiring. The sample of firms was drawn from two sources and data included two different variables regarding the role of affirmative action in hiring for the last position filled.

63 Kurtulus compared the occupational position of minorities and women at firms holding federal contracts during $1973-2003$ by using a longitudinal data set of over 100,000 large private-sector firms across all industries and regions in the US.

64 In the US, the terms Hispanic and Latino are often used interchangeably to refer to someone of Latin American origin. It is not a separate racial category, though Hispanic is a separate and very large ethnic group in the US Census (see https://www.census.gov/newsroom/blogs/random-samplings/2021/08/measuring-racial-ethnic-diversity-2020census.html for more information). In Ireland, Hispanic is not a separate category in the ethnicity question in the Irish Census (see Chapter 2 for a discussion of the ethnicity categories in Ireland).

65 Miller used establishment-level administrative data collected by the US Equal Employment Opportunity Commission (EEOC) covering the years 1978-2004. The author limited the sample to establishments located in metropolitan statistical areas (MSAs) where at some point between 1978 and 2004, the Black share of the working age population was at least 5 per cent.

66 Regulated firms are mandated to make a 'good faith' effort to employ minorities at rates (at least) proportional to their shares of the local and qualified workforce.

67 The authors matched characteristics and counts of private sector, full-time, full-year workers ages 18 to 64 years, obtained from the March Current Population Survey, to employers by state, industry and year, as identified from the 1963-1987 County Business Patterns data. 
overall employment growth is a strong contextual factor influencing the success of affirmative action: these policies are more likely to have an impact in growing establishments (Leonard, 1990).

While in general affirmative action policies are much less widely used, and evaluated, in Europe, the Organisation for Economic Co-operation and Development (OECD) (2008a) has identified a number of countries where such policies have been implemented. In the Netherlands, the Wet Samen (Act for the Stimulation of Labour Market Participation) in 1998 obliged companies with more than 35 employees to monitor their employee immigration background on an annual basis and to implement diversity policies (OECD, 2008b). Groeneveld and Verbeek (2011), using data from annual reports, compared ethnic diversity levels in Dutch private and public sector organisations in 2001 and $2002 .{ }^{68}$ They found that policies designed to improve the management of diversity tended to increase minority representation between the two years, but that policies designed to improve recruitment of ethnic minorities did not, at least in the very short term (there was one year between observations). They speculated that these somewhat counterintuitive findings may be related to the pre-existing ethnic diversity in the organisations studied, with those adopting policies to manage diversity having a higher share of ethnic minorities and a greater commitment to diversity. They also noted that results might be different for longer-term effects. In further analysis of the same data, Verbeek and Groeneveld (2012) found no effect of affirmative action recruitment policies such as tiebreak or targets but noted that skilled labour shortages improved the labour market prospects of ethnic minority groups. Amid complaints from employers that the Act was not effective and placed an undue administrative burden on them, the policy was abolished in 2003 (OECD, 2008a).

In Norway, there has been an obligation on public sector employers to interview at least one candidate with a non-Western immigrant background since 2002, assuming they meet qualification criteria. There has been no robust evaluation of these measures, though the OECD (2012) found that the implementation of the measures coincided with a marked growth in the proportion of non-OECD immigrants working in the public sector (OECD, 2012). ${ }^{69}$ In 2009, an amendment to existing anti-discrimination legislation there obliged all public employers and private employers with more than 50 employees to promote equality and to publish information on these efforts. The OECD (2012) note less resistance to reporting from employers there than in the Netherlands, possibly because of financial and administrative supports provided to companies. No evaluations of the effectiveness of these more recent measures were found.

\footnotetext{
68 The authors analysed 8,283 annual reports provided by organisations that were filed under the Wet Samen Act.

69 A pilot tiebreak policy in the Norwegian public sector was introduced in 2008 , whereby if candidates have equal or approximately equal qualifications, a candidate from an immigrant background will be preferred.
} 
The introduction of quotas can also have unintended consequences. A recent study in Sweden found that the introduction of gender quotas in political party lists actually raised the competence of male politicians, as 'mediocre' male politicians resigned (Besley et al., 2017). ${ }^{70}$

The type of affirmative action policy implemented, as well as the ethnicity of those surveyed, can affect support for affirmative action. Using survey data, Kravitz and Klineberg (2000) evaluated attitudes towards two types of affirmative action 'typical' (quota-based) and tiebreak. ${ }^{71}$ Typical, quota-based affirmative action plans were found to be supported by Black respondents, less supported by Hispanic respondents, and opposed by White (non-Hispanic) respondents. Black respondents were also more supportive of tiebreak affirmative action plans than other groups. Contrary to quota-based affirmative action results, White respondents recorded neutral attitudes towards tiebreak plans and did not differ significantly from Hispanic respondents in this regard. The most consistent predictor of opposition for quota-based affirmative action plans was the belief that such policies give unfair advantages to minorities. Similarly, the only consistent predictor of support for tiebreak affirmative action policies is the belief that such policies did not give unfair advantages to minorities. Similar research by Kravitz (2008) also found that, for White respondents, the strength of affirmative action was linked to the strength of opposition to these measures, with the most negative attitudes linked to quota-based policies. ${ }^{72}$ In an Irish context, a study of gender balance in one civil service department found that the introduction of a tiebreak policy for senior appointments and other gender balance initiatives within the civil service resulted in some civil servants believing that promotions were now biased in favour of women. While this policy explicitly referred to cases where the male and female candidate were of 'equal merit', the study found that some workers believed that women were being promoted over men who were more qualified for the position (Enright and Russell, 2020). ${ }^{73}$

Additionally, perceptions surrounding affirmative action can impact support for these policies. In one such study, Aberson (2003) found that policies which include

70 Competence is measured as an individual's earnings relative to other people of similar age and labour market characteristics, with higher relative earnings signalling higher competence. Applying this model to Swedish register data for the earnings of the whole population, the authors measured the competence of all politicians in seven parties, 290 municipalities, and ten elections (for the period 1982-2014). The authors asked how competence was affected by a zipper quota, requiring local parties to alternate men and women on the ballot, which was implemented by the Social Democratic Party in 1993.

$71 \quad$ Kravitz and Klineberg (2000) evaluated these attitudes by using data from the expanded 1998 version of the Houston Area Survey, a telephone survey of public opinion conducted each spring since 1982. The interviews were conducted in either English or Spanish during February and March 1998 by Telesurveys Research Associates. The full data set consisted of representative samples of 424 White people, 403 Black people, and 405 Hispanic people.

72 The paper reviews the legal basis of affirmative action and is followed by a review of research on the ongoing existence of workplace discrimination, the economic impact of affirmative action on target groups and organisations, and stigmatisation of target group members by others and by target group members themselves.

73 The authors analysed survey responses from 904 civil servants in the Department of Agriculture, Food and the Marine of the Irish Government. 
a justification for their implementation, for example by stating the policy is to 'compensate for past discrimination', received greater support. ${ }^{74}$ Using telephone survey data, Golden et al. (2001) found that support for affirmative action policies differed based on whether respondents saw these policies as monitoring systems or quota systems. ${ }^{75}$ Respondents who saw affirmative action policies as a monitoring system (a means to make sure an employer monitors whether they employ qualified minorities in proportion to their relative population size) were significantly more positive towards affirmative action policies than respondents who saw it as a quota system (when the government forces employers to meet quotas for minorities) (ibid.). These differences remained even when the sample was limited to male, female or White respondents. These findings highlight the importance of communication by the organisation regarding the introduction of affirmative action policies.

The literature indicates that perceptions of merit and fairness, in particular, strongly influence support for affirmative action policies. Aberson and Haag (2003) found that belief in merit, that is that employers should base hiring decisions exclusively on ability, predicted opposition to affirmative action in general but was unrelated to support for tiebreak policies. ${ }^{76}$ Participants who stated they valued diversity were also more likely to support affirmative action policies. Individuals who perceived affirmative action as fair were more likely to support these policies in general, as well as tiebreak policies. A laboratory experiment by Hing et al. (2002) also found that a strong belief in the principle of merit was related to a greater opposition for affirmative action policies that include preferential treatment. ${ }^{77}$ There was also an effect for perceptions of workplace discrimination, with greater perceptions of discrimination associated with less opposition to preferential treatment. A meta-analysis of research on attitudes to affirmative action by Harrison et al. (2006) highlighted that highly rigid affirmative action plans violate 'merit or equity-based justice norms'. The authors state, 'if one wished to fan the

74 The authors examined the responses to a questionnaire on affirmative action completed by 415 undergraduate and graduate college students. Participants answered a series of questions (seven-point scales rated from one to seven) indicating: agreement/disagreement with the policy; fairness/unfairness of the policy; and effectiveness/ineffectiveness of the policy. Participants then responded to questions assessing the personal impact of affirmative action policies. A final set of questions examined demographic factors (for example, participant ethnicity). The authors conducted a new analysis of a dataset of 1,053 English-speaking adults via telephone by the Northwestern University Survey Laboratory (NUSL) between May and June 1993. The final sample contained 631 women and 422 men over the age of 18 years. The median age of the respondents was 42 years. Non-White respondents were intentionally oversampled so that the survey included 302 people of colour and 706 White people.

76 The authors administered an investigation of how beliefs relate to support for affirmative action policies. In total, 273 White undergraduates participated in an investigation of how beliefs relate to support for affirmative action policies. The sample was predominantly female (71.1 per cent) and traditionally college age.

77 The authors carried out a study to investigate people's attitudes to affirmative action when faced with significant workplace discrimination. Data were collected across three semesters and participants were 108 undergraduate students (40 men, 68 women) at the University of Waterloo in Canada, who participated for course credit. Only students who had lived in Canada for 13 years or longer were selected to participate in all studies, so as to increase the likelihood that participants had been socialised with North American equity norms. 
flames of AAP resistance, positioning them as quotas would be an effective strategy' (Harrison et al., 2006, p. 1027). ${ }^{78}$

Findings on the effectiveness of affirmative action are mixed. Although the research literature links these policies to increased minority applicants and representation in the labour force, perceptions of these policies by majority group members, particularly quota-based policies, tend to be negative. Research has indicated that 'affirmative action hires' are perceived as less competent than other employees both when such policies involve preferences and when the policies are undefined (Kravitz, 2008). Indeed, a number of authors note that following extensive discussion of the legitimacy and efficiency of quotas in the US, the use of 'high-strength' affirmative action and quotas has largely been discontinued (OECD, 2013; Fibbi et al., 2021). Hard quotas are also rare in OECD countries that have introduced affirmative action-like policies in the labour market (OECD, 2013). The implementation of 'lower strength' affirmative action policies offers a potential way to avoid backlash. These policies do not involve quotas, which challenge notions of meritocracy and fairness, and thus may not be durable solutions. However, even tiebreak policies need to be carefully communicated: employers should also publicise the details of these policies to reduce perceptions of unfairness and reduce discrimination towards affirmative action beneficiaries (Enright and Russell, 2020). Targeted recruitment towards racial and ethnic minorities has the potential to decrease discrimination and increase the chances that well-qualified minority members are employed (ibid.). These are discussed in Section 4.4.

At a more general level, public procurement policies can be used by governments as a strategic tool to strengthen diversity and equal treatment. These are fairly widespread in OECD countries, though mostly with regard to incentivising the hiring of women and those with disabilities, as opposed to ethnic minorities (OECD, 2020). As found regarding within-organisation policies, they vary in the conditions attached and how rigidly they are applied, from giving preference to firms with a diverse workforce in tiebreak situations to reserving some contracts for social enterprises working for the inclusion of disadvantaged groups (ibid.). While the OCED (2020) point out that conditions need to be easy to understand and implement in order to ensure that the procurement process does not become unduly cumbersome, the principle of the State offering a financial incentive for promoting diversity and combating racial discrimination through procurement does seem to hold promise.

78 The authors gathered size effects from published and unpublished articles, performed data-based review searches, sent queries to professional news groups and discussion lists and contacted authors of prior articles to identify manuscripts under review or otherwise unpublished. Overall, the authors search netted 110 investigations with enough data for effect size estimation, collectively involving over 29,000 people in 126 independent samples. 


\subsubsection{Financial incentives: Wage subsidies}

Active labour market programmes (ALMPs) seek to support the unemployed to return to work (Kelly et al., 2011). A long-standing component of these is the use of wage subsidies. Wage subsidies aim to create incentives that alter employer and/or worker behaviour and can also be used to incentivise the hiring of disadvantaged workers in the labour market. The OECD (2020) argue they can be used to 'strengthen the business case for diversity with regard to workers with disabilities, as well as migrant and older workers' (OECD, 2020, p. 49). Although many wage subsidies employed across countries do not specifically target migrants, they have often proved effective for this group (OECD, 2020; Kluve, 2006). Subsidies are usually paid to either the employer or the employee for a fixed period. They can incentivise employers to hire migrants who do not have work experience in their host country (Anderson and Huang, 2019).

Despite wage subsidies being implemented in many OECD countries, few countries analyse their impact on employment rates using robust evaluation methods. The majority of evaluations on these types of measures have taken place in Nordic countries and have demonstrated that the measures yield largely positive results. For example, an evaluation of ALMPs used in the Nordic labour market ${ }^{79,80}$ found that wage subsidies show the most positive results on the probability of employment for immigrants, whereas public job creation programmes showed negative or insignificant results. ${ }^{81}$ Wage subsidies were found to have resulted in higher post-programme employment rates for all migrant groups with the exception of those from Latin America (Nekby, 2009).

Research also consistently finds that such subsidies are more effective than other ALMPs. In one such study, Butschek and Walter (2014) analysed the effects of four ALMPs on the employment of immigrants using a meta-analytic review of 33 empirical estimates. ${ }^{82}$ The authors examined the effects of training, job search assistance, wage subsidies and subsidised public sector employment on the employment of immigrants in Europe. Wage subsidies were found to have a significant positive effect on the labour market outcomes of migrants. In contrast, all other ALMPs yielded insignificant effects on employment. The authors conclude 'that only wage subsidies can be confidently recommended to European policymakers' (Butschek and Walter, 2014, p. 14). Similarly, Clausen et al. (2009)

79 The authors carried out a meta-analysis of studies by collecting a sample of 34 studies estimating ALMP effects on immigrants' probability of or hazard to employment in seven countries (Denmark, Finland, Germany, the Netherlands, Norway, Sweden and Switzerland).

80 These typically target those who have been long-term unemployed, immigrants and long-term recipients of social security benefit.

81 This has also been found in Ireland for the unemployed (O'Connell, 2002).

82 The authors collected 93 estimates from 33 empirical studies of the effectiveness of four types of ALMPs employed across Europe to combat immigrant unemployment. The authors gathered the relevant studies by following a search protocol and by performing a meta-analysis. 
found significant positive effects for private sector wage subsidies in Denmark but not for other ALMPs measured (employment programmes taking place in the public sector; education and training; mixed special programmes; counselling and upgrading; and special employment programmes in private sector firms).$^{83}$

A literature review by Anderson and Huang (2019) again found that wage subsidies had a significant positive impact on employment. Further, wage subsidies were the only type of ALMP programme measured that produced a significant impact. The other programmes included: training; wage subsidies for private sector jobs; public employment; services (counselling, job training); and sanctions. In particular, the authors highlight Denmark's step model as an effective ALMP. In the first step of this model, new immigrants are enrolled in language courses. In the second step, they participate in ALMP programmes designed to help them find jobs. In the third step, employers can receive wage subsidies to hire immigrants for a maximum period of one year. Although the wage subsidy is the most effective part of this intervention, it is infrequently used.

One concern with subsidised wage policies is that employers will rely on subsidised workers instead of regular contract workers and may be reluctant to offer permanent positions to migrants participating in such programmes when the subsidies finish (OECD, 2014; Nekby, 2009). It is therefore important to ensure that these policies are carefully designed and used as a temporary measure. In addition, such policies should be conditional on employers not substituting existing workers with subsidised workers (OECD, 2014). The OECD (2014) recommends combining these programmes with training on the job as this will improve the skills of the worker as the subsidies are reduced. In addition, although wage subsidies have proved effective in increasing employment of migrants, they are often underrepresented in these types of programmes. Data from Germany show immigrants are more likely to be assigned to training and public works programmes than wage subsidy programmes compared to German natives (Butschek and Walter, 2014).

Overall, the findings on wage subsidies are positive. The results show that not only are wage subsidies effective in improving the employment prospects of migrants, but they are also more effective than many other types of ALMPs.

No studies of the impact of wage subsidies on the employment prospects of ethnic minorities or migrants in Ireland were found. However, a study by Whelan et al. (2020) conducted in Ireland evaluated the effects of the Social Inclusion and Community Activation Programme (SICAP) on attaining employment. SICAP involves a number of different pre-employment support measures that are

83 The authors used data on immigrants in Denmark from several administrative registers collected and merged by Statistics Denmark. The dataset contains information on 21,568 immigrants. 
delivered within the local community through one-to-one or group sessions. ${ }^{84}$ Whelan et al.'s (2020) study compared a group of individuals who had received at least one pre-employment intervention with a control group. The findings indicated that 21.3 per cent of the intervention group progressed to employment or self-employment following the intervention, in comparison to just 1.9 per cent of the control group. The effects of the pre-employment interventions were more pronounced among non-Irish nationals (21.7 per cent) compared to those of Irish nationals (16.8 per cent). These results are indicative of the benefits of preemployment support measures.

\subsection{WORKPLACE PRACTICES TO PROMOTE DIVERSITY}

In this section, we highlight training practices commonly used by private and public businesses to address diversity issues within the organisation and to combat discrimination. We first discuss research on the impact of diversity training before moving on to evaluations of unconscious bias training (UBT). Although these training practices appear similar, we evaluate them separately as the content of these types of training often differs. Diversity training is generally designed to raise awareness regarding diversity in the workplace and promote positive interactions between members of different groups, whereas UBT is designed to make individuals aware of biases they may not be aware they have and the impact of these biases. In some cases the goal of UBT can also be behavioural change.

\subsubsection{Diversity training to combat workplace discrimination}

Diversity training programmes are widely implemented in organisations and educational institutions in the hopes of reducing bias and discrimination and improving the representation of women and minorities in the workplace, including in more senior roles. However, research yields mixed findings as to its effectiveness. Factors such as what the diversity training covers, how it is framed and who the training targets (managers or employees) often differ across organisations. As a result, the implementation of such training programmes may produce different outcomes, some of which might be contrary to objectives. Although diversity training is widely offered in many public and private organisations, the impact of this training is often not evaluated and, where it is, the focus is often on short-term outcomes (Kulik and Roberson, 2008). Typically, workplace discrimination is broadly defined and understood to include bullying or harassment, unfair treatment in terms of working conditions and promotion/pay, as well as other forms of discrimination (McGinnity et al., 2017; see Section 2.2 for evidence of the experience of workplace discrimination in Ireland). This section 
highlights research on various outcomes of diversity training in the workplace, with a particular focus on attitudes towards diversity within the organisation, the experience of discrimination in the workplace, harassment and perceptions of fairness of such measures.

While diversity training programmes can take many forms, the central objective is to reduce discrimination towards minority or socially disadvantaged groups through either knowledge development, attitudinal work, behavioural skills or a combination of the three. ${ }^{85} \mathrm{In}$ a review of diversity training evaluations undertaken in academic and organisational settings, Kulik and Roberson (2008) demonstrated that the impact of diversity training has been generally positive with respect to learners' cognitive, affective and behavioural outcomes. Most evaluation studies have tended to concentrate on assessing attitudinal change. On this, Kulik and Roberson (2008) reported that diversity training is effective in improving attitudes towards diversity more generally; in other words, learners attained a greater appreciation of the value and importance of diversity in the workplace ${ }^{86}$ However, the findings of Kulik and Roberson's (2008) review demonstrated inconsistent support for the claim that diversity training fosters positive attitudinal effects towards specific minority groups.

Similarly, a recent meta-analysis study by Kalinoski et al. (2013) found that diversity training interventions produced only a weak effect in terms of changing trainees' attitudes towards diversity. ${ }^{87}$ Based on their findings, they argue that, in any sphere, it is difficult for training interventions to produce attitudinal change. They found that training programmes that involve social interaction, a combination of active and passive instruction and are delivered by an instructor in person are more likely to be linked with greater attitudinal change.

Importantly, both the findings of the desk-based review by Kulik and Roberson (2008) and the meta-analysis by Kalinoski et al. (2013) indicate that diversity training is moderately successful in improving trainees' cognitive knowledge and behavioural skill sets in relation to diversity in the workplace. These outcomes are indeed valuable and, as Kalinoski et al. (2013) maintain, diversity training - with appropriate recognition of its limitations - can prove beneficial.

85 As per Kulik and Roberson (2008) and Kalinoski et al. (2013), cognitive outcomes refer to learning gained in relation to knowledge of: other social groups; cultural differences; how biases, stereotyping and social categorisation can affect our behaviour; and organisation-specific content on diversity initiatives. Attitudinal outcomes relate to changes in attitudes towards diversity itself as well as towards specific social groups. Skills-based outcomes refer to the presence of interpersonal skills necessary to work in a culturally diverse environment.

86 The authors carried out a literature review on diversity education interventions with specific outlined features. Their literature search covered the 1970s to present and ultimately included 71 published articles and 74 studies.

87 The authors gathered the studies for their meta-analysis review by using relevant search engines, referencing narrative reviews, conducting ancestry reviews of relevant articles, as well as searching for unpublished studies. 
Diversity training has also been associated with a reduction in the experiences of discrimination in the workplace. Using a 2007 NHS survey of employees in the UK, King et al. (2012) examined the relationship between diversity training and experiences of discrimination among non-White staff. ${ }^{88}$ The authors found that participation in diversity training in the area of racial awareness among all staff significantly reduces the likelihood that non-White staff experienced discrimination on the basis of their ethnicity. This is undoubtedly an important consequence of the implementation of such measures in the workplace.

A US-based research study in a similar setting found that the impact of diversity training depends on who receives the training. Hirsch and Kmec (2009) found that diversity training given to management of a hospital marginally reduced the odds of that hospital receiving a personnel-related discrimination charge, whereas training given to employees marginally increased those odds. ${ }^{89}$ Of course, as the authors note, the training may have raised awareness of equality and discrimination among employees, which is linked to taking action (see Chapter 2 of McGinnity et al., 2012). So, it is not that discrimination actually increased, but rather that awareness of discrimination and knowledge of rights increased, which can be an unintended positive consequence of diversity training.

Despite having positive impacts on experiences of discrimination and overall attitudes, previous research in a US context suggests that such training may actually negatively impact minority representation in senior positions. Longitudinal research by Kalev et al. (2006) found that diversity training was associated with a 7 per cent decline in the odds of Black women being in management positions and did not significantly impact the odds for Black men. The research examined how the implementation of seven different diversity programmes affected minority representation in the private sector between 1971 and 2002 using a random sample of 708 workplaces. ${ }^{90}$ The authors found that diversity programmes which focused on organisational responsibility, such as affirmative action plans (63 per cent), diversity committees (19 per cent) and full-time diversity staff (11 per cent), were more successful in increasing minority representation in management positions. However, research also shows that both diversity evaluations and networking programmes reduced representation of Black men in management positions. An analysis of the number of diversity programmes implemented in

88 The primary data for this study came from the 2007 annual NHS of England survey of its employees, in which 155,922 individuals participated (a response rate of 54 per cent). The sample was broadly representative of the NHS.

89 The authors used data from 84 hospitals linked to Equal Employment Opportunity Commission discrimination-charge data to consider how four HR structures affect hospitals' receipt of discrimination charges.

90 The authors reviewed the impact of affirmative action plans, diversity committees and taskforces, diversity managers, diversity training, diversity evaluation for managers, networking programmes and mentoring programmes on minority representation. 
organisations revealed that for Black workers, it is the content of the programmes that matters, rather than the number.

Diversity training may also affect perceptions of fairness within organisations. Experimental research by Brady et al. (2015) found that participants are more likely to believe a company is fair and just and less likely to have engaged in sexism when the company offered diversity training. ${ }^{91}$ This effect persisted even when participants were made aware that the company's hiring practices disadvantaged women; despite being presented with evidence that equally qualified women were passed over in favour of men in the hiring process (men were selected for interview 70 per cent of the time, compared to 30 per cent of the time for equally qualified women), the presence of a diversity training programme caused women to believe that women were treated more fairly in the company. Similarly, experimental research by Kaiser et al. (2013) found that White respondents and men were more likely to perceive a company as fair when diversity structures such as diversity training were present within a company, even when evidence was presented that ethnic minorities and women were discriminated against. ${ }^{92}$ In addition, this perception of fairness due to diversity structures led high-status groups to believe that discrimination claims submitted by ethnic minorities were less valid. These studies caution that the presence of these measures does not necessarily result in fairer treatment in the workplace but can create the appearance of supporting diversity.

Much like affirmative action policies, when evaluating the impact of diversity initiatives, it is important to consider how these have been framed to staff, as this messaging can significantly impact employees' perceptions. Kidder et al. (2004) showed that respondents reported significantly more negative attitudes towards diversity programmes when they were framed as affirmative action initiatives to actively hire and promote minorities, as opposed to hiring good candidates who reflect the diversity of customers. ${ }^{93}$ In the context of ethnic diversity programmes, research indicates that it is important to ensure that White workers feel included in diversity initiatives, as this makes them more likely to endorse these types of policies within an organisation (Plaut et al., 2011). If White workers feel excluded

91 The authors recruited 119 female participants from the US through Amazon's crowdsourcing marketplace, Mechanical Turk (MTurk). Participants were compensated with a small sum of money and asked to read an identical profile of a fictitious investment company. One profile showed that the company administered a diversity training programme and the other a managerial training programme. Participants were then asked to review a list of applicants to the company.

92 Participants were invited to take part in a study in which they would learn about a company and provide impressions of the organisation. Participants comprised 245 White adults from the Us who completed the study on Amazon's online crowdsourcing marketplace, MTurk, in exchange for a small sum of money.

93 The authors recruited a sample of White male and female working professionals and managers from the evening and executive MBA programmes of four business schools located within the eastern US. As the study focuses on backlash among White respondents, the authors only reported data from the participants who identified their race as White. Participants, who each read one scenario, were asked to imagine they were a mid-level manager at a fictitious company and subsequently respond to questions. 
by diversity policies, they can potentially perceive these policies as working against them or being unjust. The authors argue that the fact that the purportedly 'inclusive' ideology of multiculturalism is not perceived as such by White workers may account for their low support for diversity efforts (ibid.). Research by Dover et al. (2016) in the US found that White respondents were more likely to believe that they would be treated unfairly and experience anti-White discrimination when applying for jobs at companies that highlighted their pro-diversity values compared to those who did not express such values. ${ }^{94}$ Further experiments by the authors showed that White men had concerns about being discriminated against and performed worse in interviews for companies who had pro-diversity values.

Additionally, on messaging and communication, a lack of explanation as to why workers and managers are receiving diversity training can lead to a backlash among trainees and negative behaviour towards minority workers. Research by Sanchez and Medkik (2004) found that (non-White) co-workers of managers or supervisors (trainees) who completed diversity training were more likely to report differential treatment than co-workers whose managers or supervisors had not completed the training. ${ }^{95}$ In qualitative interviews, some non-White co-workers of trainees who reported high levels of differential treatment indicated that because trainees had not been informed about why they were sent on these training courses, trainees believed that they had been nominated to attend the training by their non-White co-workers. The lack of an adequate explanation as to why trainees were selected to attend training courses therefore resulted in resentment and differential treatment. This potential for backlash highlights the need to frame diversity training as a tool to improve workplace diversity for all, in order to prevent it being perceived as a form of punishment for 'bad' behaviour, thereby creating tension in the workplace.

Research by Dobbin and Kalev (2016) on why diversity initiatives sometimes fail highlights that compulsory measures such as mandatory diversity training for staff, particularly if framed negatively and linked to sanctions, can actually decrease the proportion of minorities in managerial positions. In contrast, voluntary measures such as mentoring or diversity taskforces had positive effects on the proportion of minorities in management. ${ }^{96}$ Dobbin and Kalev (2016) argue strongly that measures implemented in organisations to improve diversity and decrease discrimination should focus on voluntary rather than compulsory participation,

94 The authors administered a study that was completed by 644 participants recruited via Amazon's crowdfunding resource, Mechanical Turk, in exchange for a small fee.

95 The authors carried out a quasi-experimental design to evaluate the effects of cultural diversity awareness training among 125 managers and supervisors. Approximately half of the participants attended a cultural diversity awareness training session, with the other half serving as a matched comparison group. Each participant was designated a coworker who evaluated the extent to which the participant engaged in differential treatment of culturally different individuals.

96 The authors analysed how various diversity initiatives affected the proportion of women and minorities in management in 829 midsize and large US firms. 
though of course in practice this is likely to mean that those most supportive of diversity will receive training, rather than those who are most opposed to such measures.

\subsubsection{Unconscious bias training (UBT)}

UBT programmes comprise a specific diversity management tool that can raise awareness of unconscious bias in the workplace. They are sometimes called implicit preferences or antibias interventions. UBT programmes aim to make participants aware of unconscious biases - the preferences or prejudices formed and held by individuals against certain people or groups outside of one's direct awareness. Some UBTs use the Implicit Association Test (see Chapter 2 for further detail) to assess the impact of training on unconscious bias. This test evaluates a person's positive or negative associations with concepts, images and words and are based on the principle that the speed of the response indicates the strength of the association (Noone, 2017). Importantly, however, not all UBTs use Implicit Association Tests and the delivery and measurement of UBTs can differ significantly.

On the back of an increased interest in interventions to reduce implicit bias, UBT has become a fashionable tool used by firms to support diversity management in the English-speaking world (Fitzgerald et al., 2019). In the UK, it was recommended that the UK government establish a free, online UBT resource to tackle the issue of implicit racism, which has been described as a 'much more pervasive and potentially more insidious [form of racism] than the overt racism associated with the 1970s because of the difficulty in identifying it' (McGregor-Smith, 2017, p. 2). Several organisations in the UK introduced UBT following the recommendation. It also become popular among multinational corporations, like Google (see Walker and Feloni, 2015). Carter et al. (2020) reported that an estimated 20 per cent of US organisations offer training intended to combat implicit bias, with this figure expected to increase.

Evidence suggests that UBT can sometimes be effective in reducing bias (Atewologun et al., 2018). A rapid evidence assessment of 18 studies on the effectiveness of unconscious bias training found that UBT can be successful in raising awareness of the potential negative impact of unconscious bias, though the evidence on changing behaviour is much more limited (ibid.). ${ }^{97}$

97 The authors conducted a rapid evidence assessment using a three-stage process. They identified evidence from online databases, including academic searches and non-academic searches, in this process gathering 57 published peer reviewed articles and 31 non-academic sources, such as reports. They then evaluated the quality of the evidence, before analysing it and drawing conclusions. 
In some cases, UBT can reduce implicit preferences in the short-term. In a review of nine such interventions, Lai et al. (2014) found an immediate reduction of implicit preferences in all interventions over the short-term. ${ }^{98}$ Similarly, in a threemonth longitudinal study, Devine et al. (2012) found that the antibias intervention reduced implicit race bias over an eight-week period. They also found that the intervention encouraged self-regulation..$^{99}$

By comparing 17 different interventions, Lai et al. (2014) found that the effectiveness of an intervention in reducing implicit racial bias varies depending on the content of each intervention. For example, interventions focusing on exposure to 'counter stereotypical exemplars, intentional strategies to overcome biases and evaluative conditioning were more effective at reducing implicit bias than interventions that featured engagement with others' perspectives and appeals to egalitarian values' (Lai et al., 2014, p. 1781). The most potent interventions were ones that invoked high self-involvement (ibid.). Fitzgerald et al. (2019) note that there is not yet enough systematic evidence to prove why some interventions are effective and others are not (Fitzgerald et al., 2019).

Despite its popularity, evidence for the long-term effectiveness of UBT is a subject of academic debate and evidence for its effectiveness to reduce discrimination in the workplace is limited (Dobbin and Kalev, 2018). In many cases, UBT can have little to no effect (Fitzgerald et al., 2019). There is also very little evidence to show that UBT can change explicit bias or behaviour. In their review of 985 studies on a wide range of prejudice-reduction interventions, not just UBT in workplaces, Paluck and Green (2009) found a lack of robust evidence on whether such training reduces bias. ${ }^{100}$ They argued that field experimental evaluations that provide evidence of long-term behaviour change are necessary if prejudice reduction is to be proven. In their rapid evidence assessment on unconscious bias training, Atewologun et al. (2019) found that while UBT raises awareness of the issue (see above), UBT and antibias training are unlikely to eradicate unconscious bias and have a limited impact on changing behaviour. More research on the impact of UBT on behavioural outcomes is needed to better understand this relationship (Fitzgerald et al., 2019).

98 The authors held a research contest to experimentally compare the effectiveness of interventions for reducing the expression of implicit racial prejudice. Teams submitted 17 interventions that were tested an average of 3.70 times each, across four studies.

99 The authors administered a 12-week longitudinal study completed by 91 non-Black introductory psychology students. Throughout the study, participants completed the Black-White Implicit Association Test and several explicit measures. The Implicit Association Test was administered in the lab at three time points - just prior to the intervention manipulation, four weeks after the manipulation and eight weeks after the manipulation.

100 The authors identified 985 published and unpublished reports over a five-year period that ended in spring 2008. Reports included those from observational, laboratory and field experimental literature. 
UBT can also have unintended negative consequences (Kulick and Roberson, 2008; Fitzgerald et al., 2019; Atewologun et al., 2019). It can reinforce negative stereotypes because sometimes biases are strengthened when people are asked to avoid them (Fitzgerald et al., 2019). Following a review of the academic literature on UBT, a written ministerial statement said that as there was little evidence that UBT training changes behaviour, the measure would no longer be used among UK civil service departments (Cabinet Office, 2020). Similarly, the Commission on Race and Ethnic Disparities called on organisations to move away from funding UBT programmes and to focus instead on providing alternative interventions to promote fairness (Commission on Race and Ethnic Disparities (UK), 2021).

In part, the lack of evidence for UBT and antibias interventions is due to the varied structure of UBT programmes across people and place, which makes it difficult to measure effectiveness or draw firm conclusions about its value in countering discrimination. In addition, while the Implicit Association Test is a popular tool, some academics argue that it is limited in its ability to predict 'who will discriminate against whom' (Oswald et al., 2013, p. 188). Although UBT and antibias interventions are widely used in both business and academic settings, a lot of studies, such as laboratory experiments, that seek to assess the effectiveness of such training programmes tend to be conducted in university settings leading to questions of their external validity. This means that, not only is it difficult to draw firm conclusions about the impact of anti-bias interventions in general, it is even more challenging to find evidence to support the effectiveness of UBT and antibias trainings to specifically reduce discrimination in the workplace.

UBT can be a useful tool for encouraging people to talk about discrimination and increasing knowledge (Noon, 2017; Herbert, 2021). While it is limited insofar as changing behaviour or reducing explicit bias are concerned, evidence suggests that it can be useful in terms of raising awareness and initiating a conversation about prejudice and discrimination (Atewologun et al., 2019). Carter et al. (2020) argue that if well designed, UBT can initiate a ripple effect for change in an organisation. Examples of good design in UBT training include appreciating that anti-bias training by itself may not suffice: ideally it needs to be accompanied by accountability structures (staff or groups who have responsibility to meet diversity goals) and part of a broader diversity and inclusion strategy. Training should focus on both increasing awareness and providing strategies for changing behaviour, including assisting trainees to create their own plan for behavioural change (ibid.). Importantly, then, UBT should not be thought of as a unique solution for the reduction of race-based bias, but potentially as one element in a wider, systemic approach towards prejudice reduction (Devine et al., 2012). It may be easier to change practices rather than people's attitudes: this is the subject of the next section. 


\subsection{RECRUITMENT PRACTICES}

People from ethnic minority groups and immigrants may face significant discrimination in job recruitment. Numerous field experiments indicate a substantial level of discrimination in hiring, particularly of non-Western immigrants and/or ethnic minorities, though effects do vary across countries (see Chapter 2) (Zshirnt and Ruedin, 2016; Bertrand and Duflo, 2017; Quillian et al., 2019). In response to literature pointing towards the continuing discrimination against ethnic minority groups in terms of access to the labour market, there is a growing interest in different policies and practices that may be able to remove or reduce recruitment discrimination for minority groups. Of course, there are many factors that influence hiring decisions, and it is important to note that racial attitudes are only one element (Pager and Shepard, 2008).

\subsubsection{Formalisation of recruitment practices}

The formalisation of hiring practices refers to the implementation at an organisational level of structured systems and procedures that require employers to make decisions based on relevant and objective criteria and are maintained over time. The degree to which hiring practices are formalised or structured in this way varies across different organisations. The public sector typically employs more formalised recruitment processes than the private sector, which often recruits via networks, word of mouth and employee referrals (Byron, 2010). Not all recruitment is formal in Ireland: survey evidence from 2016 suggests that one-third of young adults (aged 20-34 years) got their jobs via social networks (see Figure 4.1 below). ${ }^{101}$

Formalised hiring practices may include the implementation of fixed procedures around hiring, such as advertising vacant posts, shortlisting candidates for interview, use of consistent interview questions and the use of job tests. This may also include diversity on interview boards and even psychometric job testing. The intention of these practices is to limit individual discretion and thereby mitigate the effects of discrimination (Pager and Shepard, 2008). Research found that reforms that increase transparency in promotion and hiring, such as job postings, eligibility for openings and hiring decisions, create a more diverse workforce by expanding the applicant pool and 'eliciting accountability' among hiring managers (Dobbin et al., 2015, p. 1034). ${ }^{102}$

There is generally positive evidence for the potential of formalised hiring practices to reduce labour market inequality. Results from field experiments in the public

101 Some people may have heard about a vacancy through social networks even though the hiring process was formal. However, this does imply that without the contact, the person would not have got the job.

102 The authors examined how bureaucratic equality reforms affect the shares of White, Black, Hispanic and Asian men and women in management following 816 private sector workplaces over 32 years. 
sector highlight the potential for formalised organisational procedures to increase minority group representation (DiPrete and Soule, 1986; Moulton, 1990). Similarly, there is evidence to support the claim that workforce inclusiveness directly correlates with the degree of recruitment formalisation (Bjørnshagen and Ugreninov, 2020). ${ }^{103}$

Importantly, however, formalised hiring practices may in some contexts produce negative consequences. A problem with formalised hiring practices is that rules and systems are subject to the influences and biases of the in-group (Pager and Shepard, 2008). Additionally, there is evidence that the rules can be unbiased but selectively enforced, with greater leeway and flexibility afforded to White/majority applicants. The prevalence of selective enforcement in formalised hiring practices is evidenced by the results of a survey in which one-fifth of Norwegian public employers reported that personal suitability was one of the most important eligibility criteria applied while hiring (Tronstad, 2010). This category is highly subjective and can lead to the prioritisation of majority groups in the hiring process (Wilson et al., 1999; Squires, 1994). Moreover, evidence indicates that increased bureaucratisation, not limited to the formalisation of hiring practices, does not necessarily reduce discrimination and needs careful implementation (Jewson and Mason, 1986).

Job testing technologies at the initial screening stage of the recruitment process can improve hiring decisions and reduce bias compared to informal assessments. Hoffman et al. (2018) studied the impact of introducing job tests in 15 low-skilled service sector firms. They found that cohorts hired after the introduction of job testing had substantially longer tenures than candidates hired before job testing was introduced. ${ }^{104}$

Other studies have found that standardised tests can disadvantage minority groups. In the US, the National Research Council (1989) considered the use of a federally-sponsored employment test, the General Aptitude Test Battery (GATB), to match jobseekers to requests for job applicants from private- and public-sector employers in the US. They questioned how widely this test should be used, citing findings from their review of evidence that minority applicants who could perform successfully on the job would be screened out of the referral group in greater proportions than the equivalent in the majority group. In another study, Autor and Scarborough (2008) explicitly tested whether introducing standardised job tests for employment screening improved selection but reduced minority hiring. The authors used data from a large service sector firm (1,363 outlets) across 47 states

103 The authors used data on 1,501 Norwegian enterprises collected from a survey conducted from 13 September to 15 October 2017. The survey was intended to obtain information on attitudes and practices towards the inclusion and recruitment of young people with mental health problems. 
in the US that moved from informal to formal hiring process over the course of a year. The formal application process for jobs with the firm included an electronic application form, following which applicants completed a personality test based on the five-factor model of personality. ${ }^{105}$ The results showed that while minority applicants performed somewhat worse in the hiring tests, ${ }^{106}$ the move from informal to test-based worker screening had no measurable impact on the proportion of minority candidates hired. No studies were found of the impact of job tests on diversity in hiring in Ireland.

These studies suggest that standardised tests, like other formal procedures, can be a valuable screening tool in job selection. However, they need to be applied carefully to ensure that they do not unintentionally disadvantage eligible minority candidates.

\subsubsection{Anonymous application procedures}

Anonymous application procedures (AAP) typically refer to practices and policies that omit from the recruitment process questions relating to certain personal information, such as name, gender, appearance (photo), age or any other information that might identify the ethnic or disadvantaged status of a job applicant. Typically, AAPs aim to remove bias from the initial review of job applicants by focusing on merit and by removing information related to the characteristics of the candidates that are not relevant to their potential job performance (Hiscox et al., 2017). Goldin and Rouse (2000) observed that blind auditions for symphony orchestras have a significant impact on gender composition. In their field experiment in Ireland, McGinnity and Lunn (2011) found that candidates with Irish names are twice as likely to be called to interview than those whose name signals a minority background, even though these candidates had equivalent educational qualifications and job experience. ${ }^{107}$ This suggests that firstly, there was substantial discrimination at the first stage of hiring in Ireland for the jobs tested (in 2008) and, secondly, that removing names from CVs should considerably reduce this.

In recent years, several studies and experiments have been undertaken to explore the impact of AAP, or name-blind recruitment, on hiring. These initiatives differ significantly in terms of context and methodology, making it challenging to draw any conclusions about the effectiveness of the measure in general terms. Despite

105 These tests have previously been found to predict 'worker productivity, training proficiency, and tenure'. The results from these personality tests are analysed into percentiles and managers in the firm were strongly discouraged from hiring applicants with scores in the lowest quintile.

106 The authors do note that the differences between Black, White and Hispanic scores were relatively modest compared to other tests.

107 In fact, to ensure equivalence, CVs were actually rotated between Irish and minority candidates in this. See McGinnity et al (2009) for further details of how the experiment was conducted. 
such limitations, in a review of European AAP initiatives, Krause et al. (2012) observed that there is a general encouraging trend for AAP to lead to increased interviews for disadvantaged groups. ${ }^{108}$ Results from two experiments conducted by the public administration in a Dutch city indicate that while minority candidates receive lower call-back rates with standard applications, the differences in terms of call-back rates disappears when AAP practices are implemented (Bøg and Kranendonk, 2011).

Similarly, results from an experiment conducted in parts of the local administration in the Swedish city of Gothenburg between 2004 and 2006 suggest that AAP increases the chances of an invitation to interview for women and applicants of non-Western origin (Aslund and Skans, 2012). ${ }^{109}$ However, the same study found little evidence to suggest that AAP has a positive effect on the outcome of job offers in relation to non-Western applicants. On this point, it is worth bearing in mind that field experiments which test both stages of the recruitment process have consistently shown that discrimination against minorities is highest at the first stage of the selection process (Boevenkerk et al., 1995). In fact, Bøg and Kranendonk (2011), in a field experiment in the public sector in the Netherlands, found no evidence of discrimination against minority applicants at the second stage (job offers to candidates who had been interviewed), irrespective of whether applications were anonymised or not, though the authors found substantial discrimination at the first stage (call to interview). ${ }^{110}$

Krause et al (2012) conducted an experiment in Germany involving eight public and private organisations that volunteered to review anonymous applications in specific departments for different job types. The results found that 41 per cent of those surveyed estimated that their chances of being called back for an interview were higher through AAP than the conventional recruitment process. More specifically, the results indicated that women and people from a migrant background had a better chance of being called back for an interview when AAP was implemented (Krause et al., 2012). This study demonstrates the benefits of the AAP approach. Moreover, anonymising written, or online applications is typically not difficult administratively, with standardised application forms that are

108 This research was administered by the Federal Anti-Discrimination Agency. Eight organisations took part in the project. All organisations agreed on the scope of anonymisation for applications and the first organisation started the anonymisation process in September 2010.

109 The authors analysed recruitment data from the local administration of the Swedish city of Gothenburg after the local council decided that AAP was to be implemented as a pilot project. Data from job openings within these two districts provided the authors with estimates of how recruitment processes work under AAP.

110 The higher discrimination at first stage (call to interview) could imply a higher standard for ethnic minority candidates by the second stage. See Bøg and Kranendonk (2011) for further details. 
completed by the applicants appearing as the most effective and efficient way to make applications anonymous (Banerjee and Duflo, 2017). ${ }^{111}$

Findings regarding an initiative organised by the French Public Employment Service involving 1,000 firms in eight local labour markets show that outcomes are not always positive. This study found that when AAP is implemented, while women benefit, migrants and residents of deprived neighbourhoods suffer. The findings demonstrated that ethnic minority groups received lower call-back rates with AAP than the standard application process. The initiative found that the gap in interview rate between minority and majority candidates worsens by around ten percentage points when résumés are made anonymous (Behaghel et al., 2015). ${ }^{112}$ The authors explained this surprising finding in the (self) selection of the 62 per cent of firms who participated in the study: participating firms tended to hire relatively more minority candidates using the standard application procedure. Anonymisation did not allow them to favour minority candidates. Thus, these findings are not generalisable to 'what would have happened' if mandated to all firms. Overall, Krause et al. (2012) observed that AAP can lead to increased chances of being called back to interview for ethnic minority groups, with the effects of AAP crucially depending on the pre-existing situation in the respective organisation. AAP can reduce discrimination if it is present beforehand, but it can also prevent the employer from applying measures such as affirmative action, at least in the first stage of the hiring process (Krause et al., 2012). Thus, anonymising applications may be difficult to combine with targets for diversity in recruitment.

A study by Hiscox et al. (2017) also highlights how anonymisation may hinder diversity in recruitment. Their study involved an individually randomised control trial carried out by the Australian Public Service involving over 2,100 public servants from 14 agencies. ${ }^{113}$ Participants were asked to shortlist randomly assigned applications for a hypothetical senior role in their agency. The findings revealed that minority males were 5.8 per cent more likely to be shortlisted and minority females were 8.6 per cent more likely to be shortlisted when identifiable compared to when applications were anonymous. The study suggests that when all information is available to recruiters in the public service, recruiters discriminated in favour of women and ethnic minority groups (Hiscox et al., 2017).

111 Rinne (2018) also noted that while a standardised application is very efficient, other anonymisation methods, such as blacking or whiting out information on applications, can be costly.

112 The programme was conducted over ten months in eight (out of 100) French government departments, at branches of the public employment service (PES) located in urban areas. Résumés were matched with vacancies and then sent to research assistants in charge of the randomisation at the central PES offices. If the vacancy is assigned to the treatment group, all the résumés are given a number and anonymised by the research assistant. 
A name-blind pilot recruitment project carried out by the Government of Canada involving 17 participating organisations and 2,226 candidates including 685 members of visible minorities revealed that there is no net benefit or disadvantage with the name-blind recruitment assessment method for visible minorities (Government of Canada, 2018). ${ }^{114}$ No evaluations of AAP in Ireland were found.

Despite evidence pointing towards the effectiveness of AAP in reducing discrimination at the initial stage of the recruitment process, there are several limits to the policy that must be considered. Even with anonymous job applications for the first stage, candidates' identities are typically revealed when the candidate is called to interview. Thus, there is little evidence on whether AAP positively impacts the outcomes of actual job offers for disadvantaged applicants or applicants of non-Western origin (Rinne, 2018; Aslund and Skans, 2012). Of two Swedish experiments that tested this, one found that AAP was associated with both higher call-back rates and higher job offers for minorities: in the second, this effect was found for women but not for migrants (Aslund and Skans, 2012). Depending on the organisational context, anonymous job applications may benefit one ethnic minority group at the expense of another (Krause, et al. 2012).

Rinne (2018) argued that AAP may simply postpone discrimination to later stages of the hiring process, but there is no clear evidence of this. As noted above, most discrimination takes place at the call-to-interview stage $(B \emptyset \mathrm{g}$ and Kranendonk, 2011)..$^{115}$

AAP may also have the unintended effect of frustrating other efforts towards the promotion of diversity and inclusion policies in the workplace. Evidence from the randomised controlled trial carried out by the Australian Public Service highlights that voluntary trials are more likely to attract participants who support gender equality and diversity, meaning that they may already have policies in place to promote diversity and inclusion. Mixed experimental evidence highlights that while AAP is promising, it is not a universal remedy to counter discrimination in the labour market and that the policy should not be made mandatory (Rinne, 2018). It is not possible to anonymise 'in-person' applications for jobs, for example in construction or retail. In addition, like many other initiatives, AAP focuses on 'levelling the playing field' at one point in time. It does little to tackle the structural disadvantages faced by ethnic minority groups before applicants enter the labour market - for example, discrimination in the education system that leads to minority candidates having lower educational qualifications (Krause, et al. 2012; see also

114 This project involved the launch of 27 external processes between April and October 2017 across 17 participating organisations. Overall, 54 independent reviewers participated in the pilot, resulting in 4,452 independent screening decisions.

115 This experiment with anonymous applications ran from 1 August 2006 to 1 February 2007. During this period, all new vacancies were included in the experimental sample either as control or treatment. 
Section 1.2). Further research on whether AAP can be effective at combatting bias at later stages in the recruitment process is needed, though this may be difficult to conduct.

\subsubsection{New technologies}

Emphasis on the removal of bias from recruitment and selection processes has given rise to the emergence of new technologies. Data-driven HR analytics aim to use statistical (data mining) techniques to predict uncertain outcomes, such as the performance of potential employees, and to monitor the success of recruitment and retention (OECD, 2020). Similarly, some organisations have turned towards the use of algorithms and machine learning as potential tools to combat discrimination in the recruitment and selection processes.

New technologies have the potential to reduce labour market discrimination. Atypical or under-represented job candidates can have improved chances of being hired when algorithms are used (OECD, 2020). In this instance, labour market gatekeepers (those recruiting) who are susceptible to unconscious bias are removed from the hiring process.

Evidence from field experiments suggests that such new technologies can reduce discrimination in the labour market. For example, the results of a field experiment by Cowgill (2019) on hiring for full-time, white-collar office jobs found that, compared to candidates shortlisted by both human and machine, candidates selected by machine alone are 14 per cent more likely to pass a subsequent doubleblind face-to-face interview and 18 per cent more likely to accept job offers when extended by the employer. ${ }^{116}$ In addition, the results showed that the screening (or shortlisting) algorithm increased the hiring of non-traditional candidates, including racial minorities, as well as candidates without a job referral, graduates from nonelite colleges and candidates with no prior work experience (Cowgill, 2019).

The results of another recent study also suggest that algorithmic decision aids could help firms identify alternative choices of potential directors, thereby opening up board seats to a broader set of candidates with more diverse backgrounds and experiences, candidates who would have otherwise been overlooked (Erel et al., 2019). ${ }^{117}$ New technology can reduce the role played by managerial bias by

116 The author developed a decision-making model that makes predictions about when machine learning algorithms can improve human biases and then tested such predictions in a field experiment hiring workers for white-collar jobs.

117 The authors constructed a large database of publicly traded US firms and independent directors appointed between 2000 and 2014. They built several machine learning algorithms designed to predict director performance using director, board and firm level data available to the nominating committee at the time of the nominating decision. The authors then compared the algorithms' selections of directors to those chosen by firms. 
providing alternatives to the pre-existing organisational structure (Hoffman et al., 2018; see Section 4.3.1 for more on job-testing technologies).

Despite the evident benefits of machine learning, such new technologies are not necessarily bias-free themselves. Neither are they assumed to have the capacity to entirely eliminate bias from the decision-making process. There are fears around the extent to which algorithms programmed using historical data can codify and implement historical biases (Cowgill, 2016; Barocas and Selbst, 2016), which could potentially reduce the chances of historically disadvantaged and vulnerable groups relative to majority groups in recruitment or promotion. These algorithms are maintained by individuals who are also susceptible to discrimination. The same can be true of artificial intelligence talent acquisition software. If the specialists creating the software are biased, or the (historical) data they are working with reflect biased past decision-making, new technologies can reinforce pre-existing inequalities in labour market outcomes (Yarger, 2019). Despite these caveats, however, new technologies do offer the potential to combat discrimination in hiring and increase diversity in the labour market.

\subsection{NETWORKING PRACTICES IN RECRUITMENT AND IN THE WORKPLACE}

A significant body of research in labour market sociology has highlighted the importance of social networks - 'who you know' - for finding a job (Lin, 1999). The resources or information possessed by these networks or contacts is known as social capital, and can include knowledge about job opportunities, links to potential employers, how to apply for jobs and what criteria matter. Strong ties (close friends or kin) tend to be with people who are similar in terms of social position, ethnicity or language. An individual's weak ties or acquaintances tend to be less similar in terms of social position, ethnicity or language and, in addition, these ties (acquaintances) form bridges to link an individual to other social networks. Thus, the individual will receive more novel information - for example, about job openings - than from their own social network. Disadvantaged groups in the labour market may not have the right connections to access this social capital. For example, research has found people from immigrant and ethnic minority backgrounds tend to have fewer contacts with people in higher social positions and get fewer job leads (McDonald et al., 2009).

A study by Petersen et al. (2000), which examined information on over 35,000 applicants to a high-tech firm in the US over a ten-year period, found dramatic differences between ethnic groups in hiring: 80 per cent of White people found their job through a friend or professional network, compared to 5 per cent of Black 
people and 2 per cent of Native Americans. ${ }^{118}$ Asians ( 25 per cent) and Hispanics (33 per cent) were in an intermediate position in this regard. ${ }^{119}$ Interestingly, the authors reported that ethnic differences in recruitment are eliminated when the method of referral is considered, suggesting that the lack of ethnic diversity in the firm is primarily due to how people are referred to the job. The findings of this study suggest that the impact of social networks on hiring is strong, and may be more important than any direct action taken by individuals in an organisation (Pager and Shepherd, 2008). There is also evidence of this from the perspective of recruiters: a large international survey of HR representatives fielded by the OECD in 2017-2018 found that over half of them cited too few qualified applicants from minority groups as the main obstacle to diversifying staff in their organisation (OECD, 2020). ${ }^{120}$ In Ireland, data from a 2016 special module of the EU Labour Force Survey on young people in the labour market found that advertisements and social networks were the most successful methods young people (aged 20-34) used to find their current job. The findings from Ireland were similar to those of the EU as a whole (see Figure 4.1). ${ }^{121}$ Here, the term social networks refers to both friends, relatives and acquaintances and cases where employers contacted the respondent directly regarding employment. The results highlight the importance of such connections in attaining employment.

118 This study used the outlined information to analyse the impact of sex, race and social networks on the hiring process in a mid-sized high technology organisation. In total, the authors had information on 35,229 applicants, 3,432 of whom received offers and 2,870 received acceptances. All applicants were given a brief initial interview, and all received a rating based on a psychological personality test.

119 The authors noted that finding a job by social networks is particularly prevalent in the software industry.

120 The OECD, together with the Paris Dauphine University and with the support of national HR associations, conducted an online survey in 2017-2018 to gather evidence on the experiences and views of HR professionals regarding diversity practices in their firms. Responses do not provide a representative picture of the practices of HR managers or companies in any given country (OECD, 2020).

121 See Eurostat table Ifso_16findmet for more information. 


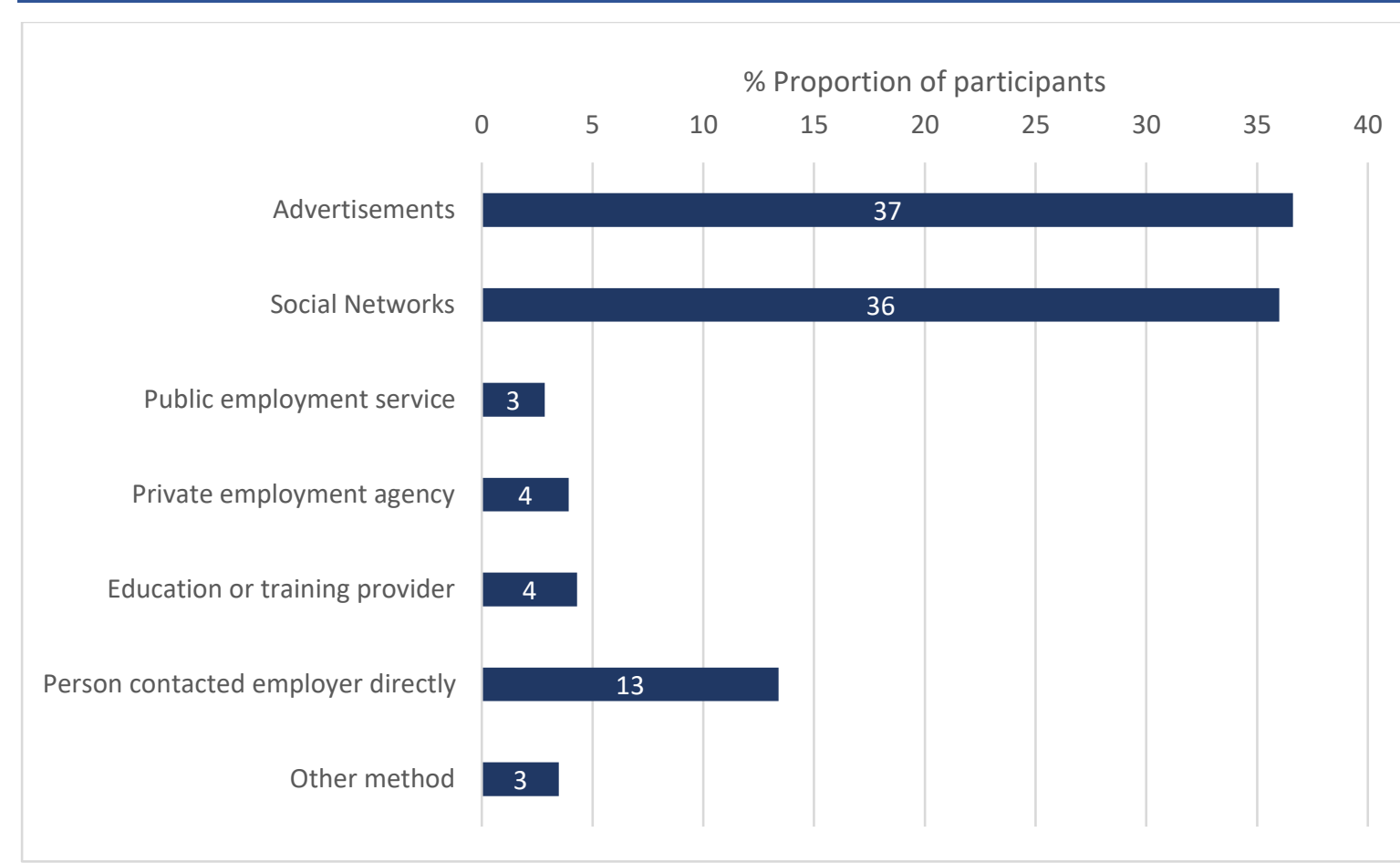

Source: EU-LFS Special module 2016

Notes: $\quad$ Analysis is restricted to employees aged 20-34. Social networks include both friends, relatives, and acquaintances and cases where employer contacted the respondent directly.

Diversity measures can mitigate the lack of social capital among immigrants and ethnic minorities, both in recruitment and in promotion within an organisation. In recruitment, these measures can take a number of forms, including outreach or advertising activities to inform minority applicants about vacancies and how to apply, as well as internships or trainee positions targeted at disadvantaged communities to give minority applicants some experience, job skills and contacts with prospective employers - a 'first foothold in the employment ladder' (Mullen et al., 2021, p. 22).

In the US, companies that implement a college (third-level) recruitment programme targeting women and ethnic minorities showed higher female and minority representation in management positions. Using a large study of 829 midsize and large firms in the US from 1972 to 2002, Dobbin and Kalev (2016) found that, within a five-year period, college recruitment targeting women increased the proportion of female managers by an average of 10 per cent. Programmes to increase female representation also increased the proportion of Black and Asian male and female managers, as well as Hispanic women in management, by between 8 and 18 per cent. The authors argued that managers who recruit from universities have positive motivation to recruit the best candidates and tend to become 'diversity champions' in their organisation. However, only around 15 per cent of the firms in their study have special college recruitment programmes for women and ethnic minorities. 
Many public administrations in OECD countries have outreach campaigns and traineeship programmes targeting specific groups in order to build a workforce that is representative of the public they serve (OECD, 2020). Many outreach campaigns target those in education, either in secondary school or university. In Switzerland, the public administration liaises with universities to recruit more women. The French public service offers internships to students who attend schools with a high share of disadvantaged pupils. In Germany, a campaign in Hamburg encouraged young people from a migrant background to apply for internships in public administration. In Berlin, the 'Berlin Needs You' campaign works through a network of 30 schools and 60 companies, providing career guidance, training, and information (ibid.). Unfortunately, no evaluations of these European measures have been found.

Initiatives have also focused on diversifying police forces through outreach campaigns in Chicago, London and Vienna. In Germany, 14 out of 16 federal states have outreach activities in place and monitor the country of origin of applications and those recently appointed to the police (Ghelli and Pross, 2019). ${ }^{122}$ In Berlin, the number of applicants of migrant origin has rapidly increased in recent years, from 12 per cent in 2008 to 32 per cent in 2016, with migrant-origin applicants making up 30 per cent of new hires, slightly higher than the proportion of the Berlin population of migrant origin (ibid.). The Berlin police have introduced a number of initiatives; as well as participating in the 'Berlin Needs You' campaign they have developed a diversity charter and employ police staff of a similar ethnic profile to migrants to provide contacts and advice to those applying for employment. It is of course not possible to tell which of these initiatives is most effective; however, the increase in the proportion of migrant-origin applicants is remarkable. It is also true that in other German federal states, the proportion of police from a migrant background is much lower than the proportion of migrants in the State overall.

The OECD (2020) argue that liaising with stakeholder/ representative groups of the minority communities is crucial for outreach campaigns to be effective. In the Netherlands, public authorities work with migrant organisations and networks to promote recruitment. In Ireland, the Public Appointments Service has advertised job opportunities to under-represented groups over social media, including Facebook, Twitter and LinkedIn. No evaluations of the impact of these outreach activities have been conducted. ${ }^{123} \mathrm{~A}$ recent report, entitled Travellers in the mainstream labour market (Mullen et al., 2021), highlighted the importance of internships in the public sector as 'enablers' of Traveller employment in the 
mainstream Irish labour market, as reported by Travellers themselves. ${ }^{124}$ The Immigrant Council of Ireland run a migrant-councillor internship scheme to promote migrant participation in Irish politics. ${ }^{125}$ College internships also provided important contacts with prospective employers, though of course internships can be problematic for low-income groups if they are not properly funded and do not cover living costs. More general research on internships and their impact on future career prospects has found that paid, structured internships with some element of training and mentorship have a much greater impact on subsequent career prospects than unpaid internships (O'Higgins and Pinedo, 2018). ${ }^{126}$ In addition, placements/traineeships can be particularly beneficial if they can be made permanent or there is a potential for a job offer after successful completion of the internship (ibid.). The Oireachtas Work Learning (OWL) training programme for people with intellectual disabilities in the Irish Civil Service is an example of such a programme.

An important indicator of the success of outreach campaigns like these is the pool of applicants applying for different posts. For this reason, it is important that the background of applicants is recorded and monitored, so that any company can monitor the diversity (or lack of diversity) in their applicant pool and assess the effectiveness of any measures undertaken to increase diversity. If a target is set regarding the proportion of managers within an organisation from a particular minority group, for example, then the background of managers should be recorded. This underscores the importance of equality monitoring of both applicants and new recruits, both in the public sector and within organisations more generally.

The public sector can play an important role in communicating the benefits of inclusive workplaces (OECD, 2020). As such, the State can be a role model for the private sector, even though a much greater proportion of employment is in the private sector (for example around four out of five employees in Ireland work in the private sector). ${ }^{127}$

Large organisations or companies often find it easier to implement diversity-led recruitment policies than small or medium-sized enterprises (SMEs) (OECD, 2020). SMEs have fewer resources and recruitment channels and thus may be more subject to the bias of personal networks in recruitment. In the OECD survey of HR managers, 20 per cent of firms with 250 employees or less (these count as SMEs)

\footnotetext{
124 Social enterprises are another important enabler of mainstream employment (Mullen et al., 2021).

125 See https://www.immigrantcouncil.ie/campaign/migrant-councillor-internship-scheme.

126 The authors analyse data from two sample surveys of interns: a survey of young Europeans who have participated on at least one internship (or traineeship) and an internet-based survey of interns (primarily) in international organisations, undertaken by the Fair Internship Initiative (FII) in 2016.

127 This is based on the number of employees in Q3 2019 and includes semi-state bodies in the public sector. See Table A2, https://www.cso.ie/en/releasesandpublications/er/lfs/labourforcesurveylfsquarter42019/.
} 
reported outreach campaigns, compared to 40 per cent of firms with over 250 employees. In Ireland, most employees work in smaller firms. For example, of workers in the private sector in Ireland in 2017, 64 per cent worked in firms of less than 100 employees; in fact, over half of employees ( 52.6 per cent) worked in firms with less than 50 employees (Keogh et al., 2020). ${ }^{128}$

How can smaller firms be supported? In France, a recruitment agency (Mozaik RH) specialises in fostering diversity by matching candidates from a migrant origin with local businesses. ${ }^{129}$ The German WeIKMU project targeted highly educated young people with migrant parents in SMEs through networking events, job fairs and a multilingual guide for minority graduate placements. SMEs are also offered support (OECD, 2020). However, there are no evaluations of whether these initiatives have been successful in increasing diversity among the SMEs who participated.

Focusing on the role of social networks within an organisation, mentoring and how mentoring operates is another way of understanding how different people progress through an organisation. This in turn sheds light on how diversity (or its lack) can come about in senior positions. Athey et al. (2000) developed a theoretical model which highlights that even when diversity is found at entry level, if senior colleagues tend to mentor those of the same 'type' (such as in terms of gender or ethnic background), entry-level employees from the majority group will benefit from mentoring, acquire more specific human capital and progress more quickly. Thus, without intervention, the upper level of the company will lack diversity. To address this, 'cross-group' mentoring is a strategy that can be used to foster diversity. In teaching the junior staff they are mentoring and sponsoring them for key training and assignments, mentors help give their charges the skills and experience they need to develop and advance in an organisation. Typically, mentors then come to believe that their protégés merit these opportunities, regardless of their background (Dobbin and Kalev, 2016).

Thomas (2001) studied the career trajectories of minority and White professionals at three major US corporations, combining in-depth case studies with an analysis of 500 promotion records at one of the companies studied. ${ }^{130}$ The most successful minority professionals forged mentoring relationships with widely diverse individuals who offered them challenging assignments and expanded responsibilities. Mentors also provided career advice and developmental support.

128 These figures are based on Labour Force Survey data from 2017 and exclude the self-employed without employees and the public sector.

129 This initiative is funded by multiple sources, including public funding of some programmes, revenue from services sold, private sponsorship and philanthropy. See https://www.fondation-mozaik.org/le-projet/ for further details of the organisation's activities.

130 The three companies were large - one commodity manufacturer, one electronics company and a high-tech firm. They were deliberately selected as having a good track record on diversity, in order to provide examples of good practice. 
This study found that White employees fast-track early, with minorities following a slower career path, some even leaving the organisation as their careers stagnate in middle management. Thomas (2001) also found that while White men find mentors on their own, women and ethnic minorities often need help from a formal programme, as White male executives do not feel comfortable reaching out informally to young women and men, yet are eager to mentor assigned protégés. ${ }^{131}$

Dobbin and Kalev (2016) in their study of 829 firms found significantly greater diversity among management of those who employ mentoring programmes (around 10 per cent of firms in their sample). Within five years, mentoring programmes boosted the managerial representation of minority women: Black (by 18 per cent), Hispanic (by 24 per cent) and Asian American (by 24 per cent). Focusing specifically on men, the figure for Hispanic men was 9 per cent and for Asian American men was 18 per cent. ${ }^{132}$

Dobbin and Kalev (2016) focused on other initiatives within companies that sought to increase contact between minorities. Social contact theory has played an important role in understanding group relations: the basic premise is that social contact between individuals from different groups under optimal conditions may reduce prejudice and ameliorate threat perception (Pettigrew and Tropp, 2006). The original four conditions proposed by Allport (1954) are: equal status between the group in the situation; common goals; intergroup cooperation; and the support of authorities, law or custom. In their research review, Pettigrew and Tropp (2006) found strong support that these conditions generally enhance the positive effects of social contact, though not all are essential for intergroup contact to achieve positive outcomes. ${ }^{133}$ As such, a teamworking environment may be more likely to meet these conditions than other social encounters. A number of measures have been evaluated that aim to increase contact within organisations. Another strategy is to rotate management trainees through different departments ('cross-training'). The main purpose of rotation is to expose trainees to a variety of roles within the organisation, but it also exposes both managers and trainees to a wider variety of people. Dobbin and Kalev (2006) found positive, though modest, impacts on diversity at management level in companies that implemented cross-training: a between 3 and 6 per cent increase in minority groups in management roles, depending on the group. ${ }^{134}$ The authors note that while the effects are much more

131 Thomas (2002) also discusses situations where the mentoring relationship does not work so well, and strategies to deal with this.

132 Findings were not significant for Black men.

133 Pettigrew and Tropp (2006) also found that, of the four optimal conditions, institutional support may be an especially important condition for facilitating positive contact.

134 Cross training in an organisation was associated increases in representation - of 3 per cent for White women in management, 3 per cent for Black men and women, 6 per cent for Asian men and 4 per cent for Asian women. Hispanic men did not benefit; in fact, within five years their representation at management level had dropped by 4 per cent. 
modest than those of mentoring or college recruitment efforts, these measures were much more common among the companies they studied, with one-third of US firms using self-managed teams for core operations and four-fifths using crosstraining.

Sponsorship, or support from an individual in a highly influential position of leadership, can also promote career advancement for ethnic minorities once they have entered the workplace. Sponsorship is different from mentoring: while mentors provide protégés with support and career advice, sponsors take on the role in a more 'hands-on' way by publicly advocating for their protégé and seeking opportunities to advance their career. Sponsors 'stick their neck out' for their protégés (Hewlett et al., 2010, p. 5). Sponsorship also differs from mentoring in that sponsors are typically in highly influential positions and have significant institutional and organisational knowledge about the place of work, while the recipients of sponsorship are typically standout individuals. In contrast, mentors can be from any level in the organisation to anyone in the organisation (Perry and Parikh, 2019).

Findings from research carried out by Hewlett et al. (2012) involving focus groups, one-on-one interviews and a survey of 3,929 respondents suggest that sponsorship can have a positive impact on career advancement for ethnic minorities. The findings showed that 53 per cent of African Americans with a sponsor were satisfied with their rate of advancement, compared with 35 per cent of those without such advocacy. Similarly, 55 per cent of Asians with a sponsor were content with their rate of advancement, compared with just 30 per cent of Asians without such backing (Hewlett et al., 2012). Both sponsorship and mentoring have been identified as coping mechanisms for Black women from racial microaggressions in the workplace (Holder et al., 2015). ${ }^{135}$ This suggests they may offer additional benefits beyond career advice or improving prospects for advancement.

Sponsorship can also enable individuals to ask for more from their workplace. In a US survey of 2,952 men and women, spearheaded by American Express, Deloitte, Intel, and Morgan Stanley, Hewlett et al. (2010) found that when it comes to asking for a pay raise, most men (67 per cent) and women (70 per cent) resist confronting their boss. ${ }^{136}$ With a sponsor, however, nearly half of men and 38 per cent of women summoned the courage to do so (ibid.). While this study focused on women's career progression, its results suggest that the support mechanisms

135 The authors conducted semi-structured interviews with 10 Black women who had worked as senior-level corporate professionals and used a phenomenological methodology to uncover the lived experiences of these women.

136 These women and men were aged between 21 and 62 years, held at least a bachelor's degree and at the time of research were employed in certain white-collar occupations. 
offered by sponsorship may empower under-represented groups, including ethnic minorities, to progress in the workplace.

\subsection{PAY TRANSPARENCY IN THE WORKPLACE}

Pay is an important component of workplace discrimination, as well a key measure of job quality and rewards to work. Measures to address the pay gap, for example, by improving transparency around employee pay and salary, may contribute to reducing workplace discrimination. Gaps in hourly pay may be experienced by different groups of employees in a workplace; when arising between women and men, it is known as the gender pay gap) (Blau and Kahn, 2017), while that arising betweeen ethnic minority and majority employees is known as the ethnicity or racial pay gap (Mandel and Semyonov, 2016). Though the scale of the gap can differ across countries, gender pay gaps exist in most developed countries, with women earning less than men in the US (Blau and Kahn, 2016), the EU (Boll et al., 2017) and in Ireland (Doris, 2019). Gender pay gaps in Ireland tend to be lower in the public sector, where there are established pay scales and less employer discretion in remuneration (Russell et al., 2005; Doorley et al., 2021).

Some argue that part of the reason the gender pay gap exists is because it is hidden, and recently a number of countries have focused on pay transparency laws to promote equal pay. For example, Denmark introduced legislation requiring large firms to report wage statistics related to gender in 2016 (Bennedsen et al., 2019). In the UK, firms with over 250 employees are required by law to report salaries and bonuses according to gender (Baker et al., 2019). In Ireland the Gender Pay Gap Information Act 2021 has recently been enacted. ${ }^{137}$ This will require employers to publish information relating to the remuneration of employees. As yet, no countries have introduced mandatory ethnicity reporting, though the introduction of mandatory ethnicity reporting in 2021 has been called for by several bodies in the UK (IHREC, 2021).

As these changes are relatively recent, less is known about whether pay transparency is effective at reducing the gender pay gap. A study carried out in Denmark analysed the impact of a law that required firms with more than 35 employees to provide information related to their salary. It found that increased disclosure around salaries led to a reduction in the gender pay gap (Bennedsen et al., 2019). ${ }^{138}$ A study of the impact of public sector salary disclosure laws in Canada

137 See Gender Pay Gap Information Gap 2021 for details:

https://data.oireachtas.ie/ie/oireachtas/act/2021/20/eng/enacted/a2021.pdf. The regulations do not apply to an employer with fewer than 50 employees.

138 The authors used a dataset from the Integrated Database for Labor Market Research (IDA database) at Statistics Denmark combined with firm-level outcomes from the Danish Business Register. The authors used a statistical technique known as 'difference-in-difference' analysis to compare the effect of regulation on male wages to that of its effect on female wages, and thus estimate the impact of the regulation on the gender wage gap. 
using administrative data found robust evidence that the laws reduced gender pay gaps in university faculty salaries (Baker et al., 2019).

Differences in pay between ethnic minority and White employees are often not reported, in part due to a lack of data related to race in EU countries (OECD, 2020). Racial pay gaps have been the focus of research in the US for much longer, including work which distinguished gender differences in trends and sources of the racial pay gap (Mandel and Semyonov, 2016). However, if further research corroborates these findings that pay transparency reduces the gender pay gap, this suggests that increased reporting of data related to ethnicity, as part of greater pay transparency overall, may also help to reduce the ethnicity pay gap.

\subsection{SUMMARY}

This chapter considers a range of different measures and evaluations of their effectiveness, where these were found. It categorises four different types of measures: state-sponsored interventions, training practices, recruitment practices and networking practices. It is sometimes difficult to compare studies and interventions due to variations in terms of content, how they are presented and how they are applied. Comparing studies and interventions is also challenged by the clear variation in the volume of research on the effectiveness of different interventions, with measures such as public procurement, for example, receiving relatively little academic attention when compared with the extensive coverage of diversity initiatives and evaluations of labour market programmes. There is no single measure that emerges as clearly superior, though research has highlighted some models that seem more promising, as well as some that may be problematic.

Affirmative action is much more common in the US, where organisations must implement affirmative action in order to be eligible for federal contracts. In some cases, affirmative action has been proven to mitigate the effects of labour market discrimination, providing opportunities for people from minority groups to access and be mobile within the labour market. However, perceptions around and the reception of affirmative action policies can lead to negative consequences for minority candidates who are hired and, in some cases, can lead to such policies being discontinued. High-strength affirmative action measures, with quotas and preferential treatment of minority groups, while increasing the representation of minority groups, have experienced considerable backlash from majority groups. This is linked to these practices being perceived as violating equality or merit-based norms. Affirmative action hires are viewed by some as less productive. Following discussions in the US about the efficiency of such high-strength affirmative action policies, such quotas have largely been discontinued (OECD, 2013). However, 'tiebreak' policies, whereby a minority is hired in the case of equal qualifications, 
may be more acceptable, and thus more durable. Here too, however, how these policies are presented is key.

Wage subsidies can be very effective with a generally positive impact on labour market outcomes for minority groups. This is especially true for migrants and other disadvantaged groups, whose employment prospects can be significantly improved by wage subsidies. Policymakers could usefully consider implementing financial incentives for private employers to hire ethnic minority groups and disadvantaged migrant groups, such as refugees, in order to facilitate labour market integration. Such a policy should be carefully implemented in line with OECD recommendations, so as to ensure that these subsidies are a temporary measure and do not act as a substitution for existing workers. Diversity training is a widely implemented and popular intervention across both public and private sector organisations. Evidence suggests that diversity training can be used as an effective tool to improve overall attitudes to diversity and reduce workplace discrimination when training is provided to managers. However, the presence of diversity training initiatives may not assist in increasing diversity in senior positions and can potentially create the illusion of fairness even in the presence of clear discriminatory practices. In particular, if training is compulsory and/or if badly framed it can be potentially problematic. If majority group members do not feel included in the intervention, trainings may be met with backlash. In addition, diversity trainings that do not significantly impact attitudes and behaviour may be used by organisations to 'tick the box' in terms of pro-diversity efforts. Research suggests that voluntary measures are more effective than compulsory ones. We return to this point in the report's conclusion.

UBT, though widespread, has been shown to have limited effectiveness in terms of changing behaviour, something that has led to pushback on this measure. A problem in terms of evaluating effectiveness is that UBT delivered in companies is typically not evaluated. Instead, most evaluations are carried out in academic circles. Further to this, where UBT is evaluated in the workplace, there is little evidence to suggest that it changes behaviour, although it can raise awareness about bias. Another criticism of this intervention is that is can negatively reinforce stereotypes. UBT also suffers from the same disadvantage as diversity training in that companies can identify an intervention as unconscious bias training and, either intentionally or unintentionally, use the training to tick the pro-diversity box.

Considering formal recruitment methods, there is evidence to suggest that formalised recruitment is associated with greater diversity than recruitment through social networks. Companies that hire through a formalised recruitment process are likely to be more diverse, although, importantly, increased bureaucratisation does not directly correlate with increased diversity. There are some caveats to this measure in terms of the rules of the system still being devised 
by the 'in-group' and reflecting their values. In some cases, research shows that job testing/standardised tests may, contrary to their objective, contribute to continued discrimination against ethnic minorities. If carrying out standardised tests as part of the formalisation of recruitment processes, it is critical to do so with attention paid to the testing design and with efforts included to mitigate the effects of in-group bias in the setting up of the associated rules and procedures.

Anonymous application procedures (AAP) are usually positive, with research highlighting their capacity to increase call-back rates for people from minority backgrounds. Importantly, however, this is not always the case, and it is not always possible to carry out AAP at the same time as other diversity interventions. For example, affirmative action, with its goal of improving the labour market outcomes of disadvantaged groups, is incompatible with procedures that require anonymity. Importantly, while anonymous applications can be used as a tool to promote diversity in the workplace, evaluations of hiring processes that use AAP can also represent a significant means of evaluating and monitoring the levels of discrimination at play.

Evidence suggests that new technologies and algorithms can be significant in terms of removing bias from the hiring process and promoting representation of minority groups. Again, however, although algorithms and machine learning are certainly further removed from the negative impact of labour market gatekeeper bias, such technologies are not entirely immune from these concerns. Similar to formalised recruitment, if implementing machine learning as part of the hiring process, it is critical to give attention to design.

Social networks play a significant role in recruitment and understanding labour market inequality (Lin, 1999). Given this, it is not surprising that efforts to address the lack of networks of minority applicants are proven to be very effective. This includes interventions such as outreach in universities, internships and traineeships, all of which will provide people from ethnic minority backgrounds with networks to access social capital. In the same vein, cross-group mentoring and sponsorship can both have positive effects in terms of providing mentees/protégés with knowledge and access to aspects of the labour market. 


\section{CHAPTER 5}

\section{Summary of key lessons and implications for policy}

\section{$5.1 \quad$ KEY LESSONS}

This report presents a review of evidence of the existence and extent of discrimination in the Irish labour market, and international evidence of the effectiveness of measures to combat or reduce it and promote ethnic diversity. This chapter summarises key findings and their implications. It also notes where gaps were found and the limits of evidence, as well as opportunities for evaluation and monitoring in Ireland in the future. We note that measures to combat labour market discrimination are different from those addressing hate speech or harassment on public transport, though reduced labour market discrimination may have (positive) spill-over effects to other life domains.

As a backdrop to developing measures to combat labour market discrimination, Chapter 2 reviews what we know about the existence and extent of racial discrimination in the Irish labour market and which groups are most affected. Using a wide range of sources and evidence, there are consistent indicators of labour market discrimination against the Black and Irish Traveller ethnic groups (see Chapter 2, especially McGinnity et al. 2018; 2020; 2021), with the highest rates of discrimination and lowest employment rates experienced by Irish Travellers (McGinnity et al. 2017; 2021; Watson et al. 2017). This suggests that these groups may be in most need of targeted interventions. Other non-Irish ethnic groups are more likely to experience discrimination in the workplace than 'White Irish', for example, those of Asian or 'Other' ethnicity and White non-Irish groups, though differences are less marked than for the Black ethnic group and Irish Travellers.

Following the Organisation for Economic Co-operation and Development (OECD) (2013) and Fibbi et al. (2021), Chapter 3 considers anti-discrimination legislation in Ireland and internationally, the protections it offers and how it is implemented. It is difficult to measure precisely the impact of anti-discrimination law as its impact evolves over time, though Valfort (2018) argues it can help shape societal norms and foster a positive climate: it can also drive the implementation of antidiscrimination policy at organisational level (Fibbi et al., 2021). In the US, there is some evidence to suggest that anti-discrimination legislation improved outcomes for ethnic minorities, though evidence on EU anti-discrimination legislation is debated. This is partly because of differences in implementation across countries, and partly because discrimination is very hard to prove in legal proceedings. Evidence suggests that both the costs, in terms of time and money, and low likelihood of success may deter individuals from taking action. Sanctions for 
discrimination are also important, but here too, evidence suggests significant implementation challenges exist.

As anti-discrimination law is not self-enforcing, it is most likely to be effective where an individual is supported to take action. Taking action against discrimination can be costly, time consuming and complex, and evidence suggests only a tiny fraction of those who experience discrimination in Ireland do so (McGinnity et al., 2012). For labour market discrimination in Ireland, the Irish Human Rights Equality Commission (IHREC) and the Work Relations Commission play a key role. The lack of a statutory right to legal aid for racial discrimination cases taken to the Work Relations Commission has been identified as a significant barrier to taking action, given the considerable resources required (CERD, 2019). The IHREC has a strategic litigation role, taking cases in the public interest which may establish precedents to motivate others to take action. Equality and human rights bodies such as the IHREC are also important in campaigns to raise awareness of discrimination among employers, rights holders and the general public, as well as providing information on how to take action. Enabling the victims of discrimination to recognise discrimination and take appropriate action is an important part of any overall policy approach to combat it.

Chapter 4 considers a range of different measures and evaluations of their effectiveness, where these were found. Evidence suggests that no one measure was superior but that some were more promising than others. Challenges arose collating evidence due to the variation in the content of these measures, and the diverse organisational and national contexts in which they were implemented. We try to draw general conclusions while noting the Irish context may differ from where cited studies took place. In addition, measures vary in amount of evidence found: affirmative action policies, at least in the US, have been extensively researched, whereas little has (yet) been written on machine learning or the impact of outreach activities.

Affirmative action is much more common in the US than in Europe, as ever since the 1960s organisations there must implement it in order to be eligible for federal contracts. While evidence suggests that the highest strength of affirmative action with quotas and preferential treatment of minorities does increase the representation of minority groups, the practice has experienced considerable resistance from majority groups. In some cases, this is linked to the perception that these policies violate equality or merit-based norms. While, in principle, there may be grounds for unequal treatment in favour of minority groups who have been seriously discriminated against in the past, in practice this is hard to implement as it challenges notions of meritocracy. For example, hard or fixed quotas have been associated with considerable backlash in the US, where quota-based hiring has been largely discontinued (OECD, 2013; Fibbi et al., 2021). Tiebreak policies, where 
a minority is hired in the case of equal qualifications, may be more acceptable, and thus more durable, though evidence suggests these practices also need to be clearly communicated. The limited evidence from Ireland suggests that here too these methods may be associated with perceptions of unfairness. A study of one civil service department found that, following a tiebreak gender balance initiative, some respondents believed promotions were biased in favour of women (Enright and Russell, 2020).

Wage subsidies can be very effective in terms of improving the labour market outcomes of disadvantaged groups, such as migrants or people from ethnic minority backgrounds. However, it is critical that they are designed in accordance with $O E C D$ recommendations to ensure that subsidies are a temporary measure and do not result in the substitution of existing workers.

Evidence suggests that diversity training is moderately successful in improving trainees' cognitive knowledge and behavioural skill sets in relation to diversity in the workplace, with some evidence for improving attitudes to diversity and reducing minorities' experience of discrimination. However, there is little evidence that either diversity training or unconscious bias training (UBT) actually changes attitudes to particular groups. There is also no evidence that diversity training increases representation of ethnic minorities at senior level. Furthermore, if diversity training is compulsory and/or badly framed it has also been shown to be potentially problematic. One issue with diversity training is that it can increase managerial and majority-group perceptions of fairness in an organisation, and engender beliefs that discrimination has been eliminated, regardless of whether this is actually true, thus inhibiting further efforts to reduce it.

In recruitment, there is evidence to suggest that formalised recruitment, at its most basic level, is associated with greater diversity than informal recruitment via social networks. Organisations that hire via process are likely to be more diverse because the formalised process has made efforts to remove bias. In terms of specific elements, however, there are some caveats in relation to how the procedures are devised and carried out, as systems and rules in their design are subject to the biases of the in-group. The same is true of job tests; these can help to reduce bias in recruitment but care is needed so that in-group bias is not built into their design.

Evidence suggests that anonymous application procedures have a positive impact on the labour market outcomes of minority groups, although this is not always the case. In addition, anonymisation cannot be combined with recruitment methods such as tiebreak affirmative action policy, which aims to increase diversity by targeting specific groups. The emergence of new technologies, such as machine learning and algorithms for recruitment, are promising, although it is important to 
ensure the algorithms themselves are bias free, and not simply codifying historical bias in an organisation's recruitment procedures.

Given the importance of social network in recruitment - that is, finding a job through family, friends or acquaintances - it is not surprising that proactive measures to address the lack of appropriate networks by minority applicants are shown to be very effective. Measures include initiatives such as outreach in universities, internships and traineeships. Once a job has been secured, mentoring and sponsorship can also be significant in terms of granting access to information and career advancement.

In terms of more general lessons or principles, drawing from the findings of Chapters 3 and 4, it appears that policies based on a 'punitive' approach to 'enforcing the legislation' are insufficient without complementary policies to promote equal opportunities. A combination of such policies together with sanctions for non-compliance or discriminatory behaviour by companies would increase employer incentives to comply with the legislation (OECD, 2013).

Dobbin and Kalev (2018) consistently found that voluntary measures are more effective at increasing diversity and reducing discrimination than compulsory measures (see also Dobbin et al., 2015). This is challenging, as with opt-in measures sometimes those least in need of the intervention 'volunteer'. However, it is important to note that some measures backfire, particularly if individuals feel they are being forced to modify their opinions or that their autonomy/decision-making latitude is being reduced. The most effective kinds of measures have positive motivation and 'buy in' from the majority population, which enables them to be durable and effective in the long term. Dobbin and Kalev (2018) highlight the effectiveness of positive incentives ('carrot'), as opposed to punitive sanctions ('stick') at organisational level.

Another important point is that racial prejudice (an attitude) is not the same as racial discrimination (a behaviour). The two may be linked, but an individual may be prejudiced against certain groups but still hire them, because of procedures that are put place. Similarly, an individual may not be prejudiced but rarely hire minorities simply because they do not advertise their positions and their social networks are composed of people like themselves. Likewise, UBT may increase awareness but there is little clear evidence that it changes behaviour or increases diversity when undertaken in an organisation. Related to this is the fact that evidence seems to suggest it is easier to de-bias practice than de-bias people (Dobbin and Kalev, 2018). 
Policies and organisational-level measures to increase equality and diversity that have shown to be effective for other groups, such as women, people with a disability, older workers, or others disadvantaged within the labour market, could be effectively used to improve ethnic minority outcomes (OECD, 2020). Some such measures, for example reasonable accommodation for those with a disability, may not apply to the needs of ethnic minorities. Others, however, like reducing bias in recruitment, outreach measures, mentoring and sponsorship, should improve outcomes for minority groups more generally. If an organisation finds a measure targeted at one group to be effective, it should also be effective for another group. For example, successes in labour market inclusion programmes for those with a disability could be leveraged to develop measures targeting ethnic minorities (Whelan et al., 2019).

There may of course be a positive feedback loop from measures that change outcomes for minorities: policy feedback can occur via norm setting. In simple terms, a policy is introduced, behaviour and/or group outcomes change in response to this, but so also do norms or expectations of a group. With more diversity and more minority individuals in senior positions, expectations of labour market achievement of the minority group by both the majority group and minority group members themselves may change. Stereotypes about underachievement may be challenged and modified. Such a change can happen over the longer term and be difficult to detect (though see Gangl and Ziefle (2015) for a discussion of norm-setting regarding parental leave policy).

Ideally, measures should be as easy as possible to implement. Where measures are too complex to understand and/or administratively burdensome, this is shown to lead to poor implementation or lack of implementation at all (OECD, 2020). As the OECD (2020) note, the public sector can lead by example, as can very large private sector organisations, though most private sector employment in Ireland consists of small to medium enterprises. In fact, firm size recurs throughout Chapter 4 as an issue to consider. Some effective measures may simply not be viable for small companies with low profit margins - outreach for example, or machine learning. Formal recruitment is expensive, and some effective measures are costly to implement. Supports for small companies may need to be somewhat different: for example, wage subsidies or other financial incentives may be more effective here. Policy may need to be more innovative in supporting the use of such measures.

Another issue raised by the OECD (2020) is how closely policies should be targeted and how many combinations of disadvantage should be considered. The lived experience of discrimination is complex and intersectional, as discussed in Chapter 1. Yet policies or schemes cannot possibly account for many combinations of disadvantage, and if they attempt to closely target measures, they may become too narrow to either achieve targets or reach intended participants: they may also 
become too complex for either potential participants or providers to understand. Some balance needs to be struck between effective targeting of disadvantaged groups/those most in need, and maximum cost effectiveness in policy design to impact the outcomes of a larger number of individuals (ibid.)

The focus of many of the measures reviewed has been on combatting unfair treatment on the basis of race, ethnicity or nationality, typically where candidates have the same level of skills and qualifications but minorities are disadvantaged. But as noted in Chapter 1, disadvantage can accumulate, with discrimination in the education system having a serious impact on later life chances. In Ireland, this is most clearly illustrated by the situation of Irish Travellers. Watson et al. (2017) found that two-thirds of the disadvantage experienced by Travellers in employment rates is due to extremely low levels of education. Without efforts to improve the educational attainment of Travellers, poor labour market outcomes are likely to persist. This is rather different from the other ethnic minority groups in Ireland, as for the most part their educational qualifications are relatively high, compared to the Irish population (McGinnity et al., 2018). For those educated abroad, relevant issues include qualifications recognition and English language training, where relevant, so individuals can leverage their qualifications (McGinnity et al., 2020). Education and training was largely beyond the scope of this study, where the focus was on labour market discrimination, though these issues are clearly linked.

\subsection{IMPLICATIONS FOR MONITORING, FUTURE RESEARCH AND DATA NEEDS}

One of the most significant points in this report is the importance of monitoring, and this is for two reasons. Firstly, it is vital to monitor outcomes: that is, to document the extent of the disadvantage, and whether under-representation or disadvantage exists, in order to motivate any potential action. Secondly, it is necessary to monitor the effectiveness of any measure introduced to combat disadvantage. This includes any measures to combat disadvantage among ethnic minority groups in the forthcoming National Action Plan Against Racism. Of course, in order to monitor the progress or disadvantage of minority groups, the relevant data need to be gathered. This is the purpose of an ethnic identifier, through which data on an individual's ethnicity is collected and stored confidentially, so that outcomes can be monitored.

Monitoring ethnic minority outcomes is only possible where data are collected about both the individual and their outcomes. Fibbi et al. (2021) argue that one reason why many countries fail to develop effective policies against ethnic and racial discrimination, in contrast to those addressing gender equality, is due to lack of ethnic statistics in schools, workplaces, housing and health systems. Yet, in 
policy terms, the case for collecting accurate and comprehensive data on ethnicity is compelling: to reveal inequalities between groups; to monitor potential impact of diversity policies; and to allocate resources (Balestra and Fleischer, 2018; European Commission, 2020c).

A key limitation in Ireland is that ethnicity is rarely measured, on either survey data or administrative data (Fahey et al., 2019). There are important exceptions in survey data - the Census, the equality modules, the Growing Up in Ireland child cohort study - all of which are used in Chapter 2. Yet ethnicity does not feature on regular social surveys in Ireland. This means we know nothing about the wages, working conditions, income, poverty rates, deprivation or the self-rated health of ethnic minorities. It also means we can only compare labour market outcomes such as employment rates by using Census data, which is only collected every five years and involves considerable time-lags before results are available. Balestra and Fleischer (2018) argue, with reference to collection of ethnicity data in OECD countries, that 'one way of raising the timeliness and policy relevance of the data is by including questions in regular sample surveys (rather than only in the population census)' $(2018$, p. 10). As the IHREC (2021) points out, collecting data on ethnicity is also required for assessing Ireland's compliance with international standards, such as those outlined in the International Convention on the Elimination of all forms of Racial Discrimination (ICERD).

Most urgently for labour market disadvantage and discrimination, a measure of ethnicity on the Labour Force Survey is necessary. This would permit the generation of regular labour market outcomes of different ethnic groups, as in the UK. While recent measures have been introduced to the Labour Force Survey, on foot of new Eurostat regulations - parents' country of birth and motives for migration - which will considerably enhance the evidence base on migrant integration, these changes do not include ethnicity. Given considerable resistance in some European countries to the measurement of ethnicity (see Simon, 2017), this instruction is unlikely to come from Eurostat. Capturing ethnicity at, for example, yearly intervals, might be the most cost-effective way to do this. The measurement of ethnicity in other ongoing surveys, for example the Survey of Income and Living Conditions, could potentially follow, though sample size constraints are greater in this survey (see Fahey et al., 2019).

Individuals' own reports of discrimination form an important complement to data on labour market outcomes (Blank et al., 2004; Fibbi et al., 2021). Much of what we know about the experience of racial discrimination in the Irish labour market is from Central Statistics Office (CSO) fielded modules on equality from 2004, 2010 and 2014 (see Chapter 2, also McGinnity et al., 2018). But as illustrated by the example of the General Household Survey special module on equality and discrimination in 2019 (CSO, 2019), even if surveys identify ethnic minority groups 
and field excellently-worded questions on the experience of discrimination to a representative sample, if the sample size is too small, the surveys are of limited use (McGinnity et al., 2021). In the 2019 survey of equality and discrimination, responses of all ethnic minorities needed to be grouped together, even though earlier evidence clearly indicates that the experience of the Black ethnic group differs from ethnic Asians (McGinnity et al., 2018). For these data to effectively inform the work of any anti-discrimination measures in the future, the sample size needs to be larger than it was in 2019, however this might be achieved.

As Fahey et al. (2019) note, administrative data have the potential to form an important complement to survey data in measuring group outcomes. The big advantage is that administrative data record all recipients of a given training course, medical treatment, or examination outcome, for example. If ethnicity is so recorded, this allows monitoring of both participation and outcomes. This assumes the data are usable and accessible for the purpose, which may not be the case. Were such an identifier collected on administrative data, there is great potential to monitor outcomes: perhaps not mechanisms underlying these outcomes, but at least participation and outcomes. Where data already exist, for example from the Public Appointments Service, this could be used to consider diversity in applications, and recruitment and career progression by ethnic minority groups. The equality data audit recently conducted by the Central Statistics Office in Ireland is a promising example of a mapping exercise of existing data, both administrative and survey, that could be used for monitoring group outcomes. Even though this audit covers an impressive range of administrative data sources held in Ireland, it is of note that ethnicity was only measured in a small number of datasets. ${ }^{139}$ Nonetheless, to build up the evidence base for ethnic equality monitoring, an important first step is mapping what already exists. If public bodies are required to report on the implementation of actions assigned to them under the National Action Plan Against Racism, once it is completed they will need to measure ethnicity. Use of government-held data could be supplemented by firm-level records of recruitment and progression by ethnicity.

One striking finding from this review is the diversity of measures across people and place and the lack of robust evaluations of the effectiveness of specific measures. While impact evaluations may be challenging and expensive to conduct, they are invaluable for providing evidence for others about good practice and areas for improvement (Whelan et al., 2019). Lack of policy effectiveness may be challenging for those implementing the policy, but if the most well-meaning programme is failing to meet its stated aims, funding would be better spent elsewhere. Designing cost-effective assessments of effectiveness should be an integral part of measures

139 See https://www.cso.ie/en/methods/methodologicalresearch/rp-eda/equalitydataaudit2020/for the report on the equality data audit. See also Equality Data Audit July 2020 Audit File (XLS 416KB) for the data audit itself. 
introduced. This is especially true for internal organisational measures, such as diversity trainings and unconscious bias training (UBT), which, without future more robust evaluations of their effectiveness, may continue to be implemented in some cases merely to 'tick the box' regarding pro-diversity efforts. Evaluations of particular initiatives are specific and useful but, more broadly, if ethnicity, and also potentially nationality, were incorporated into more general programme evaluations, this would help build the evidence base on the outcomes of policy measures in the labour market (see Whelan et al., 2020).

Field experiments of discrimination, where conducted, provide strong and compelling evidence (see Chapter 2). Yet there has only been one field experiment on discrimination in recruitment in Ireland, in 2008, despite a proliferation of studies elsewhere (Zschirnt and Ruedin, 2016; Quillian et al., 2019). Given that the Irish labour market has since experienced a great recession, recovery, followed by a highly disruptive pandemic, now is an opportune time to conduct another field experiment. Ideally, such an experiment would also test the effectiveness of measures to combat discrimination, not just record their existence (Bertrand and Duflo, 2017).

Another promising technique is the use of laboratory experiments to complement the findings of a field experiment. Here, a particularly promising approach involves designing laboratory experiments about how attitudes influence behaviour, either using vignette studies in hiring or promotion, ${ }^{140}$ followed by questions on (explicit) attitudes, or the Implicit Association Test of implicit attitudes (see Chapter 2). An alternative experiment would test behaviour towards different ethnic groups (for example through trust or gift-giving games) in a laboratory setting, followed up with questions probing either implicit or explicit attitudes. Such experiments have been used extensively in other countries, but not yet in Ireland (Neumark, 2018). Further investigation of the experience of discrimination in the workplace by different ethnic groups distinguishing bullying and harassment from pay and promotion would further enhance our understanding of discrimination in the workplace.

While the long-term implications of the COVID-19 pandemic are still unclear, it has had and will continue to have a significant impact on economies and societies across the globe. The pandemic will likely exacerbate inequalities and research has shown that in EU and OECD countries there is a strong likelihood of increasing longterm unemployment and a changing skills needs, as well as the possibility of weakened social networks (EMN and OECD, 2021). Against the backdrop of significant economic and societal transformations and to the extent that COVID-19 
has already, in some cases, exacerbated pre-existing inequalities in the labour market, housing, education and health, efforts towards social inclusion such as access and upward mobility for minority groups in the labour market are of critical importance. 


\section{REFERENCES}

Aberson, C.L. (2003). 'Support for race-based affirmative action: Self-interest and procedural justice', Journal of Applied Social Psychology, Vol. 33, No. 6, pp. 12121225.

Aberson, C.L. and S.C. Haag (2003). 'Beliefs about affirmative action and diversity and their relationship to support for hiring policies', Analyses of Social Issues and Public Policy, Vol. 3, No. 1, pp. 121-138.

ACAS (British Arbitration, Conciliatory, and Advisory Service) (2006). 'Back to basics ACAS' experience of equality and diversity in the workplace', ACAS Policy Discussion Paper No. 5. London: Advisory, Conciliation and Arbitration Service.

Acemoglu, D. and J. Angrist (2001), 'Consequences of employment protection? The case of the Americans with Disabilities Act', Journal of Political Economy, Vol. 109, No. 5, pp. 915-957.

Allport, G.W., K. Clark and T. Pettigrew (1954). The nature of prejudice. Boston: AddisonWesley.

Al Ramiah, A., M. Hewstone, J.F. Davidio and L.A. Penner (2010). 'The social psychology of discrimination: Theory, measurement and consequences', in Bond, L., F. McGinnity and $\mathrm{H}$. Russell (eds.), Making equality count: Irish and international research measuring equality and discrimination, pp. 84-112. Dublin: The Liffey Press.

Anderson, K. and Z. Huang (2019). 'Can immigrants ever earn as much as native workers?', IZA World of Labor, Vol. 159.

Anti-Racism Committee (2021). Interim report to the Minister for Children, Equality, Disability, Integration and Youth. Dublin: Department of Children, Equality, Disability, Integration and Youth.

Arrow, K. (1973). 'The theory of discrimination', In O. Ashonfelter and A. Rees (eds.) Discrimination in labor markets, pp. 15-42. Princeton: Princeton University Press.

Aslund, O. and O.N. Skans (2012). 'Do anonymous job application procedures level the playing field?', Industrial and Labor Relations Review, Vol. 65, No. 1, pp. 82-107.

Atewologun, D., T. Cornish and F. Tresh (2018). Unconscious bias training: An assessment of the evidence for effectiveness. Equality and Human Rights Commission, Research Report 113.

Athey, S., A. Christopher and P. Zemsky (2000). 'Mentoring and diversity', American Economic Review, Vol. 90, No. 4, pp. 765-786.

Autor, D.H. and D. Scarborough (2008). 'Does job testing harm minority workers? Evidence from retail establishments', The Quarterly Journal of Economics, Vol. 123, No. 1, pp. 219-277. 
Baker., M, Y. Halberstam, K. Kroft, A. Mas and D. Messacar (2019). Pay transparency and the gender gap. National Bureau of Economic Research: New Working Paper Series, Working Paper 25834.

Barocas, S. and A.D. Selbst, (2016). 'Big data's disparate impact', California Law Review, http://dx.doi.org/10.2139/ssrn.2477899.

Becker, G.S.(1975). The economics of discrimination. Chicago: University of Chicago Press.

Behaghel, L., B. Crépon and T. Le Barbanchon (2015). 'Unintended effects of anonymous résumes', American Economic Journal: Applied Economics, Vol. 7, No. 3, pp. 1-27.

Bennedsen, M., E. Simintzi, M. Tsoutsoura and D. Wolfenzon (2019). Do firms respond to gender pay gap transparency?, National Bureau of Economic Research: New Working Paper Series, Working Paper 25435.

Bertrand, M. and E. Duflo. (2017). 'Field experiments on discrimination', Handbook of economic field experiments, Vol. 1, pp. 309-393.

Besley, T., O. Folke, T. Persson and J. Rickne (2017). 'Gender quotas and the crisis of the mediocre man: Theory and evidence from Sweden', American Economic Review, Vol. 107, No. 8, pp. 2204-42, https://www.aeaweb.org/articles?id=10.1257/aer.20160080.

Bilgili, Ö. (2015). Evaluating impact: Lessons learned from robust evaluations of labour market integration policies. UNU Merit: Migration Policy Group.

Bjørnshagen, V. and E. Ugreninov (2020). 'Labour market inclusion of young people with mental health problems in Norway', Alter, Vol. 15, No. 1, pp. 46-60.

Blank, R.M., M. Dabady and C.F. Citro (eds.) (2004). Measuring racial discrimination. Washington DC: The National Academies Press.

Blau, F. and L. Kahn, 2017. 'The gender wage gap: Extent, trends and explanations', Journal of Economic Literature, Vol. 55, No. 3, pp. 789-865.

Bloomer, S., J. Hamilton and C. Hughes (2020). Migrant workers in the mushroom industry. Coleraine: Ulster University.

$\mathrm{B} \varnothing \mathrm{g}, \mathrm{M}$. and E. Kranendonk (2011). Labor market discrimination of minorities? Yes, but not in job offers. Munich: University Library of Munich.

Boevenkerk, F., M. Gras and D. Ramsoedh (1995). International migration papers. Dissertation. Utrecht: University of Utrecht.

Boll, C., M. Jahn and A. Lagemann (2017). The gender lifetime earnings gap: Exploring gendered pay from the life course perspective, HWWI Research Paper No. 179.

Brady, L. M., C.R. Kaiser, B. Major and T.A. Kirby (2015). 'It's fair for us: Diversity structures cause women to legitimize discrimination', Journal of Experimental Social Psychology, Vol. 57, pp. 100-110.

Breen, M.J., A. Haynes and E. Devereux (2006). 'Fear, framing and foreigners: The othering of immigrants in the Irish print media', International Journal of Critical Psychology, Vol. 16, pp. 100-121. 
Butschek, S. and T. Walter (2014). 'What active labour market programmes work for immigrants in Europe? A meta-analysis of the evaluation literature', IZA Journal of Migration, Vol. 3, No. 1, pp. 1-18.

Byrne, M. (2014). Performing distance: The response of Irish professionals to immigrants and immigration. PhD thesis. Dublin: Trinity College Dublin.

Byron, R.A. (2010). 'Discrimination, complexity and the public/private sector question', Works and Occupations, Vol. 37, No. 4, pp. 435-475.

Cabinet Office (2020). 'Written ministerial statement on unconscious bias training', gov.uk, https://www.gov.uk/government/news/written-ministerial-statement-onunconscious-bias-training.

Cano, M.Á., S.J. Schwartz, D.P. MacKinnon, B.T. Keum, G. Prado, F.F. Marsiglia, C.P. SalasWright, C.L. Cobb, L.M. Garcini, M. De La Rosa and M. Sánchez (2021). 'Exposure to ethnic discrimination in social media and symptoms of anxiety and depression among Hispanic emerging adults: Examining the moderating role of gender', Journal of Clinical Psychology, Vol. 77, No. 3, pp. 571-586.

Carrington, W.J., K. McCue and B. Pierce (2000). 'Using establishment size to measure the impact of Title VII and affirmative action', Journal of Human Resources, Vol. 35, No. 3, pp. 503-523.Carter., E.R., N. Onyeador and N.A. Lewis (2020). 'Developing and delivering effective anti-bias training: Challenges and recommendations', Behavioural Science and Policy, Vol. 6, No. 1, pp. 57-70.

Chopin, I. and C. Germaine (2019). A comparative analysis of non-discrimination law in Europe 2019, European Network of Legal Experts in Gender Equality and Nondiscrimination. Brussels: European Commission.

Clausen, J., E. Heinesen, H. Hummelgaard, L. Husted and M. Rosholm (2009). 'The effect of integration policies on the time until regular employment of newly arrived immigrants: Evidence from Denmark', Labour Economics, Vol. 16, No. 4, pp. 409417.

Collins, P.H. (2015). 'Intersectionality's definitional dilemmas', Annual Review of Sociology, Vol. 41, pp.1-20.

Committee on the Elimination of Racial Discrimination (2019). Concluding observations on the combined fifth to ninth reports of Ireland, Geneva: UN Office of the High Commissioner for Human Rights (OHCHR).

Commission on Race and Ethnic Disparities (UK) (2021). Commission on Race and Ethnic Disparities: The report. London: Commission on Race and Ethnic Disparities.

Cortina, L. M. (2008). 'Unseen injustice: Incivility as modern discrimination in organizations', Academy of Management Review, Vol. 33, No. 1, pp. 55-75.

Cowgill, B. (2019). 'Bias and productivity in humans and machines', Upjohn Institute Working Papers, Columbia Business School, pp. 19-309.

Crenshaw, K. (1989), 'Demarginalizing the intersection of race and sex: A black feminist critique of antidiscrimination doctrine, feminist theory and antiracist politics', University of Chicago Legal Forum, Vol. 1, No. 8. 
Crosby F.J., A. Lyer and S. Sincharoen (2006). 'Understanding affirmative action', Annual Review of Psychology, Vol. 57, No. 1, pp. 585-611.

Crowley, N. (2018). Equality bodies making a difference, European Network of Legal Experts in Gender Equality and Non-discrimination. Brussels: European Commission.

Crowley, N. (2020). Taking stock. A perspective from the work of equality bodies on: European equality policy strategies, equal treatment directives, and standards for equality bodies, EQUINET European Network of Equality Bodies. Brussels: European Commission.

Darity, W.A. and P.L. Mason (1998). Evidence on discrimination in employment: Codes of color, codes of gender, Journal of Economic Perspectives, Vol. 12, No. 2, pp. 63-90.

Davis, S., F. Neathey, J. Regan and R. Willison (2005). Pregnancy discrimination at work: $A$ qualitative study. Manchester: Equal Opportunities Commission.

Deitch, E. A., A. Barsky, R.M. Butz, S. Chan, S., A.P. Brief and J.C. Bradley, (2003). 'Subtle yet significant: The existence and impact of everyday racial discrimination in the workplace', Human Relations, Vol. 56, No. 11, pp. 1299-1324.

Department of Children, Equality, Disability, Integration and Youth (2021). 'Media release: Minister O'Gorman announces review of the Equality Acts', June.

Department of Justice and Equality (2017). National Traveller and Roma Inclusion Strategy 2017-2021. Dublin: Department of Justice and Equality.

Department of Justice, Equality and Law Reform (2005). Planning for Diversity - The National Action Plan Against Racism. Dublin, Department of Justice, Equality and Law Reform.

Devine, P., P. Forscher, A. Austin and W. Cox (2012). 'Long term reduction in implicit race bias: A prejudice habit-breaking intervention', Journal of Experiential Social Psychology, Vol. 48, No. 6, pp. 1267-1278.

De Vroome, T., B. Martinovic and M. Verkuyten (2014). 'The integration paradox: Level of education and immigrants' attitudes towards natives and the host society', Cultural Diversity and Ethnic Minority Psychology, Vol. 20, No. 2, pp. 166175.

Diprete, T.A. and W.T. Soule (1986). 'The organization of career lines: Equal employment opportunity and status advancement in a federal bureaucracy', American Sociological Reviews, Vol. 51, No. 3, pp. 295-309.

Dobbin, F. and A. Kalev (2013). 'The origins and effects of corporate diversity programs', in Q.M. Roberson (ed.), The Oxford handbook of diversity and work. Oxford: Oxford University Press, pp. 253-281.

Dobbin, F., D. Schrage and A. Kalev (2015). 'Rage against the iron cage: The varied effects of bureaucratic personnel reforms on diversity', American Sociological Review, Vol. 80, No. 5, pp. 1014-1044.

Dobbin, F. and A. Kalev (2016). 'Why diversity programs fail', Harvard Business Review, Vol. 94, No. 7, pp. 52-60. 
Dobbin, F. and A. Kalev (2018). 'Why doesn't diversity training work? The challenge for industry and academia', Anthropology Now, Vol. 10, No. 2, pp. 48-55.

Doorley, K., I. Privalko, H. Russell and D. Tuda (2021). The gender pay gap in Ireland from austerity through recovery, IZA Discussion Paper No. 14441. Bonn: IZA.

Doris, A. (2019). 'Ireland's gender wage gap, past and present', The Economic and Social Review, Vol. 50, No. 4, pp. 667-681.

Dover, T.L., B. Major and C.R. Kaiser (2016). 'Members of high-status groups are threatened by pro-diversity organizational messages', Journal of Experimental Social Psychology, Vol. 62, pp. 58-67.

Dovidio, J., K. Kawakami and S. Gaertner (2002). 'Implicit and explicit prejudice and interracial interaction', Journal of Personality and Social Psychology, Vol. 82, No. 1, pp. 62-68.

Duflo, E. and A. Banerjee (eds.) (2017). Handbook of field experiments. Elsevier.

ECRI (2015). ECRI general policy recommendation no. 15, Council of Europe. Strasbourg: European Commission against Racism and Intolerance (ECRI).

Eichhorst, W., A. Souza, P. Cahuc, D. Demazière, C. Fagan, N. Guimarães, H. Fu, A. Kalleberg, A. Manning, F. McGinnity, H. Rapoport, P. Scranton, J. Siegrist, K. Thelen, M. Valfort and J. Visser (2018). 'The future of work - Good jobs for all', in Werner, E. (ed.), Rethinking society for the 21st century: Report of the International Panel on Social Progress. Cambridge: Cambridge University Press, pp. 255-312.

Enright, S. and H. Russell (2020). Gender balance at work: A study of an Irish civil service department. Dublin: ESRI.

Erel, I., L.H. Stern, C. Tan and M.S. Weisbach (2018). 'Selecting directors using machine learning', National Bureau of Economic Research, Working Paper 24435.

Esses, V. (2021). 'Prejudice and discrimination toward immigrants', Annual Review of Psychology, Vol. 72, No. 1, pp. 503-531.

European Commission (2020). Communication from the commission to the European economic and social committee and the committee of the regions, A Union of equality: EU anti-racism action plan 2020-2025. Brussels: European Commission.

European Commission (2021a). Report from the Commission to the European Parliament and the Council on the application of Council Directive 2000/43/EC implementing the principle of equal treatment between persons irrespective of racial or ethnic origin ('the Racial Equality Directive') and of Council Directive 2000/78/EC establishing a general framework for equal treatment in employment and occupation ('the Employment Equality Directive'). Brussels: European Commission.

European Commission (2021b). Commission staff working document equality bodies and the implementation of the Commission Recommendation on standards for equality bodies. Brussels: European Commission.

European Commission (2021c). Guidance note on the collection and use of equality data based on racial or ethnic origin. Brussels: European Commission. 
EMN and OECD (2021). 'The impact of COVID-19 in the migration area in EU and OECD countries', EMN-OECD Umbrella Inform. Brussels: European Migration Network.

European Union Agency for Fundamental Rights (FRA) (2011). The Racial Equality Directive: Application and challenges. Luxembourg: Publications Office of the European Union.

European Union Agency for Fundamental Rights (FRA) (2012). Access to justice in cases of discrimination in the EU - Steps to further equality. Luxembourg: Publications Office of the European Union.

European Union Agency for Fundamental Rights (FRA) (2016). Second European Union minorities and discrimination survey: Roma - Selected findings. EU-MIDIS II. Luxembourg: Publications Office of the European Union.

European Union Agency for Fundamental Rights (FRA) (2017). EU-MIDIS II: Second European Union minorities and discrimination survey - Main results. Luxembourg: Publications Office of the European Union.

European Union Agency for Fundamental Rights (FRA) (2020). Roma and Travellers in six countries: Roma and Travellers survey. Luxembourg: Publications Office of the European Union.

Fahey, E., F. McGinnity and R. Grotti (2019). 'Irish attitudes to Muslim Immigrants', The Economic and Social Review. Vol. 50, No. 3, pp. 491-514.

Fanning, B. and L. Michael (2017). 'Racism and anti-racism in the two Irelands', Ethnic and Racial Studies, Vol. 41, No. 15, pp. 2656-2672.

Fanning, B. (2021). Diverse republic. Dublin: University College Dublin.

Fibbi, R., H.A. Midtbøen and P. Simon (2021). Migration and discrimination: IMISCOE short reader. Basingstoke: Springer Nature.

Fitzgerald, C., A. Martin, D. Berner and S. Hurst (2019). 'Interventions designed to reduce implicit prejudices and implicit stereotypes in real world contexts: A systematic review', BMC Psychology, Vol. 7, No. 29, pp. 1-12.

Gaddis S. (2019). "Understanding the "how" and "why" aspects of racial-ethnic discrimination: A multimethod approach to audit studies', Sociology of Race and Ethnicity. Vol. 5, No. 4, pp. 443-455.

Gangl, M. and A. Ziefle (2015). 'The making of a good woman: Extended parental leave entitlements and mothers' work commitment in Germany', American Journal of Sociology, Vol 121, pp. 511-565.

Ghelli, F. and J. Pross (2019), 'InterkulturelleÖffnung.' Die Polizei wird vielfältiger', Mediendienst Integration.

Goldin, C. and C. Rouse (2000). 'Orchestrating impartiality: The impact of 'blind' auditions on female musicians', American Economic Review, Vol. 90, No. 4, pp. 715-741.

Golden, H., S. Hinkle and F. Crosby (2001). 'Reactions to affirmative action: Substance and semantics', Journal of Applied Social Psychology, Vol. 31, No. 1, pp. 73-88. 
Government of Canada (2018), Anonymized recruitment pilot project - Final report. Government of Canada.

Groenveld, S. and S. Verbeek (2011). 'Diversity policies in public and private sector organizations: An empirical comparison of incidence and effectiveness', Review of Public Personnel Administration, Vol. 32, No. 4, pp. 353-381.

Harrison, D.A., D.A. Kravitz, D.M. Mayer, L.M. Leslie and D. Lev-Arey (2006). 'Understanding attitudes toward affirmative action programs in employment: Summary and metaanalysis of 35 years of research', Journal of Applied Psychology, Vol. 91, No. 5, pp. 1013-1036.

Haynes, A. and J. Schweppe (2017). Lifecycle of a hate crime: Country report for Ireland. Dublin: Irish Council for Civil Liberties.

Heath, A. and S.Y. Cheung (eds.) (2007). 'Unequal chances: Ethnic minorities in western labour markets', Proceedings of the British Academy. Oxford: Oxford University Press.

Herbert, F. (2021). 'Is unconscious bias training still worthwhile?', London School of Economics Diversity and Inclusion Blog, 24 March, https://blogs.Ise.ac.uk/businessreview/2021/03/24/is-unconscious-bias-trainingstill-worthwhile/.

Hewlett, S.A., M., Jackson, E., Cose and C. Emerson (2012). Key findings - Vaulting the color bar: How sponsorship levers multicultural professionals into leadership, New York: Center for Talent Innovation.

Hewlett, S.A., K., Peraino, L., Sherbin and K. Sumberg (2010). 'The sponsor effect: Breaking the last glass ceiling' in Hewlett, S.A. (ed.), Harvard Business Review Research Report, pp.1-77.

Hing, S., S. Leannes, B.D. Ramona and M.P. Zanna (2002). 'Meritocracy and opposition to affirmative action: Making concessions in the face of discrimination', Journal of Personality and Social Psychology, Vol. 83, No. 3, pp. 493-509.

Hirsch, C.E. (2009). 'The strength of weak enforcement: The impact of discrimination charges', Sociological Review, Vol. 74, No. 2, pp. 245-271.

Hirsh, E. and J.A. Kmec (2009). 'Human resource structures: Reducing discrimination or raising rights awareness?', Industrial Relations, Vol. 48, No. 3, pp. 512-532.

Hiscox, M.J., T. Oliver, M. Ridgway, L. Arcos-Holzinger, A. Warren and A. Willis (2017). Going blind to see more clearly: Unconscious bias in Australian public service shortlisting processes. Barton, ACT: Behavioural Economics team of the Australian Government (BETA).

Hoffman, M., L. B. Kahn and D. Li (2018). 'Discretion in hiring', The Quarterly Journal of Economics, Vol. 133, No. 2, pp. 765-800.

Holder, A.M.B, M. Jackson and J. Ponterotto (2015). 'Racial microaggression experiences and coping strategies of women in corporate leadership', Qualitative Psychology, Vol. 2, No. 2, pp. 164-180. 
Holzer, H.J. and D. Neumark (2000). 'What does affirmative action do?', Industrial Labor Relations Review, Vol. 53, No. 2, pp. 240-271.

Irish Human Rights and Equality Commission (IHREC) (2021). Developing a national action plan against racism: Submission to the Anti-Racism Committee.

Irish Human Rights and Equality Commission (IHREC) (2019). Strategy statement 20192021. Dublin: Irish Human Rights and Equality Commission.

Jencks, C. and M. Phillips (1998). The Black-White test score gap. The Brookings Institution Press.

Jewson, N. and D. Mason (1986). 'The theory and practice of equal opportunities policies: Liberal and radical approaches', The Sociological Review, Vol. 34, No. 2, pp. 307334.

Jones, K.P., C.I. Peddie, V.L. Gilrane, E.B. King and A.L. Gray (2016). 'Not so subtle: A metaanalytic investigation of the correlates of subtle and overt discrimination', Journal of Management, Vol. 42, No. 6, pp. 1588-1613.

Joseph, E. (2017). 'Whiteness and racism: Examining the racial order in Ireland', Irish Journal of Sociology, 26(1), pp. 46-70.

Kaiser, C.R., B. Major, I. Jurcevic, T.L. Dover, L.M. Brady and J.R. Shapiro (2013). 'Presumed fair: Ironic effects of organizational diversity structures', Journal of personality and social psychology, Vol. 104, No. 3, pp. 504-19.

Kalev A., F. Dobbin and E. Kelly (2006). 'Best practices or best guesses? Assessing the efficacy of corporate affirmative action and diversity policies', American Sociological Review, Vol. 71, No. 4, pp. 589-617.

Kalinoski, Z. T., D. Steele-Johnson, E.J. Peyton, K.A. Leas, J. Steinke and N.A. Bowling (2013). 'A meta-analytic evaluation of diversity training outcomes', Journal of Organizational Behavior, Vol. 34, No. 8, pp. 1076-1104.

Kelly, E., S. McGuinness and P.J. O'Connell (2011). What can active labour market policies do? ESRI Renewal Series, Paper 1. Dublin: ESRI.

Keogh, R., C. McDermott and J. Behan (2020). Spending review 2020: The composition of employment in small and large firms, Dublin: Department of Public Expenditure and Reform.

Kidder, D.L., M.J. Lankau, D. Chrobot-Mason, K.A. Mollica and R.A. Friedman (2004). 'Backlash toward diversity initiatives: Examining the impact of diversity program justification, personal and group outcomes', Journal of Conflict Management, Vol. 15, No. 1, pp. 77-102.

King, E.B., J.F. Dawson, D.A. Kravitz and L.M.V. Gulick (2012). 'A multilevel study of the relationships between diversity training, ethnic discrimination, and satisfaction in organizations', Journal of Organisational Behaviour, Vol. 33, No. 1, pp. 5-20.

King-O'Riain, R.C. (2007). 'Counting on the "Celtic Tiger": Adding ethnic census categories in the Republic of Ireland', Ethnicities, Vol. 7, No. 4, pp. 516-542. 
Kluve, J. (2006). The effectiveness of European active labor market policy, IZA Discussion Paper No. 2018.

Krause, A., U. Rinne and K.F. Zimmerman (2012). 'Anonymous job applications in Europe', IZA Journal of European Labour Studies, Vol. 1, No. 1, pp. 1-20.

Krause, A., U. Rinne, K.F. Zimmermann and I. Böschen (2012). 'Der anonyme Weg zu mehr Chancengleichheit: Anonymisierte Bewerbungsverfahren i m Praxistest', Berufsbildung in Wissenschaft Und Praxis, Vol. 40, No. 2, pp. 22-25.

Kravitz, D.A. (2008). 'The diversity validity dilemma: Beyond selection - The role of affirmative action', Personnel Psychology, Vol. 61, No. 1, pp. 173-193.

Kravitz, D.A. and S.L. Klineberg (2000). 'Reactions to two versions of affirmative action among whites, blacks and Hispanics', Journal of Applied Psychology, Vol. 85, No. 4, pp. 597-611.

Kulik, C. and L. Roberson (2008). 'Common goals and golden opportunities: Evaluations of diversity education in academic and organizational settings', Academy of Management Learning \& Education, Vol. 7, No. 3, pp. 309-331.

Kurtulus, F.A. (2012). 'Affirmative action and the occupational advancement of minorities and women during 1973-2003', Industrial Relations (Berkeley), Vol. 51, No. 2, pp. 213-246.

Lai, C.K., M. Marini, S.A. Lehr, C. Cerruti, J.L. Shin and J.A. Joy-Gaba et al. (2014). 'Reducing implicit racial preferences: I. A comparative investigation of 17 interventions', Journal of Experimental Psychology, Vol. 143, No. 4, pp. 1765-785.

Leonard, J. (1990). 'The impact of affirmative action regulation and equal employment law on black employment', The Journal of Economic Perspectives, Vol. 4, No. 4, pp. 4763.

Lin, N. (2001). Social capital: A theory of social structure and action, Cambridge: Cambridge University Press.

Mandel, H. and M. Semyonov (2016). 'Going back in time? Gender differences in trends and sources of the racial pay gap, 1970 to 2010', American Sociological Review, Vol. 81, No. 5, pp. 1039-1068.

McDonald, S., N. Lin and A. Dan (2009). 'Networks of opportunity: Gender, race, and job leads', Social Problems', Vol. 56, No. 3, pp. 385-402.

McGinnity F. and P. Lunn (2011). 'Measuring discrimination facing ethnic minority job applicants: An Irish experiment', Work, Employment and Society, Vol. 25, No. 4, pp. 693-708.

McGinnity, F. and M. Gijsberts (2017). 'The experience of discrimination among newly arrived Poles in Ireland and the Netherlands', Ethnic and Racial Studies, Vol. 41, No. 5, pp. 919-937.

McGinnity, F. M. Creighton and É. Fahey (2020). Hidden versus revealed attitudes: A list experiment on support for minorities in Ireland. Dublin: ESRI/Irish Human Rights and Equality Commission. 
McGinnity, F., S. Enright, E. Quinn, B. Maitre, I. Privalko, M. Darmody and M. Polakowski (2020). Monitoring report on integration 2020. Dublin: ESRI/Department of Children, Equality, Disability, Integration and Youth.

McGinnity, F., R. Grotti, S. Groarke and S. Coughlan (2018). Ethnicity and nationality in the Irish labour market, Dublin: ESRI/Irish Human Rights and Equality Commission.

McGinnity, F., R. Grotti, H. Russell and É. Fahey (2018). Attitudes to diversity in Ireland. Dublin: Economic and Social Research Institute and Irish Human Rights and Equality Commission.

McGinnity, F., J. Nelson, P. Lunn and E. Quinn (2009). Discrimination in recruitment: Evidence from a field experiment. Dublin: ESRI/The Equality Authority.

McGinnity, F., I. Privalko, E. Fahey, D. O'Brien and S. Enright (2020). Origin and Integration: A study of migrants in the 2016 Irish Census. Dublin: ESRI/Department of Justice and Equality.

McGinnity, F., H. Russell, I. Privalko and S. Enright (2021). Monitoring decent work in Ireland. Dublin: ESRI/Irish Human Rights and Equality Commission.

McGinnity, F., D. Watson and G. Kingston (2012). Analysing the experience of discrimination in Ireland - Evidence from the QNHS equality module 2010. Dublin: Equality Authority and Economic and Social Research Institute.

McGregor-Smith, R. (2017). Race in the workplace: The McGregor-Smith review, Department for Business, Energy and Industrial Strategy (UK).

McKee-Ryan, F., Z. Song, C.R. Wanberg and A.J. Kinicki (2005). 'Psychological and physical well-being during unemployment: A meta-analytic study', Journal of Applied Psychology, Vol. 90, No. 1, pp. 53-76.

Michael, L. (2021). Reports of racism in Ireland: Data from iReport.ie. Annual report 2020. Dublin: Irish Network Against Racism.

Migrant Rights Centre of Ireland (MRCI) (2020). Working to the bone: The experiences of migrant workers in the meat sector in Ireland. Dublin: Migrant Rights Centre Ireland.

Miller, C. (2017). 'The persistent effect of temporary affirmative action', American Economic Journal: Applied Economics, Vol. 9, No. 3, pp. 152-190.

Morgenroth, T. and M.K. Ryan (2018). 'Quotas and affirmative action: Understanding group-based outcomes and attitudes', Social and Personality Psychology Compass, Vol. 12, No. 3, p.e12374.

Moulton, B.R. (1990). 'A re-examination of the federal-private wage differential in the United States', Journal of Labour Economics, Vol. 8, No. 2, pp. 270-293.

Mullen, R., B. Kelly and N. Crowley (2021). Travellers in the mainstream labour market: Situation, identity and experience. Presentation to the Oireachtas Committee on Issues Affecting the Traveller Community (04 May 2021). 
Murphy, C., L. Caulfield and M. Gilmartin (2017). Developing integration policy in the public sector: A human rights approach. Maynooth University and the Irish Human Rights and Equality Commission.

National Research Council (1989). Fairness in employment testing: Validity generalization, minority issues, and the general aptitude test battery. Washington, DC: The National Academies Press, https://doi.org/10.17226/1338.

Nekby, L. (2009). Active labor market programs for the integration of youths and immigrants into the labor market. Santiago: CEPAL.

Neumark, D. (2018). 'Experimental research on labor market discrimination', Journal of Economic Literature, Vol. 56, No. 3, pp. 799-866.

Noon, M. (2017). 'Pointless diversity training: Unconscious bias, new racism and agency', Work, Employment and Society, Vol. 30, No. 1, pp. 59-76.

Nordell, J. 'Does Starbucks understand the science of racial bias?', The Atlantic, https://www.theatlantic.com/science/archive/2018/05/starbucks-unconsciousbias-training/559415/.

Organisation for Economic Co-operation and Development (OECD) (2008a). 'The price of prejudice: Labour market discrimination on the grounds of gender and ethnicity', OECD employment outlook. Paris: OECD Publishing.

Organisation for Economic Co-operation and Development (OECD) (2008b). Jobs for immigrants (Vol. 2): Labour market integration in Belgium, France, the Netherlands and Portugal. Paris: OECD Publishing.

Organisation for Economic Co-operation and Development (OECD) (2012). Jobs for immigrants (Vol. 3): Labour market integration in Austria, Norway and Switzerland. Paris: OECD Publishing.

Organisation for Economic Co-operation and Development (OECD) (2013). 'Discrimination against immigrants - Measurement, incidence and policy instruments', International Migration Outlook. Paris: OECD Publishing.

Organisation for Economic Co-operation and Development (OECD) (2014). International migration outlook 2014. Paris: OECD Publishing.

Organisation for Economic Co-operation and Development (OECD) (2020). All hands in? Making diversity work for all. Paris: OECD Publishing.

O'Higgins, N. and L. Pinedo (2018). 'Interns and outcomes just how effective are internships as a bridge to stable employment?', International Labour Organization, Employment Working Paper No. 241.

O'Mahoney, J. (2017). Traveller community national survey, The National Traveller Data Steering group and the Community Foundation for Ireland.

Oswald, F.L., G. Mitchell, H. Blanton, J. Jaccard and P.E. Tetlock (2013). 'Predicting ethnic and racial discrimination: A meta-analysis of IAT criterion studies', Journal of Personality and Social Psychology, Vol. 105, No. 2, p. 171-192. 
Pager, D. and L. Quillian (2005). 'Walking the talk? What employers say versus what they do', American Sociological Review, Vol. 70, No. 3, pp. 355-380.

Pager, D. and H. Shepherd (2008). 'The sociology of discrimination: Racial discrimination in employment, housing, credit and consumer markets', Annual Review of Sociology, Vol. 34, pp. 181-209.

Paluck, E. and D. Green (2009). 'Prejudice reduction: What works? A review and assessment of research and practice', Annual Review of Psychology, Vol. 60, pp. 339-367.

Paradies, Y., J. Ben, N. Denson, A. Elias, N. Priest, A. Pieterse, A. Gupta, M. Kelaher, M. and G. Gee (2015). 'Racism as a determinant of health: A systematic review and meta-analysis', PLoS One, Vol. 10, No. 9, https://doi.org/10.1371/journal.pone.0138511.

Perry, R. E. and J.R. Parikh, J. R. (2019). 'Sponsorship: a proven strategy for promoting career advancement and diversity in radiology', Journal of the American College of Radiology, Vol. 16, No. 8, 1102-1107.

Petersen, T., I. Saporta and M-D. L. Seidel (2000). 'Offering a job: Meritocracy and social networks', American Journal of Sociology, Vol. 106, pp. 763-816.

Pettigrew, T.F. and L. R. Tropp (2006). 'A meta-analytic test of intergroup contact theory', Journal of Personality and Social Psychology, Vol. 90, No. 5, pp. 751-783.

Phillips, T., R. Kerslake and J. Mayhew Jonas (2007). Fairness and freedom: The final report of the equalities review, Office of Public Sector Information (UK).

Plaut, V.C., F.G. Garnett, L.E. Buffardi and J. Sanchez-Burks (2011). 'What about me? Perceptions of exclusion and whites' reactions to multiculturalism', Journal of Personality and Social Psychology, Vol. 101, No. 2, pp. 337-353.

Quillian, L. (2006). 'New approaches to understanding racial prejudice and discrimination', Annual Review of Sociology, Vol. 32, pp. 299-328.

Quillian, L.A. Heath, D. Pager, A.H. Midtbøen, F. Fleischmann and O. Hexel (2019). 'Do some countries discriminate more than others? Evidence from 97 field experiments of racial discrimination in hiring', Sociological Science, Vol. 6, pp. 467496.

Reskin, B. F. (2000). 'The proximate causes of employment discrimination', Contemporary Sociology, Vol. 29, No. 2, pp. 319-328.

Rinne, U. (2018). 'Anonymous job applications and hiring discrimination', IZA World of Labour.

Russell, H., E. Smyth and P.J. O'Connell (2005). Degrees of equality: Gender pay differentials among recent graduates. Dublin: ESRI.

Sabbagh, D. (2011). 'Affirmative action: The US experience in comparative perspective.' Daedalus, Vol. 140, No. 2, pp. 109-120.

Safi, M. (2010). 'Immigrants' life satisfaction in Europe: Between assimilation and discrimination', European Sociological Review, Vol. 26, No. 2, pp. 159-176. 
Sanchez, J.L. and N. Medkik (2004). 'The effects of diversity awareness training on differential treatment', Group \& Organization Management, Vol. 29, No. 4, pp. 517-536.

Schindlauer, D. (2007). Report on measures to combat discrimination - Austria, The European Network of Legal Experts in the Non-Discrimination Field. Brussels: European Commission.

Schmitt, M., N. Branscombe, T. Postmes and A. Garcia (2014). 'The consequences of perceived discrimination for psychological well-being: A meta-analytic review', Psychological Bulletin, Vol. 140, pp. 921-948.

Siapera, E., E. Moreno and J. Zhou (2018). Hate track: Tracking and monitoring racist speech online. Dublin: Irish Human Rights and Equality Commission.

Simon, P. (2017). 'The failure of the importation of ethno-racial statistics in Europe: Debates and controversies', Ethnic and Racial Studies, Vol. 40, No. 13, pp. 23262332.

Simon, P., V. Piché and A. Gagnon (2015). Social statistics and ethnic diversity cross-national perspectives in classifications and identity politics. Springer: Imiscoe Research Series.

Sizemore, D. and W. Milner (2004). 'Hispanic media use and perceptions of discrimination: Reconsidering ethnicity, politics and socioeconomics', The Sociological Quarterly, Vol. 45, No. 4, pp. 765-784.

Small, M.L. and D. Pager (2020). 'Sociological perspectives on racial discrimination', Journal of Economic Perspectives, Vol. 34, No. 2, pp. 49-67, doi:10.1257/jep.34.2.49.

Smyth, E., M. Darmody, F. McGinnity and D. Byrne (2009). Adapting to diversity: Irish schools and newcomer students. Dublin: ESRI/Department of Education.

Squires, G.D. (1994). Capital and communities in black and white: The Intersections of race, class, and uneven development. Albany: State University of New York Press.

Thomas, D.A. (2001). 'The truth about mentoring minorities. Race matters', Harvard Business Review, Vol. 79, No. 4, pp. 98-107.

Triana, M. Del C., M.F. García and A. Colella (2010). 'Managing diversity: How organizational efforts to support diversity moderate the effects of perceived racial discrimination on affective commitment', Personnel Psychology, Vol. 63, No. 4, pp. 817-843.

Tronstad, K.R. (2010). 'Mangfold og likestilling i arbdeidslivet', Holninger og erfaringer blant arbeidsgivere og tillitsvalgte', Fafo-report, Vol. 39.

Valfort, M-A (2018). Do anti-discrimination policies work? IZA World of Labor.

Verbeek, S. and S. Groeneveld (2012). 'Do "hard" diversity policies increase ethnic minority representation? An assessment of their (in)effectiveness using administrative data' Personnel Review, Vol. 41, No. 5, pp. 647-664.

Walker, T.B. and R. Feloni (2015). 'Here's the presentation Google gives employees on how to spot unconscious bias at work', The Business Insider, 
https://www.businessinsider.com/google-unconscious-bias-trainingpresentation-2015-12? $r=U S \& I R=T$.

Watson, D., O. Kenny, F. McGinnity (2017). A social portrait of Travellers in Ireland. Dublin: Economic and Social Research Institute.

Watson, D., B. Maître and C. Whelan (2012). Work and poverty in Ireland. Dublin: Economic and Social Research Institute/Department of Social Protection.

Whelan, A., J. Delaney, S. McGuinness and E. Smyth (2020). Evaluation of SICAP preemployment supports. Dublin: ESRI.

Whelan, A., S. McGuinness and J. Delaney (2019). Valuing community development through the social inclusion programme (SICAP) 2015-2017: Toward a framework for evaluation. Dublin: Economic and Social Research Institute.

Wilson, G., I. Sakura- Lemessy and J.P. West (1999). 'Reaching the top: Racial differences in mobility paths to upper-tier occupations', Work and Occupations, Vol. 26, No. 2, pp. 165-186.

Wladasch, K. (2015). 'The sanctions regime in discrimination cases and its effects', European Network of Equality Bodies. Brussels: Belgium.

Workplace Relations Commission (2021). Annual report 2020. Dublin: Workplace Relations Commission.

Wrench, J. (2007). 'Diversity management and discrimination: Immigrants and ethnic minorities in the EU', Human Resource Management International Digest, Vol. 16, No. 4.

Yarger, L., F.C. Payton and B. Neupane, B. (2019). 'Algorithmic equity in the hiring of underrepresented IT job candidates', Online Information Review, Vol. 44, No. 22, pp. 383-395.

Zschirnt, E. and D. Ruedin (2016). 'Ethnic discrimination in hiring decisions: A meta-analysis of correspondence tests 1990-2015', Journal of Ethnic and Migration Studies, Vol. 42, No. 7, pp. 1115-1134. 
Whitaker Square,

Sir John Rogerson's Quay, Dublin 2

Telephone +35318632000

Email admindesri.ie

Web www.esri.ie

Twitter AESRIDublin 